\title{
WestVirginiaUniversity
}

THE RESEARCH REPOSITORY @ WVU

Graduate Theses, Dissertations, and Problem Reports

2016

\section{An Analysis of Narong Prangcharoen's "Three Minds" for Solo Piano}

\author{
Pawatchai Suwankangka
}

Follow this and additional works at: https://researchrepository.wvu.edu/etd

\section{Recommended Citation}

Suwankangka, Pawatchai, "An Analysis of Narong Prangcharoen's "Three Minds" for Solo Piano" (2016). Graduate Theses, Dissertations, and Problem Reports. 6748.

https://researchrepository.wvu.edu/etd/6748

This Dissertation is protected by copyright and/or related rights. It has been brought to you by the The Research Repository @ WVU with permission from the rights-holder(s). You are free to use this Dissertation in any way that is permitted by the copyright and related rights legislation that applies to your use. For other uses you must obtain permission from the rights-holder(s) directly, unless additional rights are indicated by a Creative Commons license in the record and/ or on the work itself. This Dissertation has been accepted for inclusion in WVU Graduate Theses, Dissertations, and Problem Reports collection by an authorized administrator of The Research Repository @ WVU.

For more information, please contact researchrepository@mail.wvu.edu. 
An Analysis of Narong Prangcharoen's Three Minds for Solo Piano

Pawatchai Suwankangka

A Doctoral Research Project submitted to the College of Creative Arts at West Virginia University

in partial fulfillment of the requirements for the degree of

Doctoral of Musical Arts in Piano Performance

\author{
Peter Amstutz, D.M.A., Chair \\ Andrew Kohn, Ph.D., Research Advisor \\ Lucy Mauro, D.M.A. \\ Keith Jackson, D.M.A. \\ Penprapa Klinkhachorn, Ph.D.
}

School of Music

Morgantown, West Virginia

2016

Keywords: Piano, Contemporary Thai Composers, Contemporary Piano Music, Narong Prangcharoen, Three Minds

Copyright 2016 Pawatchai Suwankangka 


\section{ABSTRACT \\ An Analysis of Narong Prangcharoen's Three Minds for Solo Piano Pawatchai Suwankangka}

This research paper studies the piano piece Three Minds composed by Narong Prangcharoen. The main focus is the analysis of its three movements: "Fierce," "Absent," and "Hesitant," of which only the first movement receives an in-depth analysis. In addition, the composer's biography, his musical style, a complete list of his composition, and historical background of Three Minds are included.

Prangcharoen, Thai native composer, became well known in the early 2000s. His music uniquely fuses Thai and Western elements. This is found in the first movement "Fierce" with the influence from ranad, a Thai wooden xylophone. As his music is bound within the context of Western concert music, the piano work Three Minds features characteristics in common with much other contemporary music. These include complex rhythms, metric change, ostinato, atonality with the preference of tritone, and the exploitation of overtone effects on the piano. 


\section{To My Family}

\section{Assistant Professor Pratoom Poompotong \\ Major General Rewat Suwankangka \\ Ms. Sani Suwankangka}




\section{With utmost gratitude to}

Dr. Andrew Kohn

Dr. Peter Amstutz

Dr. Lucy Mauro

Dr. Keith Jackson

Dr. Penprapa Klinkhachorn

Dr. Narong Prangcharoen

Mr. Wisit Satanakul

Ms. Ampai Buranaprapruck 


\section{TABLE OF CONTENTS}

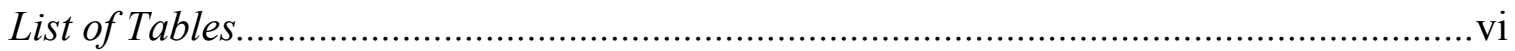

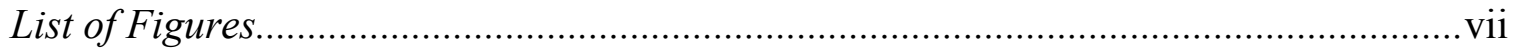

List of Examples...................................................................................................

CHAPTER ONE: PREFACE

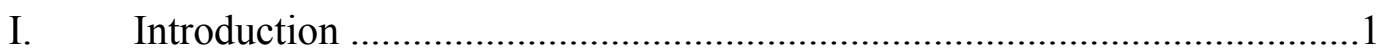

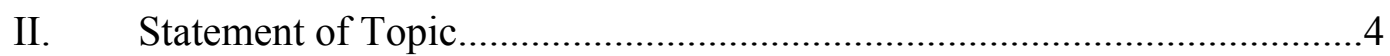

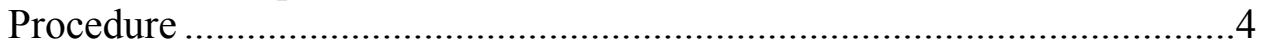

Scope and Limitations of Study .............................................................

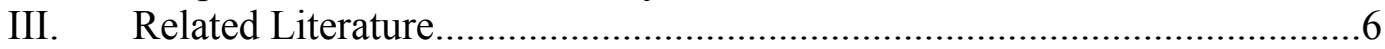

\section{CHAPTER TWO: NARONG PRANGCHAROEN AND HIS MUSIC}

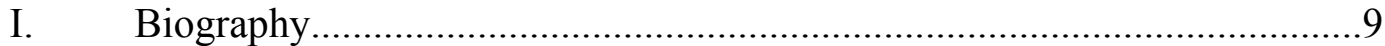

II. Narong Prangcharoen's Musical Style......................................................16

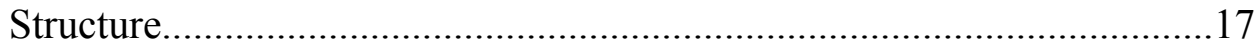

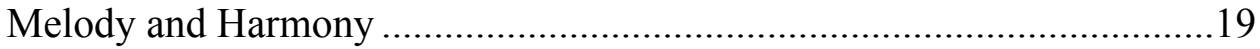

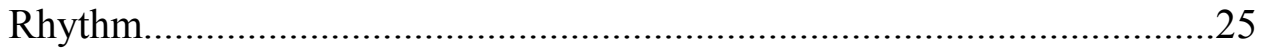

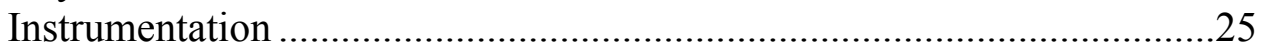

III. Complete List of Prangcharoen's Compositions ......................................27

\section{CHAPTER THREE: THREE MINDS: HISTORICAL BACKGROUND} AND STYLISTIC DISCUSSION

I. Historical Background of Three Minds .................................................43

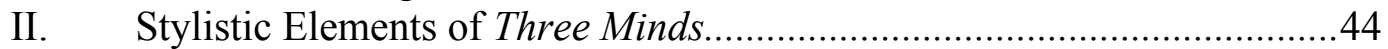

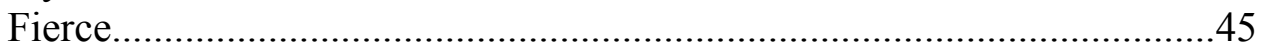

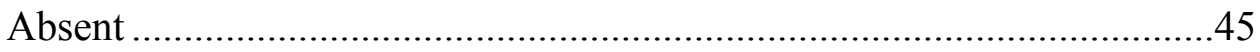

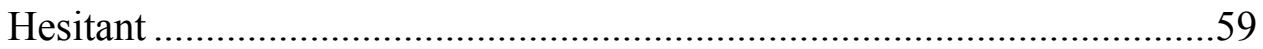

\section{CHAPTER FOUR: THE ANALYSIS OF “FIERCE”}

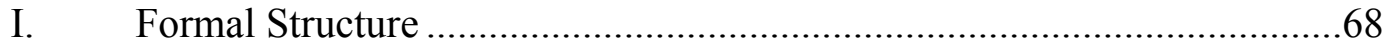

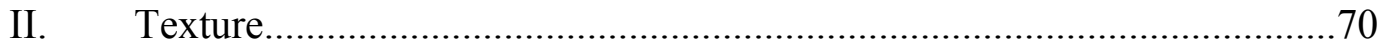

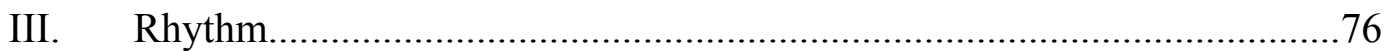

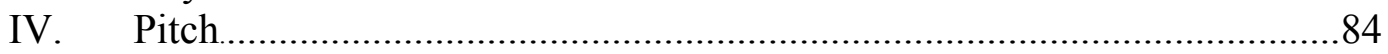

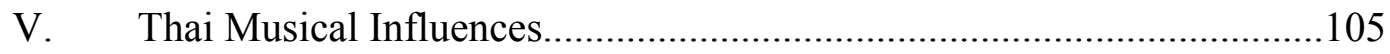

\section{CHAPTER FIVE: CONCLUSION}

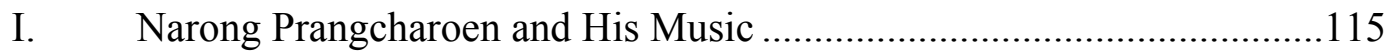

II. The Analysis of Three Minds .................................................................116

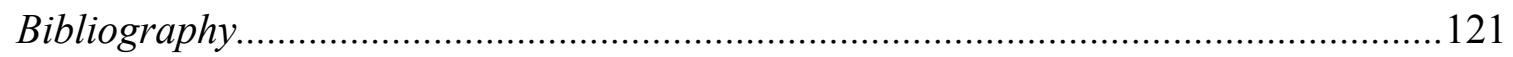




\section{LIST OF TABLES}

Table 2.1 Structures and examples of works in each structure .............................17

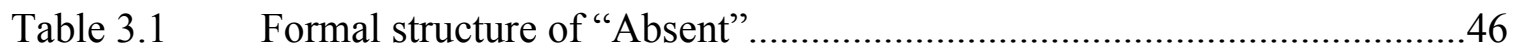

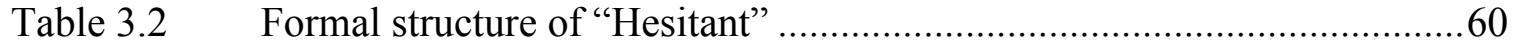

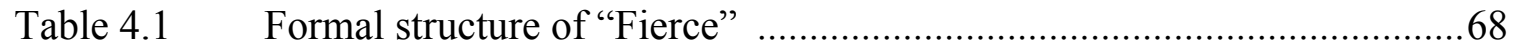

Table 4.2.1 The diagram of time signatures and groups of notes marked by accents, mm. 3-10 in "Fierce"

Table 4.2.2 The diagram of time signatures and groups of notes marked by accents, mm. 44-53 in "Fierce"...........................................78

Table 4.3 Two pitch class sets used in each section of "Fierce" ............................93 


\section{LIST OF FIGURES}

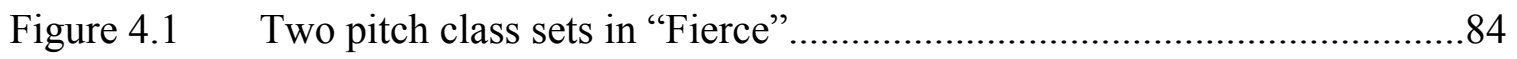

Figure 4.2 Comparison between western temperament and Thai tuning system......110 


\section{LIST OF EXAMPLES}

Example 2.1.1

Example 2.1.2

Example 2.2

Example 2.3

Example 2.4

Example 3.1.1

Example 3.1.2

Example 3.1.3

Example 3.1.4

Example 3.1.5

Example 3.1.6

Example 3.1.7

Example 3.1.8

Example 3.2.1

Example 3.2.2

Example 3.2.3

Example 3.3.1

Example 3.3.2

Example 3.3.3

Example 3.3.4

Example 3.4

Example 3.5
Dialogue, first movement, mm. 22-24.. 20

Dialogue, first movement, mm. 27-30. 21

The Temple in the Mist, mm. 1-8..... .22

Sattha, mm. 59-65. .23

Dialogue, fourth movement, mm. 306-314. .24

Three Minds: “Absent,” mm. 1-4..... .49

Three Minds: “Absent,” mm. 7-9. .50

Three Minds: “Absent," mm. 10-12..... .50

Three Minds: “Absent,” mm. 14-16... .51

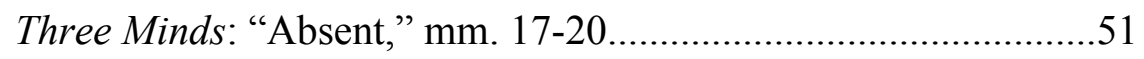

Three Minds: “Absent,” mm. 30-35...... .52

Three Minds: “Absent," mm. 38-41...... .53

Three Minds: “Absent," mm. 45-47..... .53

Three Minds: "Absent," mm. 7-9 .54

Three Minds: “Absent," mm. 26-28...... .54

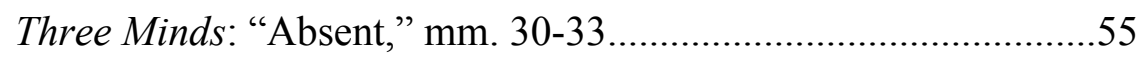

Three Minds: “Absent,” mm. 17-24..........................................56

Three Minds: “Absent,” mm. 45-53... .57

Three Minds: “Absent," mm. 1-4, 21-24 .58

Three Minds: “Absent,” mm. 7-9, 50-53 .58

Three Minds: "Hesitant," m. 1 .62

Three Minds: "Hesitant," m. 9 .63 
Example 3.6

Example 3.7

Example 3.8

Example 3.9.1

Example 3.9.2

Example 4.1.1

Example 4.1.2

Example 4.2.1

Example 4.2.2

Example 4.3

Example 4.4

Example 4.5

Example 4.6

Example 4.7.1

Example 4.7.2

Example 4.8

Example 4.9.1

Example 4.9.2

Example 4.10

Example 4.11

Example 4.12

Example 4.13

Example 4.14
Three Minds: "Hesitant," mm. 28-40.. .63

Three Minds: "Hesitant," mm. 39-43_.............................................65

Three Minds: “Hesitant,” mm. 46-49...............................................66

Three Minds: "Hesitant,” mm. 61-62.............................................66

Three Minds: "Hesitant," mm. 55-56.............................................67

Three Minds: "Fierce,” mm. 15-17....................................................

Three Minds: "Fierce," mm. 28-29.................................................

Three Minds: "Fierce," mm. 3-5 ....................................................

Three Minds: "Fierce," mm. 44-47................................................. 71

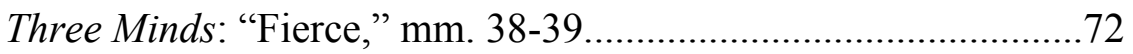

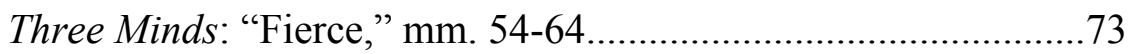

Three Minds: "Fierce," mm. 65-67...................................................

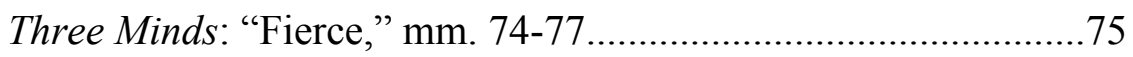

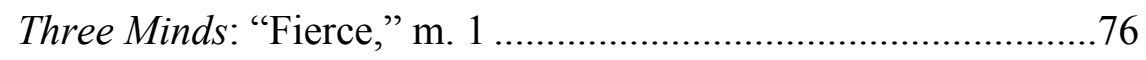

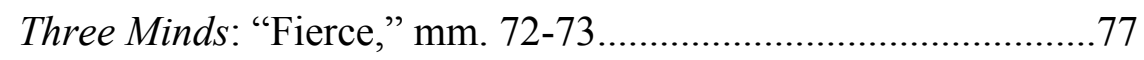

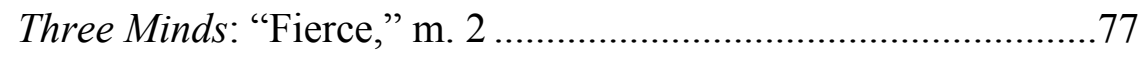

Three Minds: "Fierce," mm. 3-10...................................................

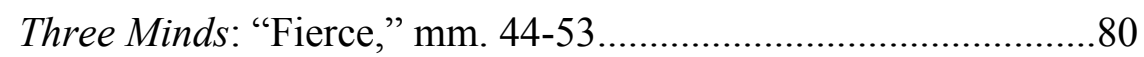

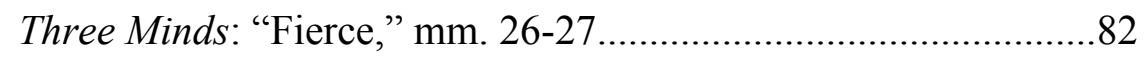

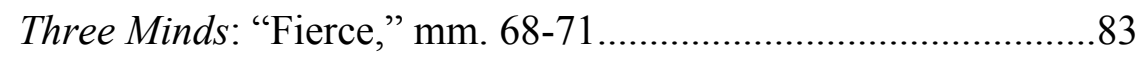

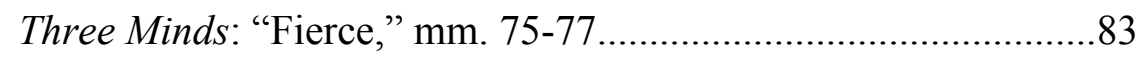

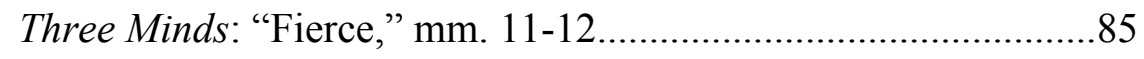

Three Minds: "Fierce," mm. 13-14.

.86 
Example 4.15

Example 4.16

Example 4.17

Example 4.18

Example 4.19

Example 4.20.1

Example 4.20.2

Example 4.21.1

Example 4.21.2

Example 4.22

Example 4.23

Example 4.24.1

Example 4.24.2

Example 4.24.3

Example 4.25.1

Example 4.25.2

Example 4.26.1

Example 4.26.2

Example 4.27

Example 4.28

Example 4.29.1

Example 4.29.2

Example 4.30
Three Minds: "Fierce," mm. 15-25.

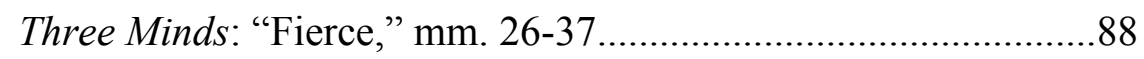

Three Minds: "Fierce," m. 53 .90

Three Minds: "Fierce,” mm. 54-64... .91

Three Minds: "Fierce," mm. 65-67. .92

Three Minds: "Fierce," m. 3 .94

Three Minds: "Fierce," m. 68 .95

Three Minds: "Fierce," mm. 15-18. .96

Three Minds: “Fierce,” mm. 38-39... .96

Three Minds: "Fierce," mm. 26-37... .97

Three Minds: "Fierce," mm. 38-43.. .99

Three Minds: "Fierce," mm. 56-62. 101

Three Minds: "Hesitant," mm. 28-29.. .102

Three Minds: "Hesitant," mm. 55-60...

Three Minds: "Fierce," mm. 74-76. .103

Three Minds: "Absent," m. 1 .103

Three Minds: "Fierce," m. 15 104

Three Minds: "Fierce," mm. 74-77. 104

Three Minds: "Fierce," m. 15 107

Three Minds: "Fierce," mm. 24-25. 107

Three Minds: "Fierce," m. 18 108

Three Minds: "Fierce," m. 21 .108 Loy Luean Sam Chan, mm. 39-42 109 
Example 4.31

Example 4.32
Choet Chin, third movement, mm. 21-23..

110

Choet Chin, fourth movement, mm. 44-47... 


\section{CHAPTER 1}

\section{PREFACE}

\section{Introduction}

Narong Prangcharoen is an active contemporary Thai composer who now resides in Kansas City, U.S.A. He was born on July 23, 1973 in Uttaradit province, Thailand. After completing his Bachelor of Music in music education from Srinakharinwirot University, Bangkok, Thailand, he relocated to the United States in 2000 as a recipient of a Graduate Teaching Assistantship at Illinois State University, majoring in composition. In 2010, Prangcharoen earned a DMA in composition from University of MissouriKansas City under the guidance of his primary teacher, Chen $\mathrm{Yi}^{1}{ }^{1}$

A highly successful composer, Prangcharoen received, in 2013, both the prestigious Guggenheim Fellowship and the Barlow Prize. He has also won many awards such as the 20th Annual American Composers Orchestra Underwood New Music Commission, the American Composers Orchestra Audience Choice Award, the Toru Takemitsu Composition Award, the Pacific Symphony’s American Composers Competition Prize, the Pacific Symphony Music Alive residency, and the Annapolis Charter 300 International Composers Competition Prize. ${ }^{2}$

His orchestral pieces have been performed by many orchestras such as the American Composers Orchestra, the Annapolis Symphony Orchestra, the Baltimore Symphony Orchestra, the Bohuslav Martinů Philharmonic Orchestra,

\footnotetext{
${ }^{1}$ Narong Prangcharoen, "Sattha for Strings, Piano, and Percussion" (DMA diss., University of MissouriKansas City, 2010).

2 Narong Prangcharoen, "Narong Prangcharoen: Biography," Narong Prangcharoen Composer, http://www.narongmusic.com/biography.php (accessed March 31, 2014).
} 
the Grant Park Orchestra, the Melbourne Symphony Orchestra, the Minnesota

Orchestra, the Oregon Symphony Orchestra, the Pacific Symphony Orchestra, the Thailand Philharmonic Orchestra, and the Tokyo Philharmonic Orchestra.

Consequently, Prangcharoen has become well known as an orchestral composer. John Corigliano considers Prangcharoen's music “contemporary and accessible,"3 Chen Yi says that his music is "colorful and powerful."4 The Chicago Sun Times calls his music "absolutely captivating." Times praises his The Migration of Lost Souls, calling it "an atmospheric work that weaves some of the spiritual and vernacular sounds of Mr. Prangcharoen's native Thailand into a skillfully orchestrated tapestry [with] moments of ethereal beauty."6

Of his catalog, currently numbering 69 compositions, ${ }^{7}$ only three are for solo piano: Temple in the Mist (2000), Three Minds (2003), and Pact Ink (2014). Three Minds is the only multi-movement piano work by Prangcharoen, and was commissioned by his former piano teacher, Bennett Lerner, an American pianist who resides in Thailand as a member of the piano faculty at Payap University, Chiangmai. It was premiered on

\footnotetext{
${ }^{3}$ Narong Prangcharoen, "Narong Prangcharoen: Biography," Narong Prangcharoen Composer, http://www.narongmusic.com/biography.php (accessed February 3, 2014).

${ }^{4}$ Ibid.

${ }^{5}$ Andrew Patner. "Grant Park Music Festival 'Looking East' Carlos Karmar with Glen Ellyn Children's Chorus." Chicago Sun-Times (June 22, 2007), quoted in Narong Prangcharoen, "Narong Prangcharoen: Press," Narong Prangcharoen Composer, http://www.narongmusic.com/pressnews/060.php (accessed September 20, 2014).

${ }^{6}$ Corinna da Fonseca-Wollheim, "Ambitious, with Ives Anchoring: American Composers Orchestra at Carnegie Hall" New York Times, Oct. 29, 2012, http://www.nytimes.com/2012/10/30/arts/music/americancomposers-orchestra-at-carnegie-hall.html $\quad \mathrm{r}=0$ \&adxnnl=1\&adxnnlx $=1398053950$ gwQO6R3ooESp6Fk/xMGqiQ (accessed April 8, 2014).

${ }^{7}$ Narong Prangcharoen, e-mail message to author, April 23, 2014.
} 
October 4, 2003 by Lerner himself at Lincoln Theater, Miami Beach, Florida. ${ }^{8}$ This composition consists of three movements: "Fierce," "Absent," and "Hesitant."

Prangcharoen's inspiration in this piece is the connection between the human mind, body, and soul. These three movements are described as different states of mind and emotions. "Fierce" represents the anger and madness of humans. In contrast, "Absent" describes the free mind without any thought. The last movement, "Hesitant," displays the confusion of the mind. Prangcharoen intends to use the different elements of music to describe the different emotions of people. ${ }^{9}$

Three Minds is recorded on Prangcharoen's first commercial album, Phenomenon (Albany, 2009). The soloist is Christopher Janwong McKiggan, a former student of Lerner, now pursuing his doctoral degree in piano performance at Rice University. ${ }^{10}$ Although this piece is available in this commercial recording and McKiggan has performed it in piano competitions ${ }^{11}$ and recitals, no research paper has yet been written on this work. As Prangcharoen's amanuensis and personal assistant, as well as a friend for almost twenty years, the author is uniquely positioned to undertake this project. Through this research paper, the author hopes to induce wider performances of Three Minds and also aid anyone who is interested in further researching Prangcharoen's style.

\footnotetext{
${ }^{8}$ Narong Prangcharoen, "Narong Prangcharoen: Chamber," Narong Prangcharoen Composer, http://www.narongmusic.com/work.php?band=Chamber (accessed February 3, 2014).

${ }^{9}$ Narong Prangcharoen, Three Minds (Kansas City, Missouri: Self-Published, 2003).

${ }^{10}$ Christopher McKiggan, "Christopher Jangwong McKiggan: Biography." http://www.christopherjanwongmckiggan.com/\#!bio/c139r (accessed February 6, 2014).

${ }^{11}$ Paul Boekkooi, "ArtSpoken \& Reviews: Unisa International Piano Competition Overview." Artslink.co.za. http://www.artlink.co.za/news article.htm?contentID=29173 (accessed February 3, 2014).
} 


\section{Statement of Topic}

The purposes of this study are:

1. To provide background information about Narong Prangcharoen and his music

2. To provide historical background to and stylistic discussion of all movements of Three Minds

3. To provide an in-depth analysis of the first movement of Three Minds.

\section{Procedure}

To achieve the stated goals, the study is divided into the following five chapters;

I. Preface

II. Narong Prangcharoen and his Music

III. Three Minds: Historical Background and Stylistic Discussion

IV. The Analysis of "Fierce"

V. Conclusion

Chapter I is the statement of the research topic which includes research objectives, procedure, scope and limitations of study, and a survey of related literature.

Chapter II provides a biography of Prangcharoen and brief information about his compositional genres and styles, as well as a complete list of his compositions.

Chapter III provides the historical background and a stylistic discussion of Three Minds. This section is divided into three sub-sections according to three movements of the work: 1) Fierce, 2) Absent, and 3) Hesitant. 
Chapter IV provides an in-depth analysis of the first movement, "Fierce." This section is divided into five sub-sections: 1) formal structure, 2) texture, 3) rhythm, 4) pitch, and 5) Thai musical influences.

Chapter V is a conclusion of this research work. It is divided into two sections: 1) Narong Prangcharoen and His Music, and 2) The Analysis of Three Minds. The first section summarizes his biography and gives the overview of his music. The second section summarizes the analysis of Three Minds.

\section{Scope and Limitations of Study}

This study focuses on the solo piano piece Three Minds by Narong Prangcharoen. All three movements are analyzed in terms of historical background and stylistic overview, but only the first movement, "Fierce," receives in-depth analysis.

The analysis of the first movement is organized around: 1) formal structure, 2) texture, 3) rhythm, 4) pitch, and 5) Thai musical influences. These elements are discussed in Chapter 4 in detail and illustrated with musical examples excerpted from the movement.

Although Thai musical influences are focused on analyzing works by the Thai composer, this topic is only discussed concerning the first movement as it is the only movement in which Prangcharoen clearly displays Thai characteristics. However, as Prangcharoen was trained in the field of Western music, not Thai traditional music, this section is viewed in the context of Western music. What creates Thai flavor and departs from normal Western music is discussed. Also the influence of a specific Thai musical 
instrument is scrutinized by using only western music notation transcription, not studying directly from Thai traditional music notation.

\section{Related Literature}

Since there is no previous analytical research paper about Prangcharoen's music, there are very limited sources of information. The most significant primary sources for this paper will be interviews with the composer, other personal communication such as electronic mailing, the score to Three Minds, written memoranda of conversations between the author and Prangcharoen, and the author's own analysis. The other existing available material will now be reviewed.

The biographical information on Prangcharoen's official website is the most recent and reliable biographical source, written by Prangcharoen himself. The website also includes performance activities, samples of recordings, a list of his compositions, and brief information on some compositions.

Prangcharoen's most recent Curriculum Vitae includes the list of compositions that he has been composing up to today and some general information on each work, including Three Minds. This Curriculum Vitae cannot be retrieved from his website.

Prangcharoen's Sattha for Strings, Piano, and Percussion, a DMA dissertation in music composition at the University of Missouri-Kansas City, 2010, provides some idea and information about that work itself and provides a complete score of Sattha. ${ }^{12}$ This provides information on Prangcharoen's compositional process and style, including his

\footnotetext{
12 "Sattha" means to have faith (in).
} 
inspiration for composing this work, as well as its instrumentation. His then-current biography is also provided in this dissertation.

Thai musical influences can be found in most of his compositional output, including Three Minds. Therefore it is helpful to know something about Thai music.

The information about Thai traditional music theory such as the tuning system used in Thai traditional music, and comparison between the Thai traditional music scale and Western music scale are not provided here. An excellent resource is "Aspects of Thai Music and Compositional Techniques in Selected Works of Jiradej Setabundhu” by Jiradej Setabundhu. This dissertation discusses the textural qualities of the "ranad ek," a traditional Thai instrument; these textures also appear in "Fierce." This resource also provides information on how traditional Thai music differs from Western music. It also includes information about the Thai tuning system, which is relevant in understanding Prangcharoen's melodic decisions in the first movement of Three Minds.

Similar to Setabundhu's work, Jittapim Yamprai's article in Early Music (xli: 3, 2013) entitled "Michel-Richard de Lalande and the Airs of Siam" provides a comparison between Western music tuning and Thai music tuning systems. Yamprai analyses a work by Lalande which was influenced by Thai traditional music heard in France. She points out certain characteristics of this music that may be a result from the influence of Thai music. These characteristics can be compared to Prangcharoen's music, which is also influenced by Thai traditional music.

Other useful sources for this study are "Introduction to Basic Ranad Playing," written by Sornchai Prathumthong, a thesis entitled "A New Solo Composition for the Thai Ranadake Derived from the Song 'Loy Luean Sam Chan'” by Pornchai Polnikrot, 
and a thesis entitled "An Analysis of Ranad Thum's Melody on Choet Chin" by Phaitoon Chaycharoen. These three sources give examples of ranad passages in western music notation and discuss techniques commonly found in ranad playing

Prangcharoen's score for Three Minds includes a personal statement that discusses his influences in composing this work and also musical elements in each movement of the work.

The CD booklet of Phenomenon includes useful information about Three Minds and other compositions. Besides Three Minds, the other works in CD are 1) Chakra for wind ensemble, 2) Sattha for strings, piano, and percussion, 3) Respiration of the Sun for orchestra, 4) Far from Home for cello solo, and 5) Phenomenon for orchestra. These are performed by the Bohuslav Martinů Philharmonic Orchestra, the Texas Tech University Wind Ensemble, Christopher Janwong McKiggan (piano), Nick Dinnerstein (cello), Andreas Hérm Baumgartner (conductor), and Sarah McKoin (conductor) Another useful resource concerning Prangcharoen's Thai musical influences is Nathinee Chucherdwatanasak's Narong Prangcharoen and Cross-Cultural Fusion in Contemporary Composition, a MM thesis in musicology at the University of MissouriKansas City, 2014. This thesis discusses specific elements in Prangcharoen's works, especially those drawn from Thai traditional music. Although the musical examples are drawn exclusively from orchestral works, it gives the useful information for the analysis of those Thai musical influences which can be found in Three Minds. 


\section{CHAPTER 2}

\section{NARONG PRANGCHAROEN AND HIS MUSIC}

\section{Biography}

Narong Prangcharoen was born in 1973 in Uttaradit province of northern Thailand. His grandmother and her children immigrated to Thailand from China. None of his family members are musicians, though his experience with Chinese and Thai popular music not just comes from listening to radio but also from tape recordings to which his father listened. He also played on a small electric keyboard with his father when other family would gather together for leisure time. ${ }^{13}$

Prangcharoen went to Anuban Uttaradit Elementary School from 1980-1985, and afterwards was sent to study at Horwang School in Bangkok. It was here that he joined the marching band and wind ensemble playing trumpet, his primary instrument. In addition to playing with these aforementioned groups, he was appointed to be his music teacher's assistant, responsible for conducting the band during the six years he studied there, though he never had systematic Western musical training in history or theory. He was mostly self-taught, and the resources available were limited to the textbooks Basic Music Theory (1933) and Harmonization (1934; revised in 1961), written in Thai by Phra Chen Duriyanga (English name: Peter Feit). ${ }^{14}$

In 1991, Prangcharoen continued his education at Srinakharinwirot University (SWU) as a music education major. This was where he first encountered organized

\footnotetext{
${ }^{13}$ Narong Prangcharoen, interview by author, Kansas City, MO, December 23, 2014.

${ }^{14}$ Feit's Thai musical textbooks include Basic Music Theory (1933), Harmonization (1934, 1961), Musical Symbols (1936), and Singing Principles (1953).
} 
Western music education. He studied music theory with Kit Young, an American pianist who was a guest lecturer at SWU at that time. This was also the first time that he experienced contemporary Western art music. ${ }^{15}$

During his college years, Prangcharoen had a chance to arrange music for the SWU Band and to conduct the band as well. He also took a conducting lesson with Vanich Potavanich, who was the resident conductor of the Thai National Symphony Orchestra (TNSO) and a visiting trumpet and conducting teacher at the college. Potavanich also gave him the opportunity to study privately on occasion with some international figures when they guest conducted the TNSO. ${ }^{16}$

Even though trumpet was his primary instrument while he was studying at SWU, his interest in piano grew after he heard a live piano recital by Kit Young consisting solely of contemporary piano music, the scores and recordings of which were rarely found in Thailand at that time. He has been fascinated ever since with the new sounds of the repertoire by the twentieth century composers that Young played at that time, such as Béla Bartók (1881-1945), Igor Stravinsky (1882-1971), and Robert Helps (1928-2001). These encounters eventually led him to study piano with Young. After a year of piano study with Young, Prangcharoen obtained a level 6 certificate of the International Examinations Board from Trinity College, held in Thailand. ${ }^{17}$ He became a part-time piano teacher for beginner students at Chintakarn Music Institute (CMI), a private music school in Bangkok. ${ }^{18}$

\footnotetext{
${ }^{15}$ For more information about Kit Young, see "Kit Young," Alliance for New Music Theater, http://newmusictheatre.org/about/artists/kit-young/ (accessed February 11, 2015).

${ }^{16}$ Narong Prangcharoen, interview by author, Kansas City, MO, December 23, 2014.

${ }^{17}$ For information regarding certifications and standards of Trinity College's International Examinations Board, see their website at trinitycollege.com, http:/www.trinitycollege.com/site/?id=55 (accessed April 3, 2015).

${ }^{18}$ Narong Prangcharoen, “Prangcharoen's Curriculum Vitae,” e-mail message to author, April 23, 2014.
} 
In SWU, Prangcharoen did not receive any composition lessons. However, until he graduated in 1995, he arranged music for SWU Band, SWU Chorus, and the wind ensemble whenever they hosted musical events on and off campus under the university's name.

After he graduated, he was accepted to be a full-time faculty member at SWU and further continued his private piano teaching at CMI. At SWU, he taught piano, music theory, and conducting. During this time, he continued taking piano lessons with Young, and sometimes, per Young's recommendation, was coached by Bennett Lerner (b. 1944), previous head of the piano department at CMI and current lecturer at the College of Music, Payap University, Chiangmai, Thailand. ${ }^{19}$ In 1999, Young moved to Malaysia, which led Prangcharoen to continue regular piano lessons with Lerner.

In 1999, Prangcharoen obtained his recital-level piano certificate from the Guildhall School of Music and Drama Examinations Board. ${ }^{20}$ He started experiencing stress and fatigue when playing piano due to his efforts to maintain the basic technical skills he acquired in his late learning. He eventually reconnected with Young for her consultation. She recommended that he try writing some music. The conversation he had with Young was a turning point that opened his curiosity to the world of composition.

Young suggested that Prangcharoen intensively study composition with Narongrit Dhamabutra (b. 1962), Professor of Music in theory and composition at the Faculty of Fine and Applied Arts, Chulalongkorn University (CU). ${ }^{21}$ Even though Prangcharoen had been taking private theory lessons with Dhamabutra about a year before, he also

\footnotetext{
${ }^{19}$ Bennett Lerner, e-mail message to author, March 13, 2014.

${ }^{20}$ This examination board later merged with Trinity College's International Examinations Board. See http://www.trinitycollege.com/site/?id=55 (accessed April 3, 2015).

${ }^{21}$ For more information about Narongrit Dhamabutra, see his personal website at narongrit.com, http://www.narongrit.com/en/index.php (accessed February 11, 2015).
} 
suggested Prangcharoen observe the theory classes that he was teaching at $\mathrm{CU}$, and that Prangcharoen take private composition lessons with him every week. This was the first time that Prangcharoen had ever had any formal training in music composition. ${ }^{22}$

Under Dhamabutra's guidance, Prangcharoen began learning fundamental skills in composition, such as how to construct a rhythm and a melody and how to transform a theme, among other things. Analysis of the same genre in which he was assigned to write helped to improve his understanding of and ability to apply formal principles. His first set of compositions was mostly miscellaneous piano pieces. He later branched out to write chamber music. After two years of having lessons with Dhamabutra, Prangcharoen had his own composition recital in 2000 at the Thai-German Cultural Center, Goethe Institute, Bangkok. The program consisted of a few small piano pieces, chamber music, choral music, and music for wind ensemble.

Prangcharoen met Stephen Andrew Taylor (b. 1965), a composition professor at Illinois State University (ISU), upon Taylor's visit to Thailand to observe SWU's music department. ${ }^{23}$ Taylor was interested in Prangcharoen's music and was impressed by his talent, especially given his late start to composition. Taylor advised Prangcharoen to continue studying with him for a master's degree in composition at ISU. Prangcharoen applied, was accepted, and began studying at ISU with a graduate assistantship in 2000 .

The most significant skills Prangchaoren learned from Taylor were how to effectively organize pitches and rhythmic materials, now major tools in his compositional process. After a year of studying with Taylor, following Taylor's departure to teach at

\footnotetext{
${ }^{22}$ Narong Prangcharoen, interview by author, Kansas City, MO, December 23, 2014.

${ }^{23}$ For more information about Stephen Taylor, see his personal website at stehenandrewtaylor.net, http://www.stephenandrewtaylor.net/index.html (accessed February 11, 2015).
} 
University of Illinois at Urbana-Champaign (UIUC), he continued composition with David Kahn Feurzeig (b.1965), Professor of Music at ISU. ${ }^{24}$

Prangcharoen obtained his master's degree in composition in 2002 and was accepted into the doctoral programs of both the UIUC and the University of MissouriKansas City (UMKC). He chose to study at UMKC not only because of the financial benefits offered to him—-such as the Graduate Teaching Assistantship, Chancellor's of Non-Resident Awards, Special Provost's Scholarship, and Composition Scholarshipwhile he was studying there, but also because of composition teacher Chen Yi (b. 1953), recommended to him as "the perfect match" by former piano and composition teachers. That phrase seemed to come true for Prangcharoen since, in UMKC under the guidance of Chen Yi, he developed a unique and distinctive voice. ${ }^{25}$

With Chen Yi, Prangcharoen learned to pay closer attention to the effectiveness of his composition, including orchestration, structural proportions, and musical style. Another enriching factor was the fact that Chen Yi's musical origin can be traced to Chinese music. She uses Chinese musical elements to create her own distinctive voice, and this method was passed on to Prangcharoen. He adapted her use of indigenous elements, creating a synthesis of Thai and Western music, a key ingredient to his distinctive musical voice.

Due to the policy of the school, Prangcharoen had to take composition lessons with all members the composition faculty. His teachers included Zhou Long (b. 1953),

\footnotetext{
${ }^{24}$ For more information about David Feurzeig, see "Faculty-David Feurzeig" The University of Vermont, College of Arts and Science, http://www.uvm.edu/ music/?Page=faculty/feurzeig.php\&SM=discovermenu.html (accessed February 11, 2015).

${ }^{25}$ For more information about Chen Yi, see "Dr. Chen Yi," The University of Missouri-Kansas City, Conservatory of Music and Dance, http://conservatory.umkc.edu/faculty.cfm?r=\%22\%2624\%20\%0A (accessed February 11, 2015).
} 
James Mobberley (b. 1954), and Paul Rudy (b. 1962). Even though Chen Yi was on leave from her teaching position at UMKC from Prangcharoen's arrival in 2002 until 2004 due to the recent Charles Ives Living Award that she received, Prangcharoen took lessons with her whenever she visited Kansas City, continuing for a total of six years.

During his time at UMKC, Prangcharoen also attended the 2003 and 2004 California Summer Music. He was nominated to be one of eight composers featured at the John Duffy Composers Institute in the 2005 Virginia Arts Festival.

At the 2005 Virginia Arts Festival, he met John Corigliano (b. 1938), who was a visiting composer of the festival. Corigliano gave him some suggestions about compositional technique, such as graphing a structural plan of the piece before writing a single note, an idea which Prangcharoen continues to use in planning the compositional structure in most of his works.

Prangcharoen was an active doctoral student. He participated in many composition competitions and received awards even while pursuing his degree. Specifically, he won the $2^{\text {nd }}$ prize of the Toru Takemitsu Composition Award in 2004, the Pacific Symphony's 2005 American Composer Competition in 2005, the ACL Yoshiro IRINO Memorial Prize, $2^{\text {nd }}$ prize of the Alexander Zemlinsky International Composition Competition in 2005, the Annapolis Charter 300 Competition in 2007, and the Silapathorn Award (Contemporary National Artist of Thailand) in 2007. ${ }^{26}$

Besides participating in numerous composition competitions, he was also an adjunct professor at Illinois State University during the 2005-2006 academic year while

\footnotetext{
${ }^{26}$ Narong Prangcharoen, "Narong Prangcharoen: Biography," Narong Prangcharoen Composer, http://www.narongmusic.com/biography.php (accessed February 11, 2015).
} 
David Feurzeig was on sabbatical leave. At ISU, he taught music theory courses and composition lessons at both the undergraduate and graduate levels. ${ }^{27}$

Prangcharoen obtained his doctoral degree in 2010. After he graduated, he continued as an active freelance composer. He won the Minnesota Orchestra Composer Institute Competition later that year. He also received both the American Composers Orchestra's 2011 Annual Underwood Commission and its 2011 Audience Choice Award. In 2013 he received both a Guggenheim and the Barlow Prize. ${ }^{28}$

Currently, Prangcharoen makes his home in Kansas City, where he teaches piano and composition at the Community Music and Dance Academy of the UMKC Conservatory of Music and Dance. He also regularly visits other places where he has artistic responsibilities. He is currently composer-in-residence of the Pacific Symphony Orchestra (Orange County, California). He has been active not only in the United States but also in various parts of Asia. He is an artistic committee member of the Beijing Modern Music Festival (BMMF). He is also a composer-in-residence of the Thailand Philharmonic Orchestra (TPO) in his native land, as well as founder and artistic director of the Thailand International Composition Festival (TICF), an annual weeklong summer music festival aimed to promote contemporary classical music's presence in Thailand and other Southeast Asian countries. ${ }^{29}$ He became a featured composer of the Theodore Presser publishing company in 2013, through which his orchestral works and wind ensemble works are currently published.

\footnotetext{
${ }^{27}$ Narong Prangcharoen, "Prangcharoen's Curriculum Vitae" e-mail message to author, April 23, 2014.

${ }^{28}$ Narong Prangcharoen, "Narong Prangcharoen: Biography," Narong Prangcharoen Composer, http://www.narongmusic.com/biography.php (accessed February 11, 2015).

${ }^{29}$ Thailand International Composition Festival was first established in 2005 by Narong Prangcharoen. For more information, see "Thailand International Composition Festival", http://www.music.mahidol.ac.th/ticf/index.html (accessed April 12, 2015).
} 
It is common for Thai composition students who study abroad to move back to Thailand after they complete their degrees. In their return, they are in pursuit of building a broader music society in Thailand. They return with new knowledge and teach younger generations in private studios and at universities in which they are employed. This is all very common.

Prangcharoen does not currently live in his native land and does not teach composition at a university, yet his contribution to the broadening of Thailand's music society is considerable. He provides a bridge between Thailand and other countries, particularly the United States. His major contribution in this effort is as founder and Artistic Director of the Thailand International Composition Festival. Through this annual event, Prangcharoen teaches composition to younger aspiring composers and musicians while he also helps to promote their works. Additionally, this summer exchange program between the Community Music and Dance Academy of UMKC Conservatory and TICF lends itself to young composers having new experiences and exploring new musical grounds.

Not only is Prangcharoen a well-established Thai composer and teacher, but he is also an ambassador for contemporary Thai and American music as well.

\section{Narong Prangcharoen's Musical Style}

Before analyzing any piece of a composer, understanding that composer's overall style is important. This chapter will provide a broad view of Prangcharoen's musical style. The discussion topics in this chapter are structure, melody and harmony, rhythm, and instrumentation. 


\section{Structure}

Once Prangcharoen finds an inspiration and does some research on the topic that moves him, structure is the very first step, one that he completes before he actually writes down a note. He usually starts from making a rough chart from the beginning to the end without minute details. He then decides the proportion of each section, including both how long it will be and which tempo he will use in each section. ${ }^{30}$

In general, the structures of Prangcharoen's works are similar to Western classical music from the common practice period. Most of his compositions are in ternary form. Prangcharoen also prefers to have different tempi within a piece. For example, if the piece is written in ternary form, the tempo of section B will be different from that of section A, whether fast-slow-fast or slow-fast-slow. Prangcharoen includes an introduction and a coda to most of his works. Table 2.1 below lists structures of Prangcharoen's works and examples of compositions in each structure as well as tempo markings of each section.

Table 2.1 Structures and examples of works in each structure

\begin{tabular}{|l|l|l|}
\hline Structure & Name of Composition & Sections \\
\hline AB & $\begin{array}{l}\text { Shadow (2003) } \\
\text { for woodwind quintet }\end{array}$ & Piu moto (mm. 40-) \\
\hline ABC & $\begin{array}{l}\text { Whispering (2008) } \\
\text { for soprano saxophone, bass } \\
\text { clarinet, piano, and percussion }\end{array}$ & Lento (mm. 1-) \\
Grave (mm. 40-) \\
Vivace (mm. 96-)
\end{tabular}

\footnotetext{
${ }^{30}$ Narong Prangcharoen, phone interview by author, Thailand, March 4, 2016.
} 


\begin{tabular}{|c|c|c|}
\hline $\mathrm{ABC}$ & Anusorn (2005) for cello and piano & $\begin{array}{l}\text { Addolorata (mm. 1-) } \\
\text { Allegro agitato (mm. 48-) } \\
\text { Adagio (mm. 108-) }\end{array}$ \\
\hline $\mathrm{ABA}$ & Phonomenon (2004) for orchestra & $\begin{array}{l}\text { Allegro agitato (mm. 1-) } \\
\text { Misterioso (mm. 32-) } \\
\text { Energico (mm. 96-) }\end{array}$ \\
\hline ABA & $\begin{array}{l}\text { Migration of Lost Souls (2012) } \\
\text { for orchestra }\end{array}$ & $\begin{array}{l}\text { Grave (mm. 1-) } \\
\text { Allegro (mm. 84-) } \\
\text { Adagio (mm. 203-) }\end{array}$ \\
\hline ABA & Lokuttra (2014) for wind ensemble & $\begin{array}{l}\text { Allegro (mm.1-) } \\
\text { Largo (mm. 149-) } \\
\text { Allegro (mm. 220-) }\end{array}$ \\
\hline $\mathrm{ABA}$ & $\begin{array}{l}\text { Elegy for a Great Person (2008) } \\
\text { for vocal and guitar }\end{array}$ & $\begin{array}{l}\text { (Same tempo throughout) } \\
\text { A (mm. 1-) } \\
\text { B (mm. 38-) } \\
\text { A (mm. 54-) }\end{array}$ \\
\hline $\mathrm{ABA}$ & $\begin{array}{l}\text { The Temple in the Mist (2000) } \\
\text { for piano }\end{array}$ & $\begin{array}{l}\text { (Same tempo throughout) } \\
\text { A (mm. 1-) } \\
\text { B (mm. 20-) } \\
\text { A (mm. 27-) }\end{array}$ \\
\hline ABA & Pact Ink (2014) for piano & $\begin{array}{l}\text { Allegro (mm. 1-) } \\
\text { Andante (mm. 61-) } \\
\text { Allegro (mm. 104-) }\end{array}$ \\
\hline
\end{tabular}


Apart from conventional forms, Prangcharoen also lets his extra-musical ideas dictate structure. An example of this is Sattha (2005). Sattha was composed in the memory of the victims of 2004 tsunami in South Asia. Prangcharoen begins the piece by imitating the cracking sound of the oceanic crust by the string instruments. Then the atmosphere becomes quiet as conveyed by the soft, vibrated, sustained note in the lower register. In the middle of the piece to the end, the music becomes more intense and louder, imitating the gigantic waves that wiped away more than 200,000 people in thirteen countries. The structure of Sattha actually emulates the event, from the vibrations resulted from the earthquake to the resultant tsunami. The beginning section has no significant melody, only the sound that portrays the undersea landslides just before the earthquake. The entire piece moves slowly; it finally ends with an enormous wave of sound. Therefore, the composition is a mirror of the extra-musical story.

\section{Melody and Harmony}

Melodic characteristics found in Prangcharoen's works can be divided into four categories.

\section{Pitch Class Sets}

Prangcharoen often determines a particular pitch class set to use in his music. An example of this is the first movement of Three Minds, discussed in detail in Chapter 4. In this case, the pitch class set permeates the whole composition, appearing both vertically as a chord and horizontally as a linear line, as well as in a transposed form. 


\section{Cryptogram as a Motif}

Prangcharoen sometimes encodes a cryptogram in his music and this cryptogram becomes a motif in a particular section where it appears. He develops and transforms the motif which becomes ubiquitous in the entire section. An example of this is in Dialogue. The cryptogram is decoded as $\mathrm{BACH}$ but he uses it in reverse order, so the notes are B-CA-Bb. Example 2.1 shows where this motif appears. The four notes are later continuously repeated, as shown in example 2.1.2.

Example 2.1 BACH cryptogram in the first movement of Dialogue

2.1.1 Mm. 22-24

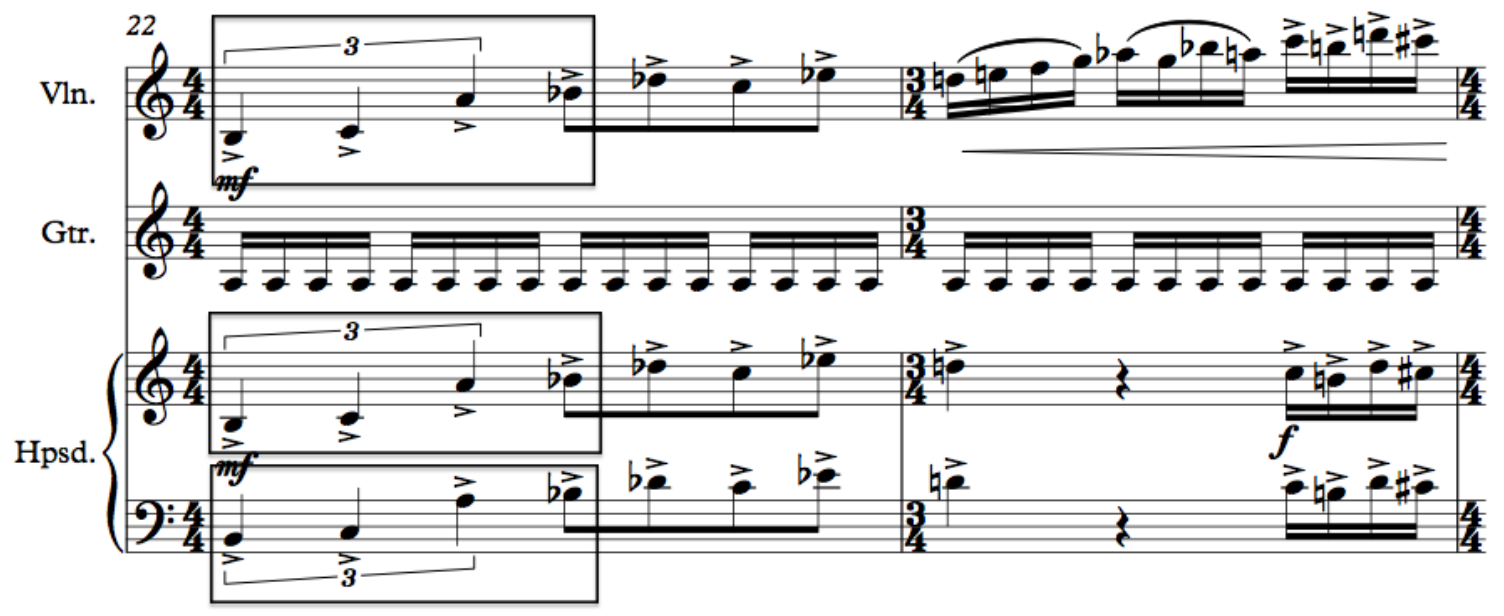




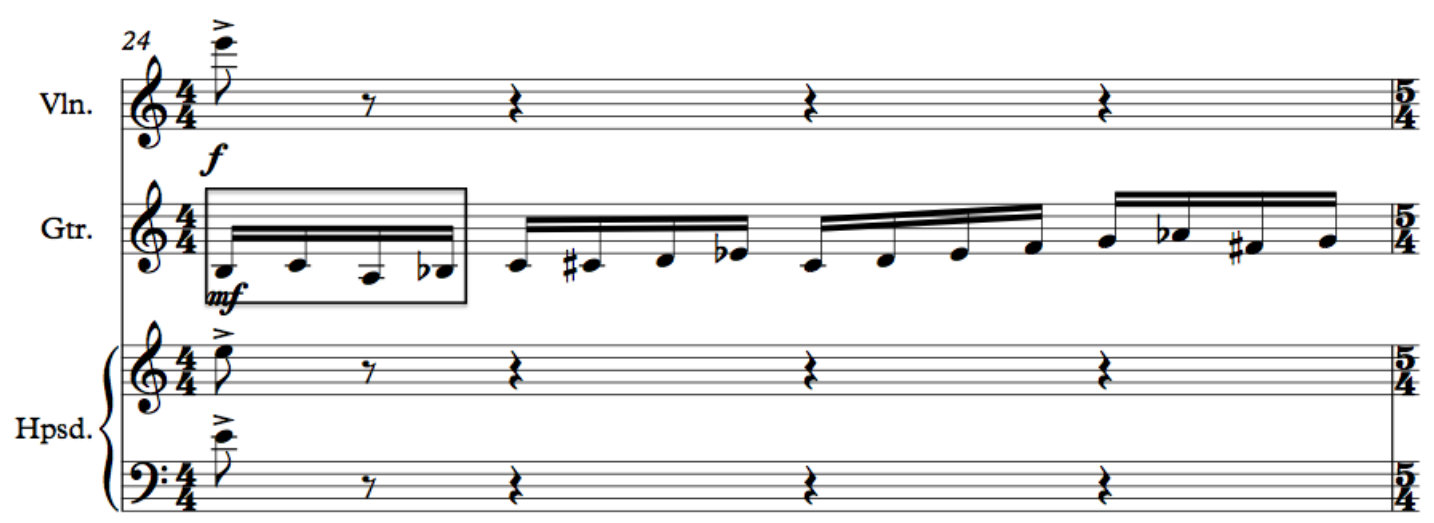

\subsubsection{Mm. 27-30}
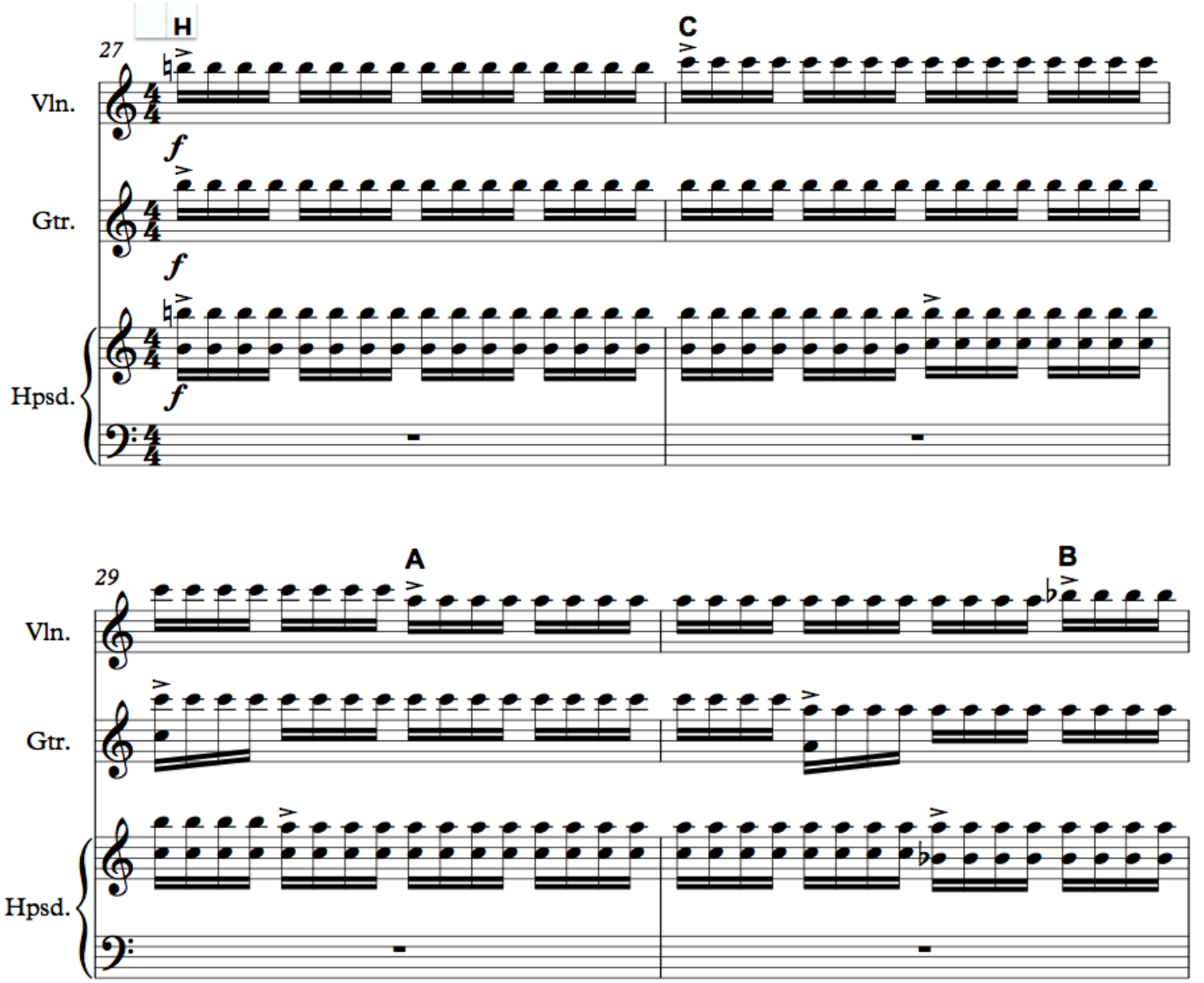


\section{Pentatonicism}

Often, a melody is constructed from a pentatonic scale, the one derived from Thai traditional music: an anhemitonic scale. ${ }^{31}$ An example of this is The Temple in the mist. Example 2.2 shows the beginning of this piece. The main notes in the right hand are F-GA-C-D.

Example 2.2 The beginning of The Temple in the mist
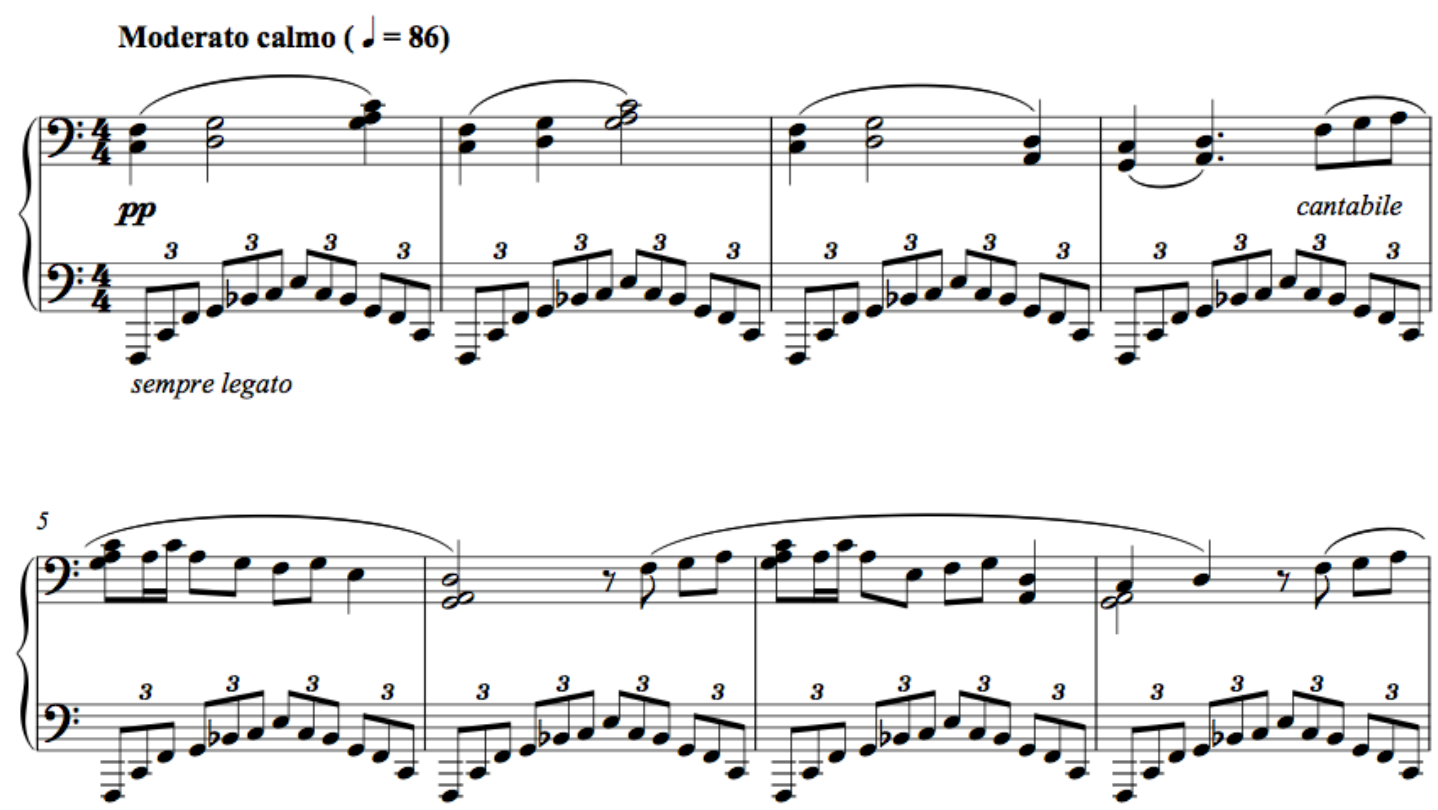

4. Quotation

Sometimes Prangcharoen quotes some tunes from Thai music or from other sources. One example is the quotation of Kap He Ruea (Song for Thai Royal Barge Procession, กาพย์เห่เรือ) in Sattha (see example 2.3). The melody of Kap He Ruea

\footnotetext{
${ }^{31}$ An anhemitonic scale is the five-note scale without half-steps, often called a "black key scale" since it can be played on the black keys of a piano.
} 
starts in $\mathrm{m} .59$ in both the viola and crotale parts and is immediately repeated (transposed) by the violins.

Example 2.3 Mm. 59-65 of Sattha
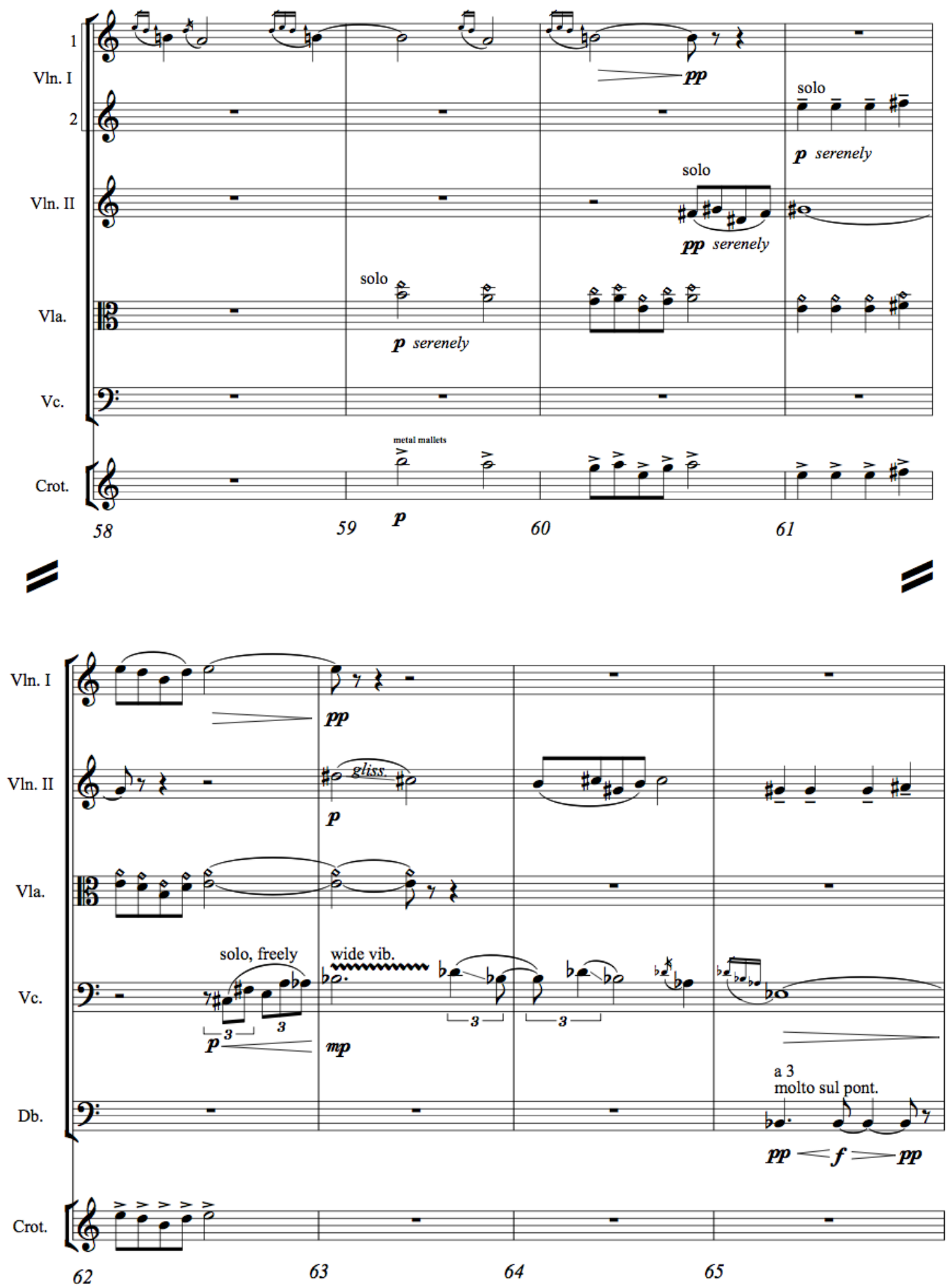
Another example of quotation is the melody from Purcell's Dido and Aeneas,

"When I am laid in earth." This appears in the fourth movement of Dialogue, mm. 306314 (see example 2.4).

Example 2.4 Mm. 306-314 of Dialogue, fourth movement
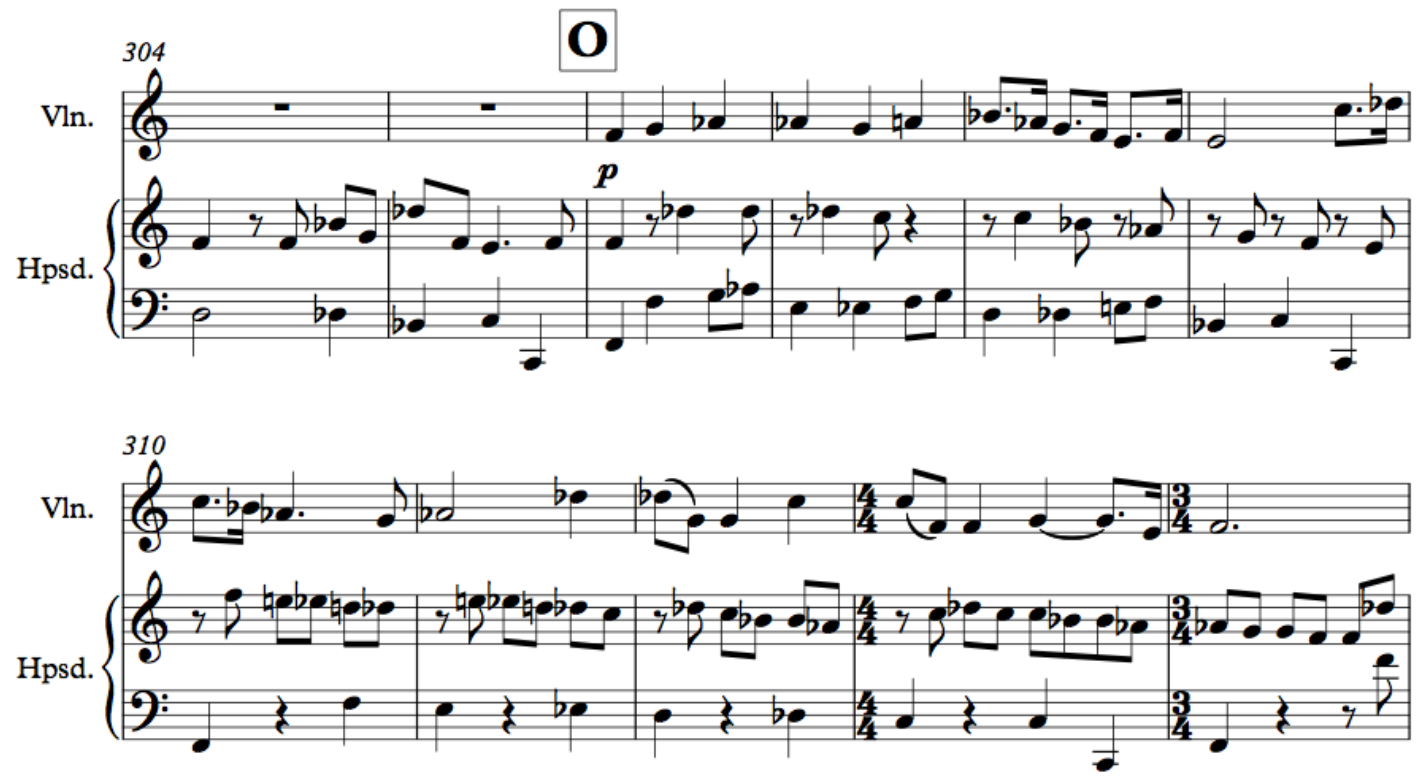

In terms of harmony, Prangcharoen does not so much plan a long-range harmonic structure, but rather plays with colors and nuances as he composes. He thinks in terms of linear motion, rather than a vertical block. He focuses on each particular line and when he combines lines together it sometimes creates a heterophonic texture like in Thai traditional music. It can be said that his melody dominates harmony. Harmony arrives after he sets all melodic ideas and colors. ${ }^{32}$

\footnotetext{
${ }^{32}$ Narong Prangcharoen, phone interview by author, Thailand, March 19, 2016.
} 


\section{Rhythm}

Prangcharoen's music is filled with the exploitation of rhythmic effects including hemiola, metric displacement, and changing meters. For example, in a certain moment within music with time signature $4 / 4$, he may put a rhythmic pattern that projects $6 / 8$. He also creates the effect of polymeter even when his notation is confined within a single time signature for all parts; each part projects an independent meter. In performance, this emulates the freedom found in Thai traditional music, in which each part generally plays what is notated but also freely fills in between the structural notes, including changing certain notes that are not on important beats. Although within Thai traditional music this element is improvised, Prangcharoen conveys this air of free creation through fully determined western music notation. The characteristic interlocking rhythms, with polymeter, usually merge into unity at a climax.

As mentioned before, Prangcharoen often accentuates notes at an irregular pace. This creates syncopation and metric displacement. In addition to these strategies of metric contradiction, he also plays frequently employs metric change.

\section{Instrumentation}

In his orchestral compositions, the trumpet often plays an important role, especially at climaxes. Even though in a soft lyrical passage, Prangcharoen also often uses the trumpet to play the melody. The trumpet section is often the most prominent part. As the trumpet is Prangcharoen's first instrument, he may be most comfortable writing for this instrument. 
As for the cello, it mostly appears in the high register. It often features contrasting dynamics when it plays the melody. Prangcharoen gives equal importance to the cello as he does to the violin, but he finds that the cello is more intense than the violin when playing a melody. ${ }^{33}$

For Prangcharoen, like other composers, the brass section is used for loud passages, while woodwinds generally suggest serenity. His music shows the influence of wind band music, reflecting years of the composer's experience in his high school's marching band. ${ }^{34}$ Thus, many passages played by the trumpet or the horn are reminiscent of marching band music. Prangcharoen also loves to use the Bartók pizzicato ${ }^{35}$ played by the double bass to double the muted brass.

Prangcharoen often uses extended techniques for instruments, especially wind instruments. This can be seen easily in the solo part of a concerto, such as in his saxophone concerto. The familiar sound of the saxophone is thereby extended into the unfamiliar. The limitation of extended techniques may make him find new sounds for his music. He recently opted for a non-western instrument — the Suona, a double reed instrument from China. This suona piece, also a concerto, bears a distinctive color, serving the composer's desire for new sound.

For special effects played by the orchestra, apart from using extended techniques in the string and wind sections of the orchestra, we also find the influence from Thai traditional music in the pervasive use of percussion instruments. Not only is there

\footnotetext{
${ }^{33}$ Narong Prangcharoen, phone interview by author, Thailand, March 4, 2016.

${ }^{34}$ Marching bands of Thai high schools practice primarily for band competitions, unlike marching bands in the United States whose primary function is to support football teams.

35 The "Bartók pizzicato" or "snap pizzicato" is produced by pulling a string upward and releasing it so that the string strikes the fingerboard.
} 
widespread use of some percussion or other, he often includes many different timbres of percussion in the orchestra and sometimes imitates techniques of Thai percussion instruments such as in The Migration of Lost Souls (2012). This big batterie results in extreme contrast within a composition, which is precisely the goal that the composer wants to reach.

\section{Complete List of Prangcharoen's Compositions} (As up to May 2016)

Despite his late start with systematic instruction in composition, beginning only in 1999 at the age of 26, Prangcharoen has written sixty-nine compositions. At first, most of his works were exercise pieces and miscellaneous piano pieces, most of which have been lost. The fifty-four surviving works consist of orchestral pieces, works for wind ensemble, concertos, chamber works, works for solo instruments, chorus, musical theater, and voice with orchestra.

Of all these genres, his favorites are writing for orchestra, wind ensemble, and concerti. Since Prangcharoen was a student of Chen Yi when he pursued his DMA at the University of Missouri-Kansas City, he still asks Yi for comments and suggestions whenever he is commissioned to write new compositions for larger ensembles. Prangcharoen feels that when he writes an orchestra piece, it takes a long time to plan even though it takes a shorter amount of time to write, whereas writing for small ensembles or solo pieces takes less time planning and more time writing. ${ }^{37}$

\footnotetext{
${ }^{36}$ Most of the information about this complete list of Prangcharoen's compositions is derived from “Prangcharoen's Curriculum Vitae," e-mail message to author, April 23, 2014. Prangcharoen's works written after April 2014 have organized and added into his curriculum vitae by author in his role of Prangcharoen's manager and personal assistant by permission of Prangcharoen.

${ }^{37}$ Narong Prangcharoen, interview by author, Orange County, CA, March 25, 2015.
} 
A list follows of Prangcharoen's large ensemble compositional output, including 20 orchestral works, 7 works for wind ensemble, 9 concertos and 1 concertino; the concertos include solo instruments with orchestra and with wind ensemble.

\section{Orchestra}

Lighter than Air (2016): Commissioned by the Pacific Symphony Youth Orchestra with the gracious support of Music Alive Grant from New Music USA. First performed on May 23, 2016 by the Pacific Symphony Youth Orchestra, Roger Kalia, conductor; Renée \& Henry Segerstrom Concert Hall, Orange County, CA, USA.

Night Sky (2016): Commissioned by the Pacific Symphony Santiago Strings with gracious support of Music Alive Grant from New Music USA. First performed on May 1, 2016 by the Pacific Symphony Santiago Strings, Irene Kroesen, conductor; Renée \& Henry Segerstrom Concert Hall, Orange County, CA, USA.

Illuminating Journey (2014): Commissioned by the Pacific Symphony Orchestra. First performed on December 11, 2014 by the Pacific Symphony Orchestra, Carl St. Clair, conductor; Renée \& Henry Segerstrom Concert Hall, Orange County, CA, USA. Rhythm of Nan (2014): Commissioned by the Designated Areas for Sustainable Tourism Administration (DASTA), with gracious support from Narikatipak Sangsanit, Chumpol Musikanon, and Anant Lerpradit. First performed on March 22, 2014 by the Bangkok Symphony Orchestra, Vanich Potavanich, conductor; National Theater Hall, Bangkok, Thailand.

New Horizons (2013): Commissioned by the Thailand Philharmonic Orchestra.

First performed on January 16, 2015 by the Thailand Philharmonic Orchestra, Jeffery Meyer, conductor; MACM Hall, Nakhon Pathom, Thailand. 
The Migration of Lost Souls (2012): Commissioned by the American Composers Orchestra with the support of Paul Underwood. First performed on October 26, 2012 by the American Composers Orchestra, José Serebrier, conductor; Carnegie Hall (Zankel Hall), New York City, NY, USA.

Illuminations (2012): Commissioned by the Beijing Modern Music Festival for their 10th Anniversary. First performed on May 18, 2012 by the China NCPA Orchestra, Lu Jia, conductor; National Centre for the Performing Arts, Beijing, P.R. China.

Echoes of Silence (2012): Commissioned by the Albany Symphony Orchestra for the American Music Festival of 2012 as part of the Capitol Region Heritage Commissions project. First performed on May 18, 2012 by the Albany Symphony Orchestra, David Alan Miller, conductor: Tory Savings Back Music Hall, NY, USA. Pubbanimitta (2011): Winner of ACO's 20th Underwood New Music Commission. First performed on June, 2011 by the American Composers Orchestra, George Manahan, conductor; Miller Theatre, New York City, NY, USA.

Delusion (2010): Commissioned by the Sunrise String Orchestra. First performed on May 7, 2011 by Sunrise String Orchestra, Poonchok Kularbwong, conductor; St. Scholastica's College, Manila, Philippines.

Namaska (2010): Winner of The Minnesota Orchestra Composer Institute, 2010. First performed on October 29, 2010 by the Minnesota Orchestra, Osmo Vänskä, conductor; The Auditorium at the Minneapolis Convention Center, Minneapolis, MN, USA.

Wisdom of the Land (2010): Commissioned by the Thailand Philharmonic Orchestra. First performed on September 23, 2010 by the Thailand Philharmonic Orchestra, Gudni Emilson, conductor; MACM Hall, Nakhon Pathom, Thailand. 
Tri-sattawat (2008): Commissioned by the Annapolis Symphony Orchestra to celebrate the tricentennial of the City of Annapolis. Winner of the "Annapolis Charter 300 International Composers Competition Prize." First performed on November 6, 2008 by the Annapolis Symphony Orchestra, Jose-Luis Novo, conductor; Maryland Hall, Annapolis, MD, USA.

Reflections of CHAKRA (2008): Commissioned by the Thailand Philharmonic Orchestra. First performed on January 15, 2009 by the Thailand Philharmonic Orchestra, Gudni A. Emilsson, conductor; MACM Hall, Nakhon Pathom, Thailand.

Tear of Dust (2008): Commissioned by the Bangkok Symphony Orchestra. First performed on February 20, 2008 by the Bangkok Symphony Orchestra, Hikotaro Yazaki, conductor; Thailand Cultural Center (Main Hall), Bangkok, Thailand.

Respiration of the Sun (2006): Commissioned by the Alexander Zemlinsky Composition Competition. First performed on June 30, 2007 by Bohuslav Martinů Philharmonic Orchestra, Andreas Hérm Baumgartner, conductor; Concert Hall of Bohuslav Martinu Philharmonic Orchestra, Zlin, Czech Republic.

Sattha (2005): Commissioned by Pacific Symphony Orchestra. First performed on November 30, 2005 by the Pacific Symphony Orchestra, Carl St. Clair, conductor; Segerstrom Concert Hall, Costa Mesa, CA, USA.

Phenomenon (2004): Winner of the Pacific Symphony's American Composer Competition 2005. Awarded 2nd prize of the Toru Takemitsu Composition Award 2004. First performed on May 30, 2004 by the Tokyo Philharmonic Orchestra, Norichika Iimori, conductor; Tokyo Opera City Concert Hall, Tokyo, Japan. 
Dharmmachakra (2004): Commissioned by Thailand National Symphony Orchestra. First performed on September 10, 2004 by Lyrique Quintette and Thailand National Symphony Orchestra, Vanich Potavanich, conductor; Thailand National Theater, Bangkok, Thailand.

Rattikarn (2001): Commissioned by Thailand National Symphony Orchestra. First performed July 25, 2001 by Thailand National Symphony Orchestra, Vanich Potavanich, conductor; Thailand National Theater, Bangkok, Thailand.

\section{Wind Ensemble}

The Rising Tide (2015): Commissioned by the Pacific Symphony. First performed on May 10, 2015 by the Pacific Symphony Youth Wind Ensemble, Gregory Whitmore, conductor; Renée \& Henry Segerstrom Concert Hall, Orange County, CA, USA.

Lokuttara (2014): Commissioned by the Barlow Endowment for Music Composition at Brigham Young University. First performed on March 22, 2015 by The President's Own United States Marine Band, Lt. Col. Jason K. Fettig, conductor; Rachel M. Schlesinger Concert Hall and Arts Center, VA, USA.

In the Dark Cloud, Light, and...(2009): Commissioned by Illinois State University for the 40th Anniversary of College of Fine Arts. First performed on October 3, 2010 by Illinois State Wind Symphony, Stephen K. Steele, conductor; the Center for the Performing Arts Concert Hall, Normal, IL, USA.

Namaskar (2009): Commissioned by Texas Tech University. First performed on April 8, 2010 by Texas Tech University Wind Ensemble, Sarah McKoin, conductor; CBDNA Southern Region Conference 2010, New Mexico State University, Los Cruces, TX, USA. 
Presage (2009): Commissioned by Kasetsart University Wind Symphony. First performed on January, 2010 by Kasetsart University Wind Symphony, Nipatdh Kanchanahuta, conductor; Kasetsart University Auditorium, Bangkok, Thailand.

Chakra (2007): Commissioned by Illinois State University Wind Symphony. First performed on April 22, 2007 by Illinois State University Wind Symphony, Stephen K. Steele, conductor; the Center for the Performing Arts Concert Hall, Normal, IL, USA. Fata Morgana (2006): Commissioned by Texas Tech University. First performed on October 5, 2006 by Texas Tech University Wind Symphony, Sarah McKoin, conductor; Hemmle Recital Hall, Lubbock, TX, USA.

\section{Concerto/Concertino}

Prangcharoen has written nine concertos and one concertino. Seven of the nine concertos were written for soloist and orchestra whereas the other two, as well as the concertino, were written for soloist and wind ensemble. As of 2011, Prangcharoen's goal has been to write only one concerto per instrument to both promote his music and its sustainability. He hopes the pieces survive on their own in the future based on their instrumental individuality. However, this case is an exception if the accompanying ensembles are of different types, for example, orchestra, string orchestra, wind ensemble. Thus, Prangcharoen wrote both a concerto for cello and orchestra, and a concerto for cello and wind ensemble. By putting all of his efforts into one concerto for an instrument, he believes each piece will be performed more since he would direct all requests for a concerto to something he has already written. 
Prangcharoen's upcoming commissions call for two additional concertos, one for piano and one for guitar, expected to be completed in 2016. Even though he has already written a concerto for piano and orchestra, Bhawangka (2002), his goal of writing one concerto per instrument came up in the later decade, and he is personally not satisfied with Bhawangka, therefore he committed to write another concerto for piano and orchestra as the commissioner requested..$^{38}$ The complete list of Prangcharoen's concerto/concertino works follows.

Seismic Waves for flute and orchestra (2016): Commissioned by the Thailand Philharmonic Orchestra. First performed on February 12, 2016 by Massimo Mercelli, flute, Thailand Philharmonic Orchestra, Alfonso Scarano, conductor; Prince Mahidol Hall, Nakhon Pathom, Thailand.

Far from Home for cello and orchestra (2014): Commissioned by the Thailand Philharmonic Orchestra. First performed on August 22, 2014 by Tapalin Charoensook, cello, Thailand Philharmonic Orchestra, Alfonso Scarano, conductor; MACM Hall, Nakhon Pathom, Thailand.

Respiration of the Earth for suona ${ }^{39}$ and orchestra (2014): Commissioned by Shi Haibin. First performed on June 5, 2014 by Shi Haibin, suona, Central Ballet Symphony Orchestra, Li Xincao, conductor; Beijing Concert Hall, Beijing, China.

Lost Horizons for bass clarinet and orchestra (2013): Commissioned by the Thailand Philharmonic Orchestra. First performed on November 7, 2013 by Henry Bok, bass clarinet, Thailand Philharmonic Orchestra, Gudni A. Emilsson, conductor; MACM Hall, Nakhon Pathom, Thailand.

\footnotetext{
${ }^{38}$ Narong Prangcharoen, phone interview by author, Thailand, March 19, 2016.

${ }^{39}$ Suona is a Chinese double-reed woodwind instrument.
} 
Maha Mantras for solo alto/soprano saxophone and orchestra (2013):

Commissioned by the 4th International Jean-Marie Londeix Saxophone Competition. First performed on July 2014 by Yo Masushita, saxophone, Thailand Philharmonic Orchestra, Dariusz Mikulski, conductor; MACM Hall, Nakhon Pathom, Thailand.

The Dawn of Darkness for tenor saxophone and orchestra (2012): Commissioned by the Thailand Philharmonic Orchestra. First performed on March 17, 2012 by Wisuwat Pruksavanich, tenor saxophone, Thailand Philharmonic Orchestra, Dariusz Mikulski, conductor; MACM Hall, Nakhon Pathom, Thailand.

Anatman for cello and wind symphony (2011): Commissioned by the UMKC Wind Symphony. First performed on April 26, 2012 by Carter Enyeart, cello, UMKC Wind Symphony, Steven Davis, conductor; White Recital Hall, Kansas City, MO, USA.

Mantras for soprano saxophone and wind symphony (2009): Commissioned by the 15th World Saxophone Congress. First performed on March 23, 2010 by John Sampen, soprano saxophone, UMKC Wind Symphony, Steven Davis, conductor; White Recital Hall, Kansas City, MO, USA.

Bhawangka for piano and orchestra (2002): Commissioned by the Thailand National Symphony Orchestra. First performed on August 8, 2002 by Bennett Lerner, piano, Vanich Potavanich, conductor, and Thailand National Symphony Orchestra; Thailand National Theater, Bangkok, Thailand.

Concertino for piano and wind ensemble (2000): First performed on July 31, 2000 by Bennett Lerner, piano, Vanich Potavanich, conductor, Srinakharinwirot Wind Ensemble; Srinakharinwirot University, Bangkok, Thailand.

Even though writing for large ensemble is Prangcharoen's favorite medium, there 
are several items of chamber music and solo instrumental music in his catalog.

\section{Chamber}

Up to this date, Prangcharoen has composed 22 chamber works, with the number of instrumentalists varying from two to five. The instrumentation includes winds, such as flute, clarinet, bass clarinet, oboe, bassoon, saxophone; brass, such as trombone and horn; strings, such as violin, viola, cello, guitar; keyboards, such as piano and harpsichord; percussion; and voice. Even a Chinese instrument, the Guqin, has been used in one of his compositions. ${ }^{40}$ Of these instruments, violin, cello, and piano are his favorite chamber instruments. ${ }^{41}$ The complete list of Prangcharoen's chamber works follows.

Perpetual Motions for saxophone quartet (2014): Commissioned by the Amigo Saxophone Quartet. First performed on July 10, 2015 by the Amigo Saxophone Quartet, Salle 22, Cité de la musique et de la danse, Strasbourg, France

Dialogue for violin, guitar, harpsichord, and voice (2014): Commissioned by Bach Aria Soloists. First Performed on February 7, 2015 by Bach Aria Soloists, Village Presbyterian Church, Kansas City, USA.

Lom 3 for viola and cello (2014): Commissioned by Alvin Wong. First performed on June 25, 2014 by Alvin Wong, cello, and Michael Hall, viola; Thailand International Composition Festival 2014, MACM Hall, Nakhon Pathom, Thailand.

Silent Echoes for viola, cello, and piano (2011): Commissioned by Amici della Musica. First performed on January 29, 2012 by members of Amici della Musica; Palamostre Theatre, Udine, Italy.

\footnotetext{
${ }^{40}$ Guqin is a 7-stringed Chinese zither played by plucking the strings.

${ }^{41}$ Narong Prangcharoen, interview by author, Kansas City, MO, December 23, 2014.
} 
Aberration of the Earth for trombone and piano (2011): First performed by the Amrein/Henneberger Duo on July, 2011, Payap University, Chiang Mai, Thailand.

Bhavana for baritone, cello, piano, and guqin (2011): Commissioned by Thomas Buckner. First performed on May 29, 2011 by Thomas Buckner and the Beijing New Music Ensemble; National Centre for the Performing Arts, Beijing, P.R. China.

Vedana for violin, horn, and piano (2011): Commissioned by the Third Angle New Music Ensemble. First performed on May 26, 2011 by the Third Angle New Music Ensemble; The Old Church, Portland, OR, USA.

Hallucinations for saxophone, Thai percussions, dancer, and painter (2009):

Commissioned by College of Music, Mahidol University for the $15^{\text {th }}$ Word Saxophone Congress. First performed on May 18, 2009 by Shyen Lee, saxophone, Manop Meechumrus, dancer, Thepsiri Sooksopha, painter, and Mahidol Percussion Ensemble; MACM Hall, Nakhon Pathom, Thailand.

Between Heaven and Earth for flute and piano (2009): Commissioned by Music Teachers National Association/Missouri Music Teachers Association. Commissioning Project Distinguished Composer Honorable Mention of 2010 Music Teachers National Association, USA. First performed on June 6, 2009 by Jonathan Borja, flute, and Christopher J. McKiggan.

Whispering for soprano saxophone, bass clarinet, piano, and percussion (2008): Commissioned by the newEar New Music Ensemble. First performed on November 1, 2008 by the newEar New Music Ensemble; Unity Temple on the Plaza, Kansas City, MO, USA.

Elegy for a Great Person for guitar and voice (2008): Commissioned by Bundit 
Ungrangsee. This piece composed in memory of HRH Princess Galyani Vadhana. It was intended for a recording project by Bundit Ungrangsee. However, that recording project was unfinished. No performance information available.

Prann for cello, percussion, and Thai percussion (2008): Commissioned by Madeleine Shapiro. This piece composed in memory of HRH Princess Galyani Vadhana. No performance information available.

Sunyata for violin, cello, and piano (2007): Commissioned by Eon Trio. First performed on July 28, 2007 by Eon Trio; Thailand Cultural Center, Bangkok, Thailand.

Vayu for flute, clarinet, violin, cello, and piano (2007): Commissioned by the New York New Music Ensemble. First performed on July 15, 2008 by the New York New Music Ensemble; Chulalongkorn University, Bangkok, Thailand.

Anusorn for cello and piano (2006): Commissioned by Madeleine Shapiro and Bennett Lerner. First performed on May 7, 2006 by Madeleine Shapiro, cello, and Bennett Lerner, piano; Greenwich House Music School, New York City, NY.

Lom 1 for flute and clarinet (2006): Commissioned by Yos Vaneesorn. First performed on December 9, 2006 by Yos Vaneesorn, clarinet and Adam Calliham, flute; Grant Recital Hall, Kansas City, MO, USA.

Pain, Loss, and... for string quartet (2003): First performed on July 26, 2003;

California Summer Music Concert, Monterey, California, reprised at California Summer Music Concert 2004.

Shadow for woodwind quintet (2003): Commissioned by Lyrique Quintette. First performed on November 16, 2003 by Lyrique Quintette (Faculty Woodwind Quintet of University of Arkansas), reprised at Asian Music Festival at University of Arkansas, 
April 7, 2004, and received Thailand premiere in September 2004.

Mantra and Maya for violin and piano (2003): Commissioned by Kit Young and the Lanna Music Festival. This piece was composed for students who participated in Lanna Music Festival 2003, Chiang Mai, Thailand as their chamber music reading activities. However, there is no official performance information.

Bencharong (2002): Commissioned by Kit Young and the Lanna Music Festival. First performed on April 3, 2002 by the Lanna Music Festival Ensemble; Lanna Music Festival, Payap University, Chiang Mai, Thailand.

Shade of the Night and the Day for flute, piano, and percussion (revised version, 2001): First performed on November 15, 2001 by Illinois State Music Faculties; Illinois State University, Normal, IL, USA

The River for wind ensemble (2000): First performed on July 31, 2000 by Srinakharinwirot Wind Ensemble, Vanich Potavanich, conductor; Goethe Institute Auditorium, Bangkok, Thailand.

\section{Solo}

There are only six compositions for solo instrument: three for solo piano plus one each for flute, viola, and cello. Five of them were commissioned by the instrumentalists themselves; the exception is a solo piano piece, The Temple in the Mist (2000), which Prangcharoen dedicated to his piano teacher, Bennett Lerner. The list of Prangcharoen's solo works follows. 
Pact Ink for solo piano (2014): Commissioned by Christopher Janwong McKiggan. First performed on September 22, 2014 by Christopher Janwong McKiggan, piano; Duncan Recital Hall, Rice University, TX.

Lom 2 for solo flute (2014): Commissioned by Luisa Sello. First performed on February 20, 2014 by Luisa Sello; Musika Follia, Vienna, Austria.

Antahkarana for solo viola (2010): Commissioned by Michael Hall. First performed on July 15, 2010 by Michael Hall, viola; Thailand International Composition Festival, Rangsit University, Pathum Thani, Thailand.

Far from Home for solo cello (2004): First performed on July 31, 2004 by Nick Dinnerstein, cello; California Summer Music Concert, Monterey, CA, USA.

Three Minds for solo piano (2003): Commissioned by Bennett Lerner. First performed on October 4, 2003 by Bennett Lerner, piano; Lincoln Theater, Miami Beach, FL, USA.

The Temple in the Mist for solo piano (2000): First performed on July 31, 2000 by Bennett Lerner, piano; Goethe Institute Auditorium, Bangkok, Thailand.

\section{Choral}

There are only two choral works that Prangcharoen has composed thus far. During his college years at Srinakharinwirot University, he was appointed to arrange popular music and some Broadway music for the SWU Chorus, who were planning related musical events, but he did not compose any choral music until he graduated. The first choral piece that he wrote is The Enchanted Wood (2000), which was written for a small choir and two pianos. The piece premiered in July 2000 during his first 
composition recital at Thai-German Cultural Institute, featuring members of SWU Chorus, under the baton of Vanich Potavanich.

His second choral piece is an unaccompanied multi-movement choral work, Poems of the Earth (2014), commissioned by the Bangkok Choral Society. A movement from this set, "Echo of the Mountain," was finished in 2009 and was premiered by the Bangkok Christian College Glee Club in June 2009 at the Thailand Cultural Center. The complete set was finished in 2014, though it has not yet been performed.

\section{Musicals}

The only musical that Prangcharoen composed thus far is Eng-Chang the Musical (2015), commissioned by the College of Music, Mahidol University, Thailand. First performed on October 12, 2015 by the Thailand Philharmonic Orchestra, Thanapol Setabrahmana, conductor; Prince Mahidol Hall, Nakhon Pathom, Thailand.

\section{Voice and Orchestra}

The only work for voice and orchestra that Prangcharoen has written is The Great Person for soprano and orchestra (2008): Commissioned by the Thailand National Symphony Orchestra and Bundit Ungrangsee. This piece composed in memory of HRH Princess Galyani Vadhana. It is a revised version from Elegy for a Great Person for guitar and voice (2008). First performed on May 5, 2008 by Mary Ungrangsee, soprano, Thailand National Symphony Orchestra, Bundit Ungransee, conductor; Thailand Cultural Center (Main Hall), Bangkok, Thailand. 


\section{CHAPTER 3}

\section{THREE MINDS: HISTORICAL BACKGROUND \\ AND STYLISTIC DISCUSSION}

Prangcharoen has more than fifty compositions published. Of these compositions, only three are written for solo piano; Three Minds is one of them. Two of the three piano works were written for Bennett Lerner, his former piano teacher, and the last of the three was written for Christopher Janwong McGiggan. ${ }^{42}$ In order to understand more on the historical background of Three Minds, the two other piano works are also discussed here.

The first solo piano work he composed was The Temple in the Mist (2000). The work was dedicated to Lerner. It is an early one-movement work that pays homage to Debussy. Prangcharoen composed the work for Lerner while Lerner was staying at a temple to meditate. ${ }^{43}$ Prangcharoen was inspired by two ideas. The first is a picture of a temple in northern Thailand at morning, covered by a mist. The second idea was the fact that the work was composed during a larger time period during which Lerner was practicing Debussy's complete piano works for a recording project. Prangcharoen presented him with a composition to give him a break from Debussy; it was not an absolute break, however, since this composition was written in the style of Debussy, one of the composers whom Prangcharoen admires.

In this piece, Prangcharoen used methods similar to those used by Debussy in his preludes, particularly his use of the pentatonic scale and heavy use of pedal to create a harmonic blur. He described The Temple in the Mist as a combination of impressionistic

${ }^{42}$ The third is Pact Ink (Kansas City, Missouri: Self-Published, 2014).
${ }^{43}$ Narong Prangcharoen, interview by author, Bangkok, Thailand, July 21, 2015. 
textures with fragments of Thai folk music, which developed into his main thematic material. $^{44}$

In addition to The Temple in the Mist and Three Minds, a work entitled Pact Ink (2014) remains his third and most recently written solo piano work. The piece was commissioned by Christopher Janwong McKiggan. Written as a spiritual complement to Paganini's opus 1, 24 Caprices for Solo Violin, it is in the form of theme and variations, an approach similar to that used by previous composers inspired by the piece. Pact Ink refers to a pact made with the devil and the ink used to validate it. The title thereby plays on the myth of Paganini selling his soul to the devil in exchange for unparalleled technical ability and an almost supernatural mastery of the violin. The music by Paganini moves like a fluid through the piece, similar to ink moving across a canvas. It is not really clear where the lines begin or end, or when the music will stop. However, when the music indeed stops with short accented chords, the lines follow the manner of a period ending a sentence, relieving the listener from the possibility of misdirection. ${ }^{45}$

Since Debussy and Paganini influenced The Temple in the Mist and Pact Ink respectively, Three Minds is the only solo piano piece so far in which Prangcharoen is not deliberately and self-consciously paying tribute to another specific composer. He draws inspiration from within himself. Specifically, these inspirations are three different minds: a fierce mind, an absent mind, and a hesitant mind. These three separate ideas became titles for each movement of Three Minds.

\footnotetext{
${ }^{44}$ Bennett Lerner, Program Note e-mail message to author, March 13, 2014.

${ }^{45}$ Narong Prangcharoen, Pact Ink (Kansas City, Missouri: Self-Published, 2014).
} 


\section{Historical Background of Three Minds}

Prangcharoen composed Three Minds in 2003 to fulfill a commission from Lerner for a solo piano piece, to be included in his concert tours both in Thailand and overseas in 2003. Lerner had already included Prangcharoen's The Temple in the Mist in his program; however, he wanted to perform another of Prangcharoen's pieces since The Temple in the Mist is a short work. During that time, Prangcharoen was studying for his DMA at the University of Missouri-Kansas City and Lerner was a lecturer at the Music Department (later College of Music), Payap University, Chiang Mai. At first, Prangcharoen wanted to write only one movement with multiple sections alternating between Allegro and Adagio tempi. He changed his mind and decided to flesh out his initial idea into three separate movements. ${ }^{46}$

Because of his Buddhist heritage, Prangcharoen experienced being a monk for a week when he was 29 years old. In Thai culture, men who reach the age of 21 are encouraged to become Buddhist monks for the period of three months, although people nowadays are often too busy to commit themselves to the ordained state for that long. Buddhists believe that if a man once in his life becomes ordained, he will enable his parents to enter heaven after they die. It is also a means to attain purity. Parents often encourage their sons to partake in this custom.

Because of this, Prangcharoen was able to experiment with meditation in the temple. Through his meditative practice, he observed how people's minds can affect their lives. He found that the human mind can change any time depending on what they are facing at the moment. When he did meditate, his mind was calm and very focused, and he

\footnotetext{
${ }^{46}$ Narong Prangcharoen, interview by author, Bangkok, Thailand, July 21, 2015.
} 
noticed three separate feelings—-ferocity, absentia, and hesitancy — coming to his mind daily.

He has also provided an anecdote concerning using the title Three Minds with the influence of Lerner's concert program. Lerner toured from September 8, 2003 to November 6, 2003. The venues of the concerts were in Thailand, Japan, and the USA. The program was entitled "Music by My Friends," featuring works written by his composer-friends, including piano works by Aaron Copland, Chester Biscardi, Christopher Berg, Donald Richie, Narong Prangcharoen, Robert Helps, Roger Zahab, Thorsten Wollmann, and Tison Street. Among these piano works, Copland's music is called Three Moods. Prangcharoen then decided to use "Three Minds" as the title and said jokingly, "Copland has Three Moods, Narong has Three Minds."

\section{Stylistic Elements of Three Minds}

Three Minds features three different styles, characters, and moods in three short pieces. In Prangcharoen's program notes, these emotions are connected to our body and soul, and can affect our life tremendously. Our mind can positively create power and energy in life, while it can also discourage us. These emotions and mind are connected to the sound of music. One thing music can do amazingly well is to create almost the same feeling in different people from different cultures. Prangcharoen intended, in Three Minds, to use music to explain his own mind in different emotions. ${ }^{47}$ From this arose the conception of the three different characteristics of the work.

\footnotetext{
${ }^{47}$ Narong Prangcharoen, preface to Three Minds (Kansas City, MO: Self-Published, 2003).
} 


\section{Fierce}

Although the order of the three movements is fast-slow-fast: "Fierce," "Absent," and "Hesitant" respectively, the compositional process did not happen in that order. The first movement, "Fierce," was finished last. This movement expresses ferocity, the most energetic emotion. It reflects human anger and madness, represented by irregular rhythms. The intense state of anger, according to the composer, is expressed by thematic material that has no accompaniment. Two thematic materials are combined at the end of the piece to picture the great energy of madness that the mind of an angry person creates. As this document focuses on this movement, all details and in-depth analysis of "Fierce" will be discussed in Chapter 4.

\footnotetext{
Absent

The second movement, "Absent," was composed and finished during the same period as the first movement. This movement describes a state of mind devoid of thought. According to the composer, when absent-mindedness occurs, we tend to introspect and perhaps recall what has happened in the past. The piece imitates this state of mind by using free harmonic progressions as well as unbounded tonality to represent free thoughts that may happen during the absent-minded state. The structure of this movement is provided below.
} 
Structure

Table 3.1 Formal structure of "Absent"

\begin{tabular}{|l|l|}
\hline Section & Measure \\
\hline A1 & $1-9$ \\
\hline A2 & $10-17$ \\
\hline A3 (incomplete) & $18-27$ \\
\hline New Material or Transition & $28-30$ \\
\hline A4 & $31-43$ \\
\hline A5 & $44-53$ \\
\hline Coda & $53-60$ \\
\hline
\end{tabular}

The piece is in strophic form with modification using variation technique. Section A1 lasts for nine measures, presented as the principal section upon which the rest of the piece is based. This section is the simplest, including only core material. This enables further elaboration later in the piece. Section A2 retains the thematic material but becomes more elaborated with one more voice added, and has different meters and rhythms from section A1. Section A3, although lasting for 10 measures, seems to be compressed, since the composer sets the melodic material in eighth-note values and repeats the fragment of the melody in sequence (see example 3.3.1; the motif comprises two identical parts, with the second half of the motif lower than the first). To compare with the two preceding sections, while the repetition of the melody in section A3 happens immediately (that is, the melodic that begins in $\mathrm{m} .19$ is sequentially repeated beginning in $\mathrm{m} .20$ ), in section A1 this sequential repetition does not happen until $\mathrm{m} .7$ of section A1 (see examples 3.1.1 and 3.1.2); in further contrast, in section A2 the melodic material is set in longer note values (see examples 3.1.3 and 3.1.4). The transition (mm. 28-30) 
presents new material with two independent lines moving in arpeggios. Section A4 is written with three staves throughout and this continues in section A5. The piece ends with a coda that features glissandi in the bass; these glissandi are prefigured in the previous sections of the piece (see Thematic Material section below). The coda also uses harmonic overtones: the right hand presses the written notes silently while the left-hand glissandi always end with low-register clusters; the clusters are then cut off, leaving the strings of the notes that were pressed silently to ring with the overtones of the previous clusters.

\section{Texture}

This slow movement is quite distinct texturally from the first movement, "Fierce." The music hardly has an unaccompanied passage. It starts with the melodic line with accompanying chords. The texture becomes more complex in each variation of the piece. At times, it is notated with three staves, which enables each part to be seen easily. However, at certain point of the piece such as m. 39 (see example 3.1.7) where the composer marks "slur for top voice" above the bass line, this passage has more than three voices - the lowest line creates an effect similar to a compound melody. These lines create, overall, a polyphonic texture. Specifically, in $\mathrm{m} .39$ the varied return of the melodic line from the beginning is now accompanied by the other lines underneath. The accompanying lines adorn the melodic line in a contrapuntal manner and create a different texture from the beginning of the piece, when the melody was harmonized with block chords. 


\section{Dynamic Interest}

The piece features a wide dynamic range as well as sudden dynamic changes. It starts piano and after the first large and rapid crescendi, mm. 16-17 and 21-22, produced through the means of a glissando, the music afterwards suddenly returns to piano. The music then returns to forte, this time with the dynamic sustained and also enhanced with accents, for all of section A5; in the coda, repeating glissandi followed by clusters further increase the volume of the piece.

\section{$\underline{\text { Rhythmic/Metric Interest }}$}

Beyond the embellishment of the same melodic line and the different textures between the beginning and later variations, the main features of varied repetition are changes of rhythms and meters, either within the same section or between the sections. The pulse keeps changing along with the metric changes and gives an asymmetrical feeling throughout the piece. Starting from the beginning, the melody is played in $4 / 4$ but changes to $3 / 8$ in the second measure. Not only does the pulse change, the quadruple time reduces to the triple time. M. 4 changes to $2 / 4$ and m. 5 moves to $9 / 8$. Metric changes are common in this piece, in imitation of the state of absent-mindedness. Uncommon rhythmic subdivisions are also featured. With these metric and rhythmic changes that characterize the piece, the music progresses in irregular pace, recalling the introspective mind with its unpredictable sequences of thoughts and its caprice. 


\section{Thematic Material}

Unlike "Fierce," this piece shows no influence from Thai traditional music. What creates coherence in the piece is the use of motifs. Example 3.1 (below) shows the melodic motif that appears throughout the work: motif 1 . This motif often appears with different rhythms each time and sometimes with intervallic alterations. Examples 3.1.1 and 3.1.2 show motif 1 that appears in section A1. Examples 3.1.3 and 3.1.4 show this motif as it appears in section A2. Section A3 has a fragment of the motif, as shown in example 3.1.5, before the melodic line plays what is here considered motif 3 (see example 3.3.1). Examples 3.1.6 and 3.1.7 are taken from section A4 and example 3.1.8 is from section A5.

\section{Example 3.1 Motif 1}

3.1.1 Mm. 1-4

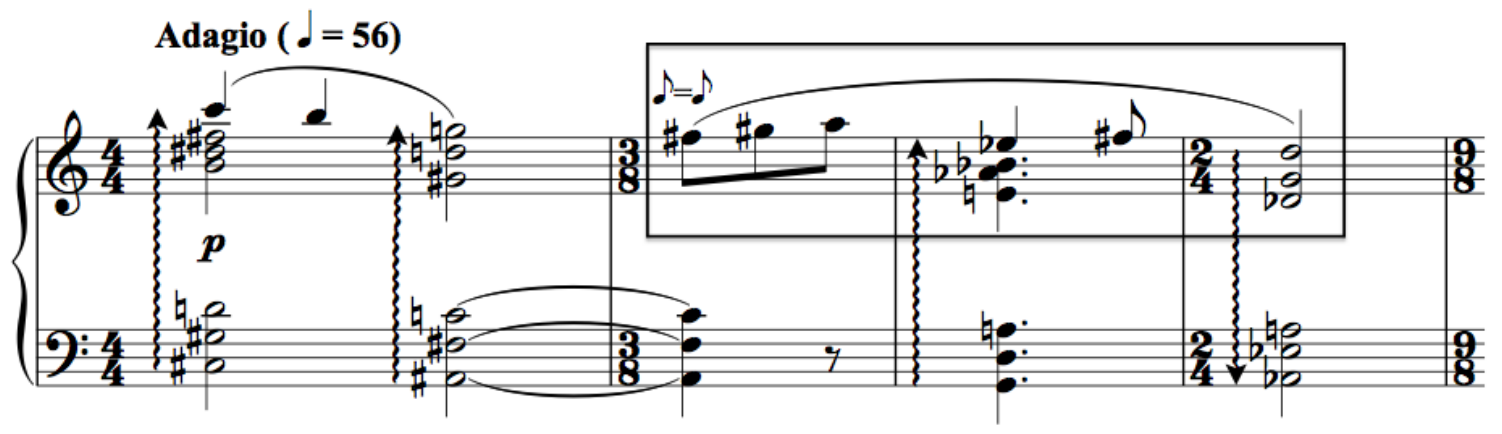


3.1.2 Mm. 7-9

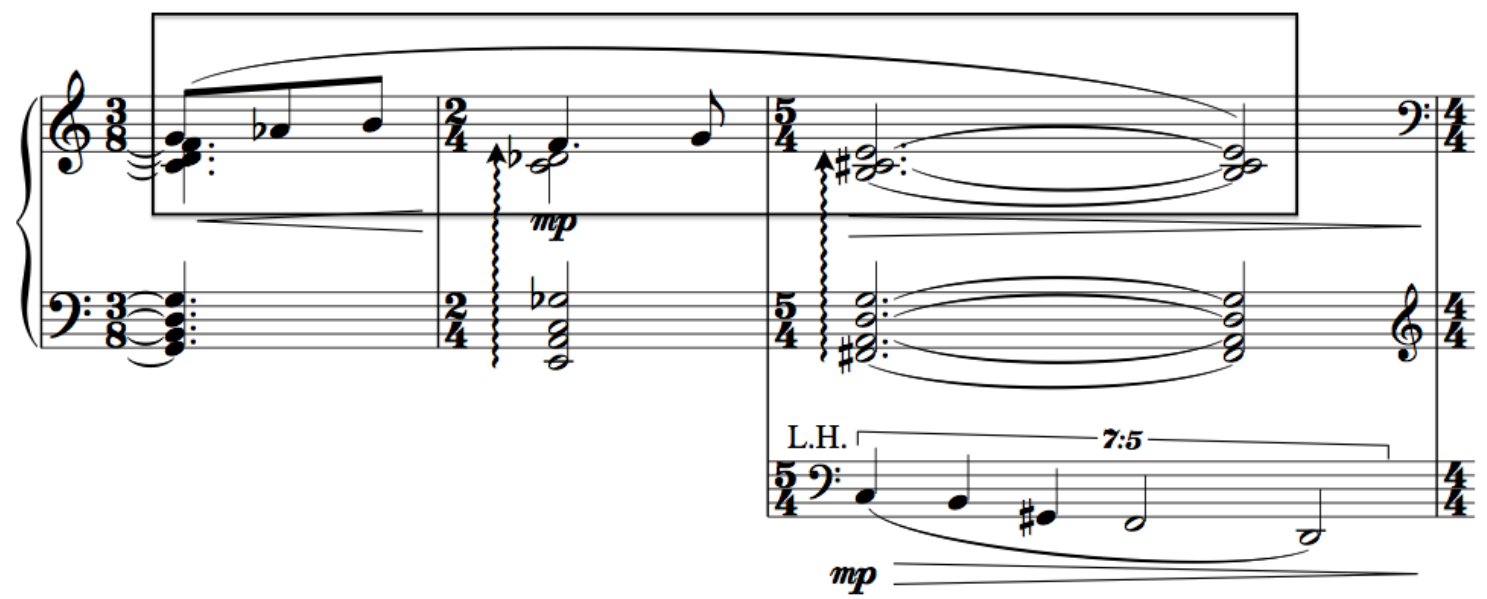

3.1.3 Mm. 10-12

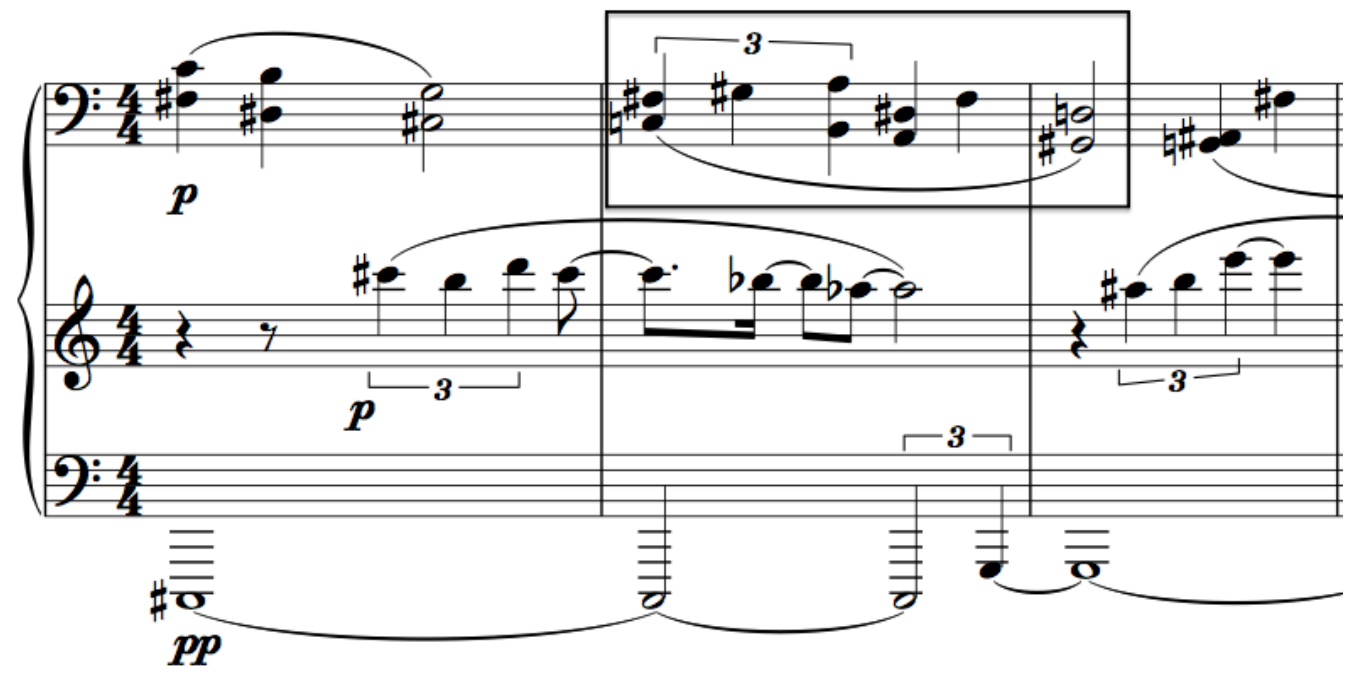


3.1.4 Mm. 14-16

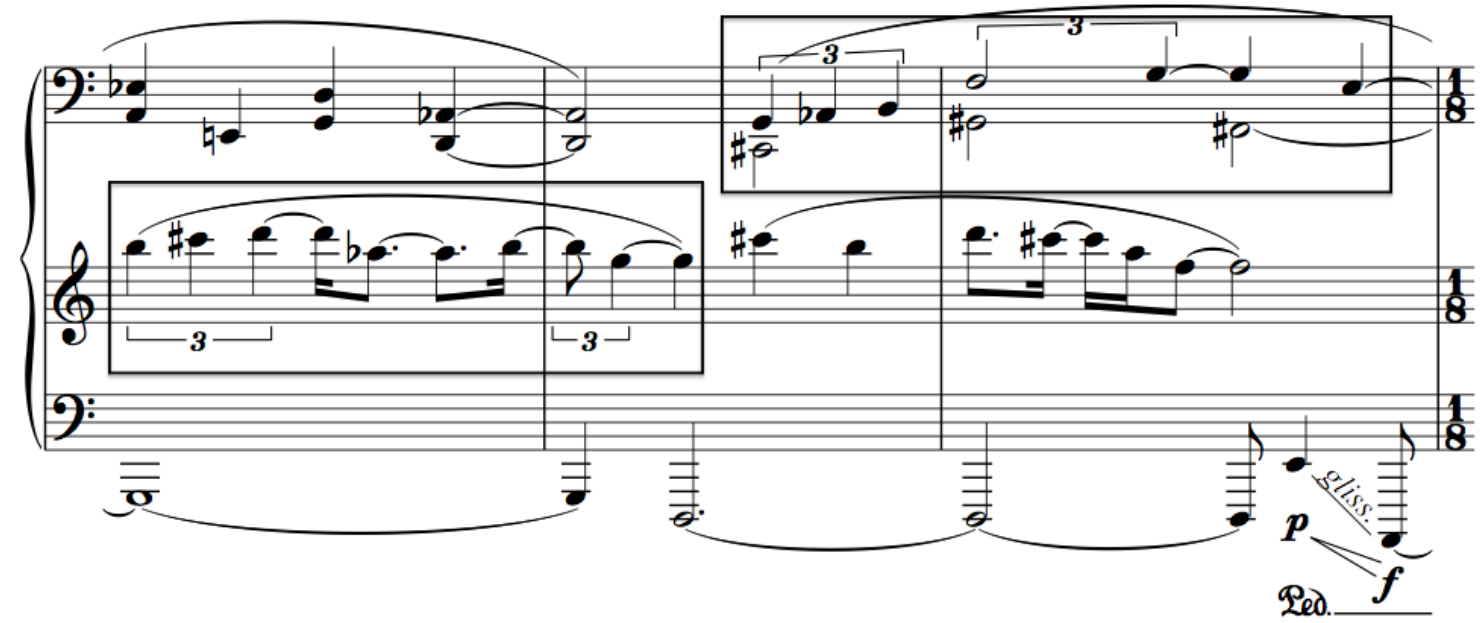

3.1.5 Fragment of motif 1 in $\mathrm{m} .18$

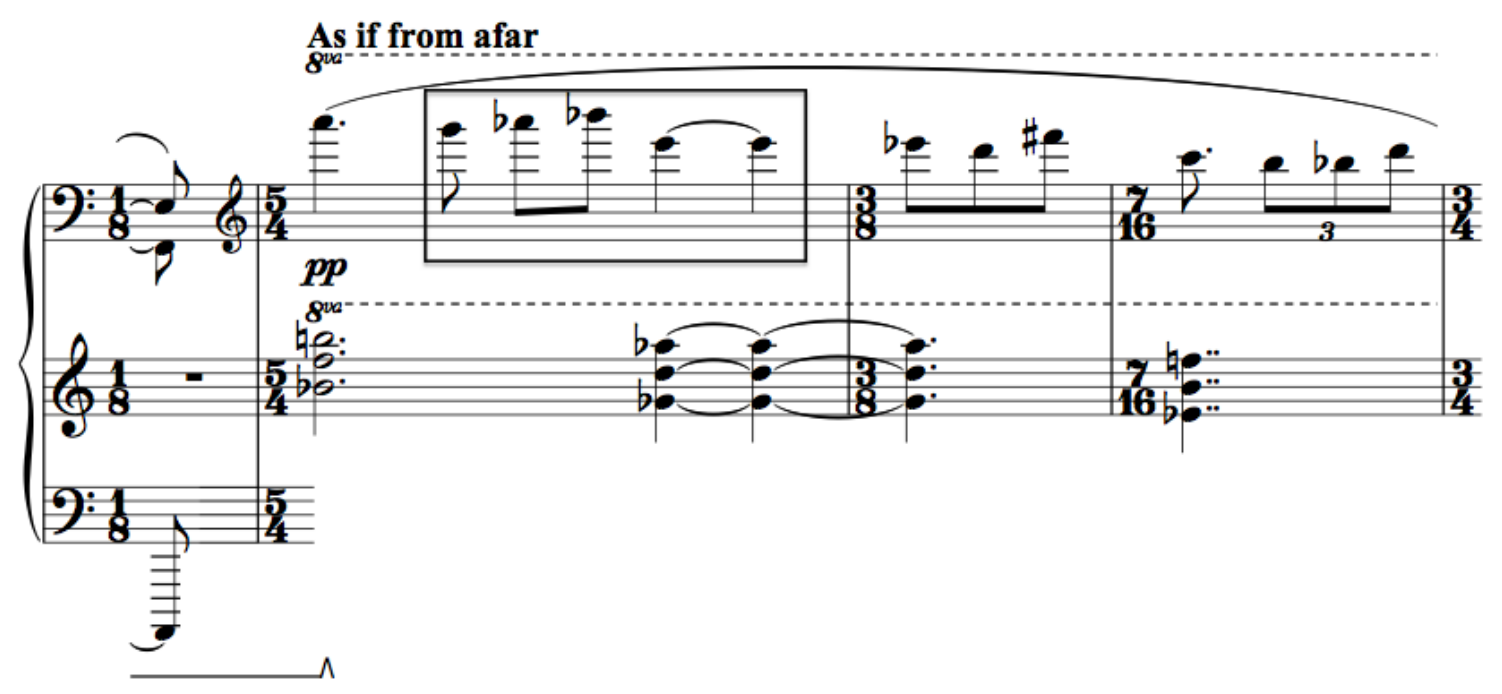


3.1.6 Mm. 30-35
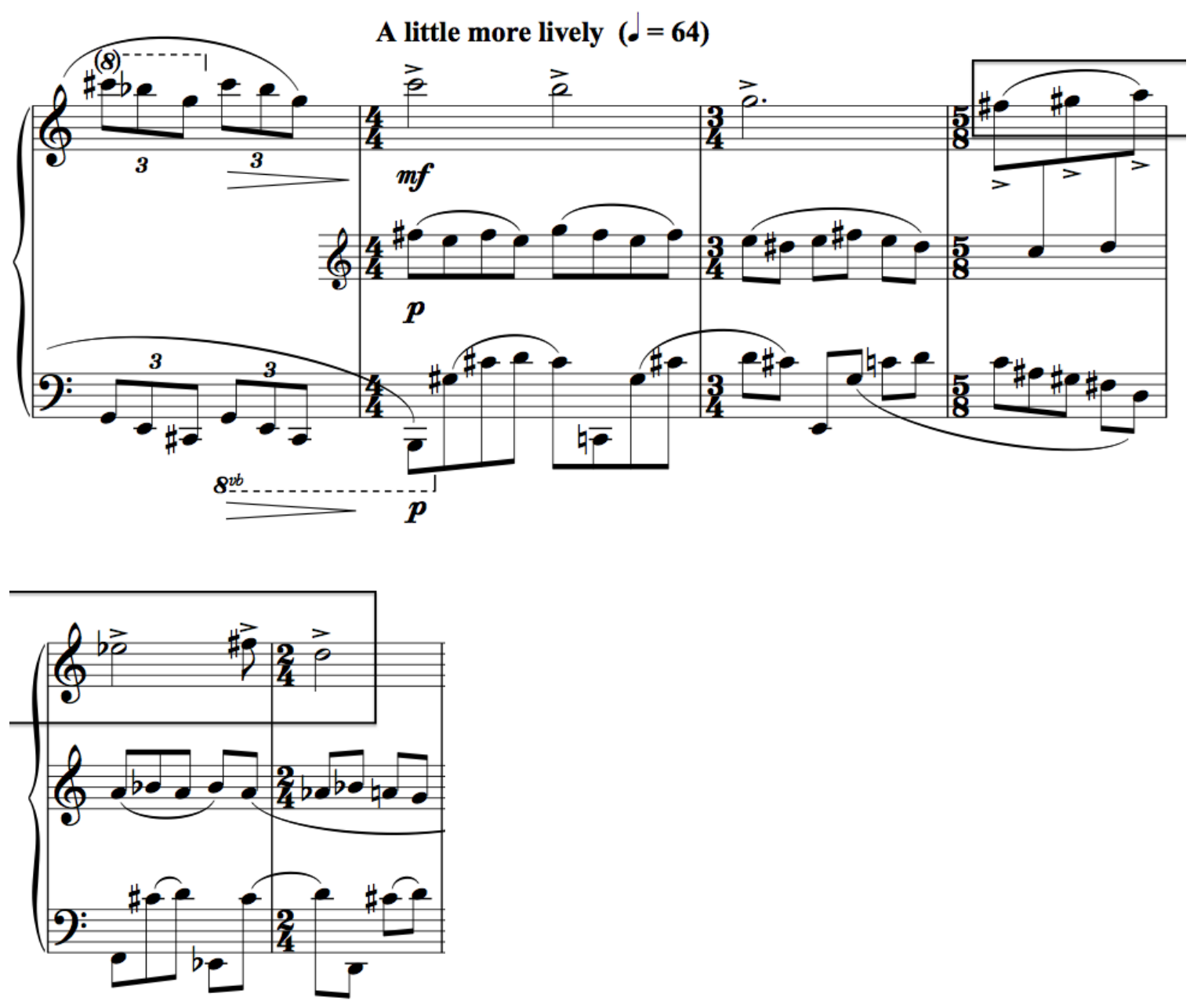

52 


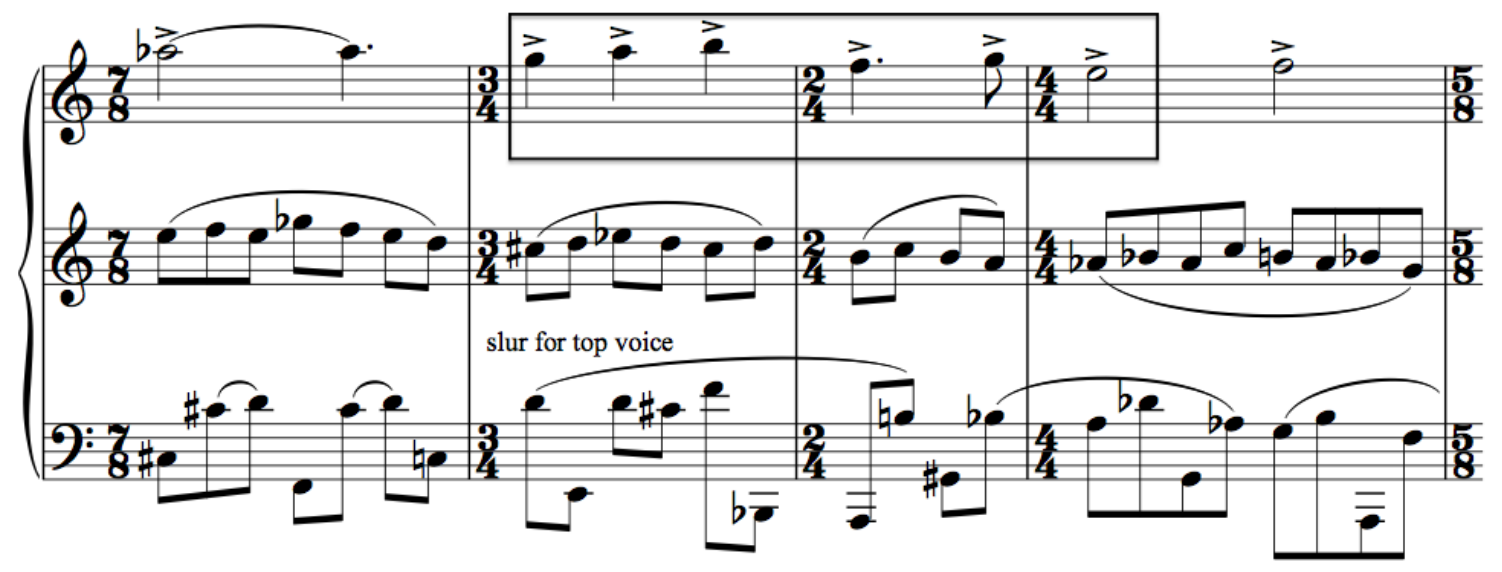

3.1.8 Mm. 45-47

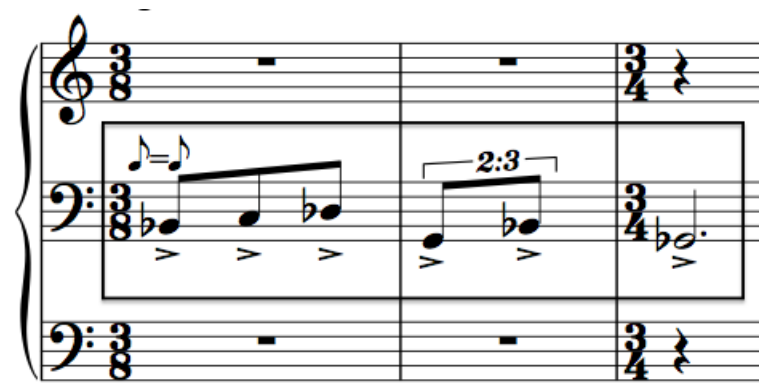

Another important motif, named here motif 2 (example 3.2), appears in the bass line three times. This descending bass line prefigures the downward glissandi that first appear in $\mathrm{m} .16$ and then repeat six times in the coda. 
Example 3.2 Motif 2

3.2.1 Mm. 7-9

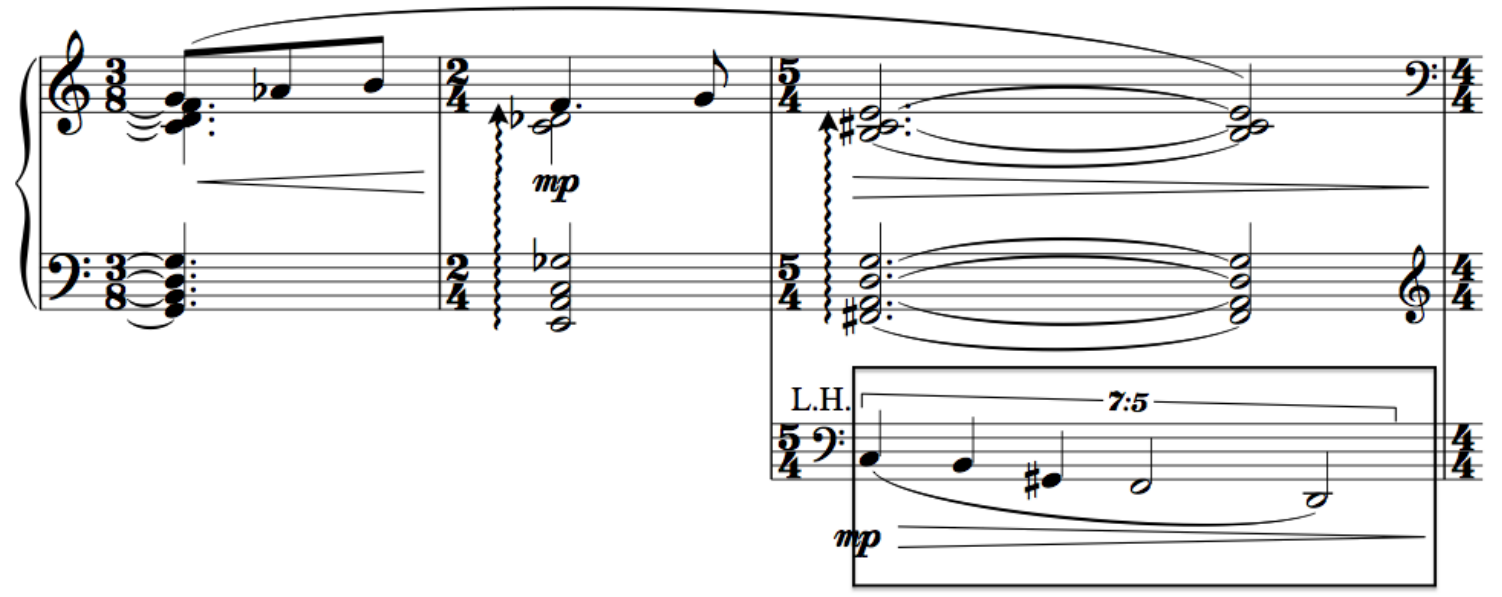

3.2.2 Mm. 26-28

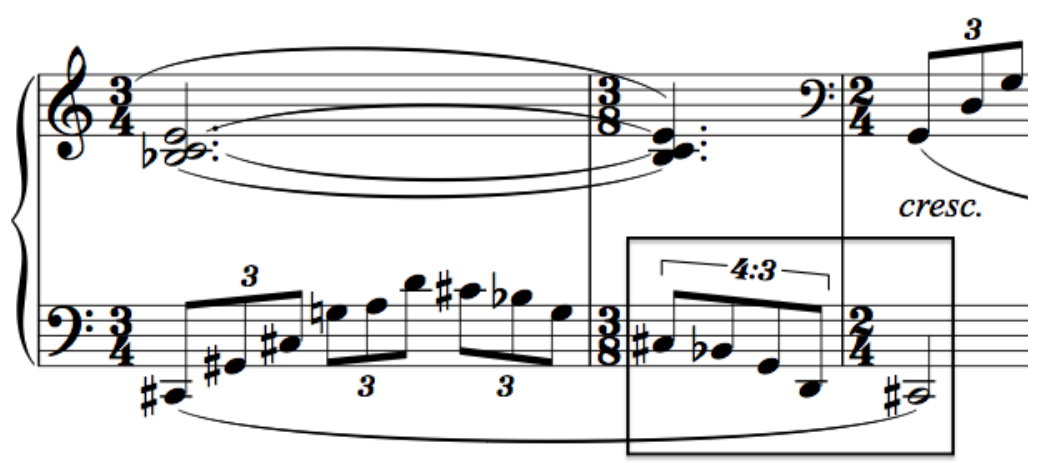


3.2.3 Mm. 30-33

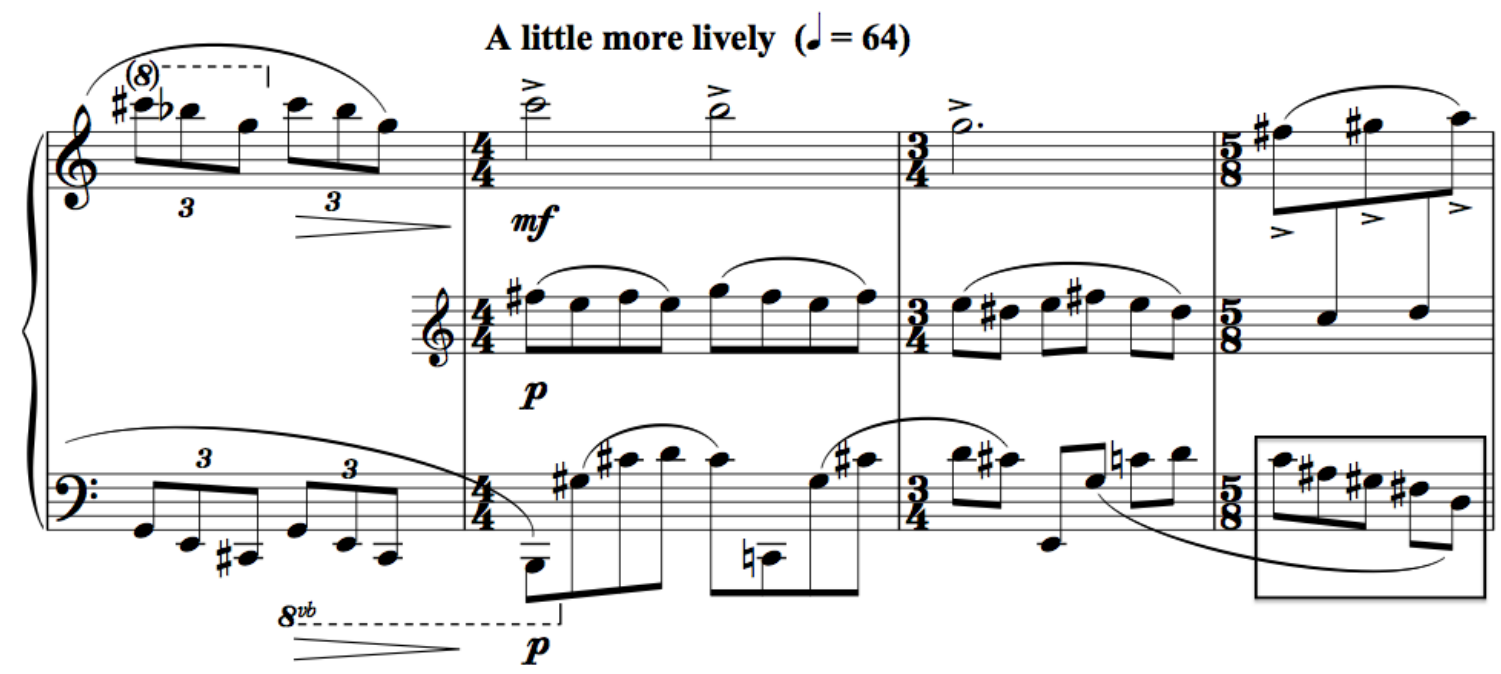

One more motif makes its appearance, named here motif 3 . This motif is a result of inversion and alteration of motif 1 . This can be seen by comparing example 3.3 with motif 1 in example 3.1. Motif 3 remains some of the intervallic structure of motif 1 but going in diverse directions. Example 3.3.3 demonstrates the comparison of motif 1 in mm. 2-4 with motif 3 in mm. 22-24. Looking at some notes that shape the direction of the line, both motifs retain almost the same intervallic structure. However, motif 3 takes melodic detours in the opposite direction between the main notes that shape the contour of the line, unlike motif 1, which is more unidirectional and straightforward. Example 3.3.4 shows another comparison: between motif 1 in $\mathrm{mm}$. 7-9 and motif 3 in $\mathrm{mm}$. 51-53. The intervallic structure remains almost the same. What distinguishes motif 3 from motif 1 is, therefore, the melodic detours in the first part of motif 3. 
Example 3.3 Motif 3

3.3.1 Mm. 17-24
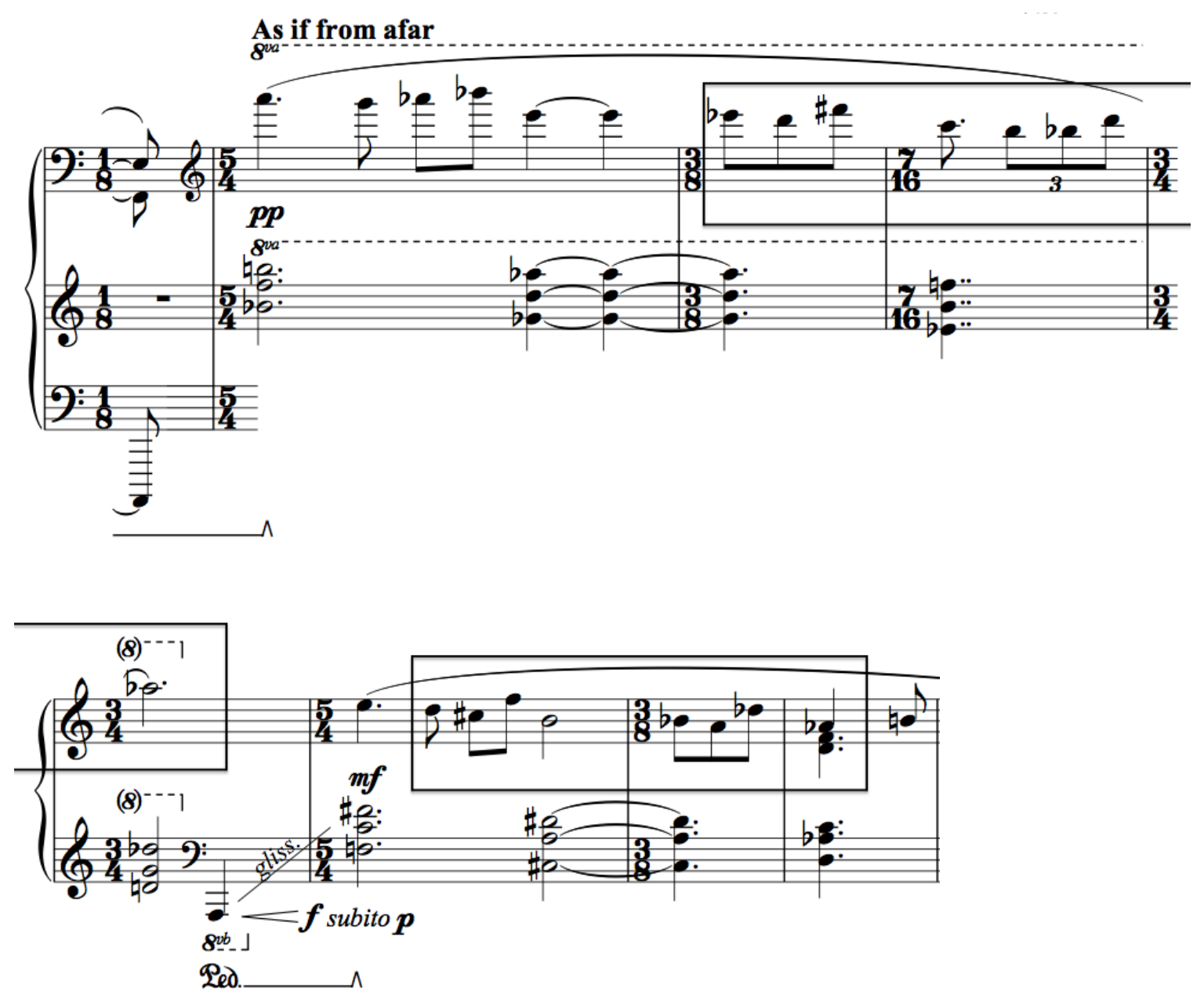
3.3.2 Mm. 45-53

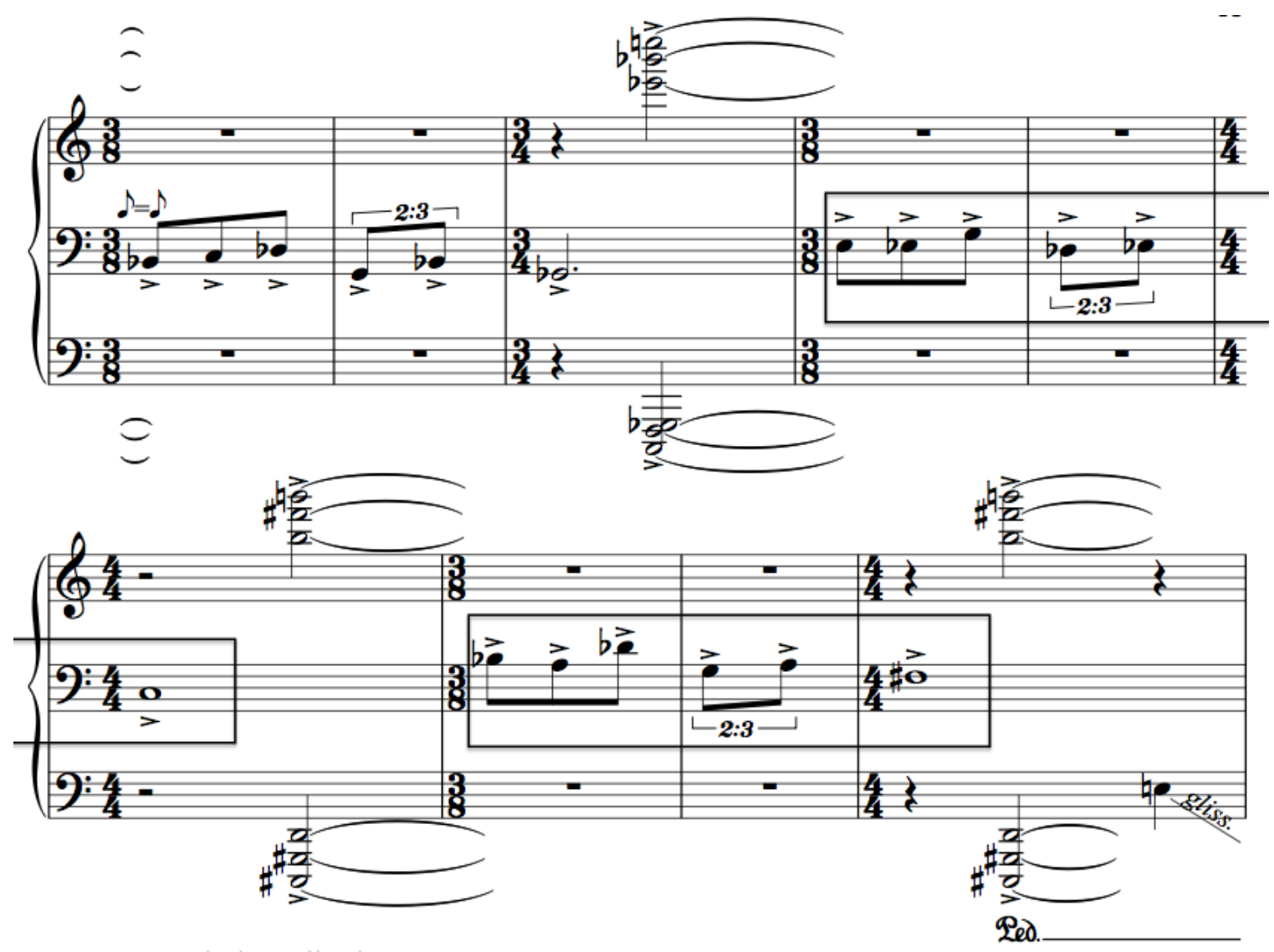


Example 3.3.3 Comparison of motif 1 in mm. 2-4 and motif 3 in mm. $22-24$
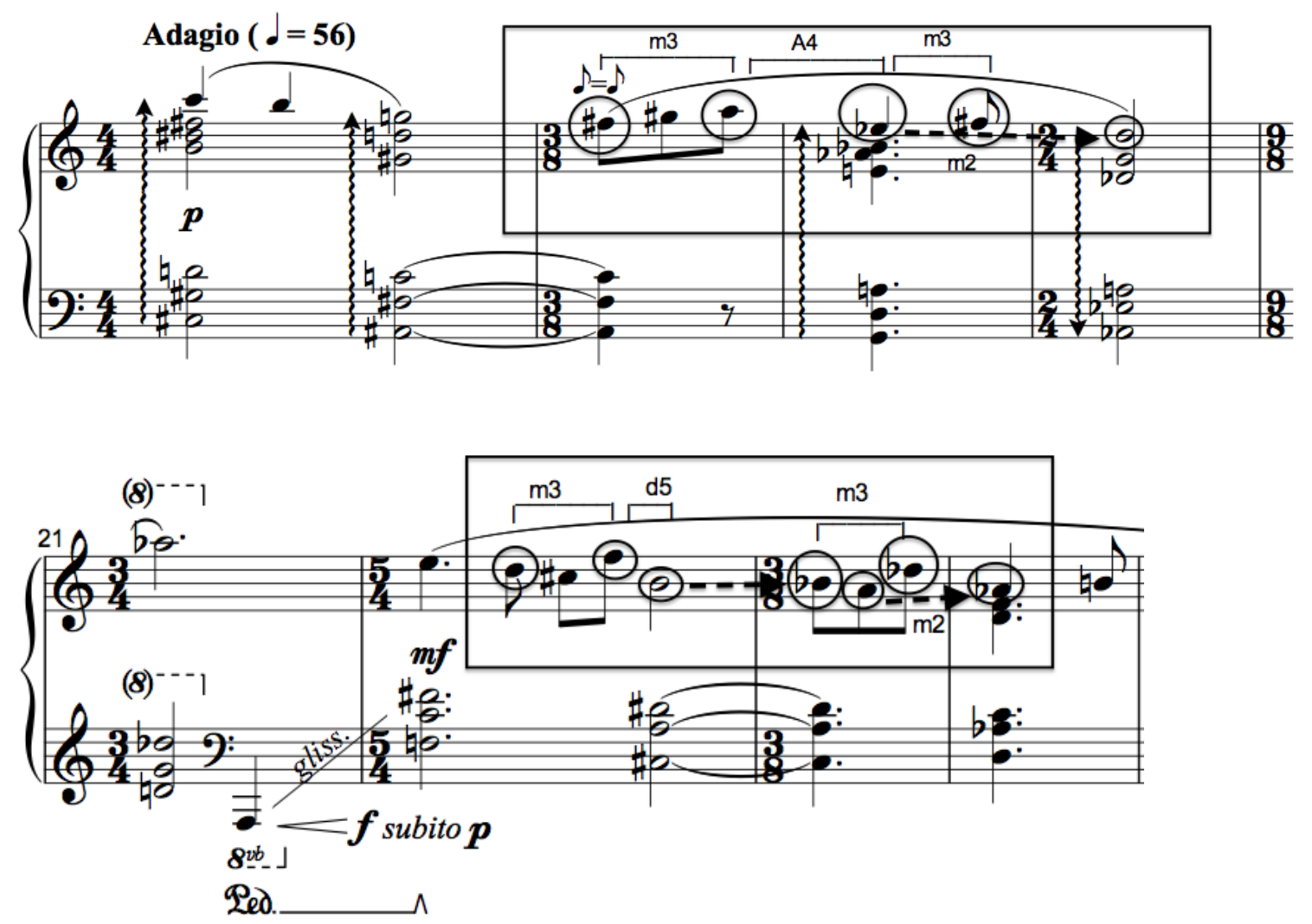

Example 3.3.4 Comparison of motif $1 \mathrm{in} \mathrm{mm}$. 7-9 and motif $3 \mathrm{in} \mathrm{mm.} \mathrm{51-53}$

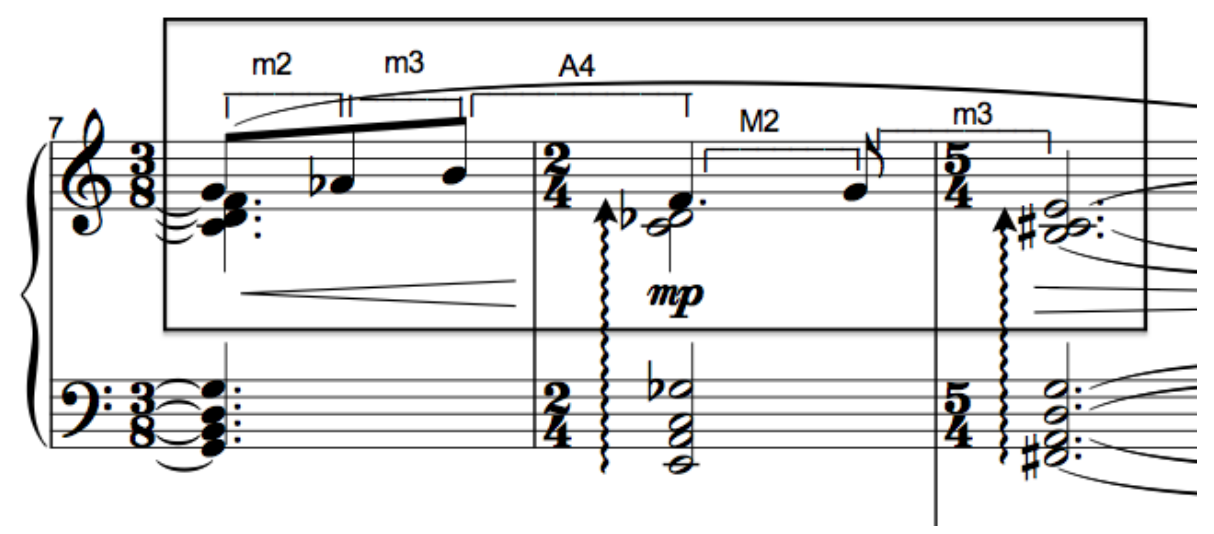




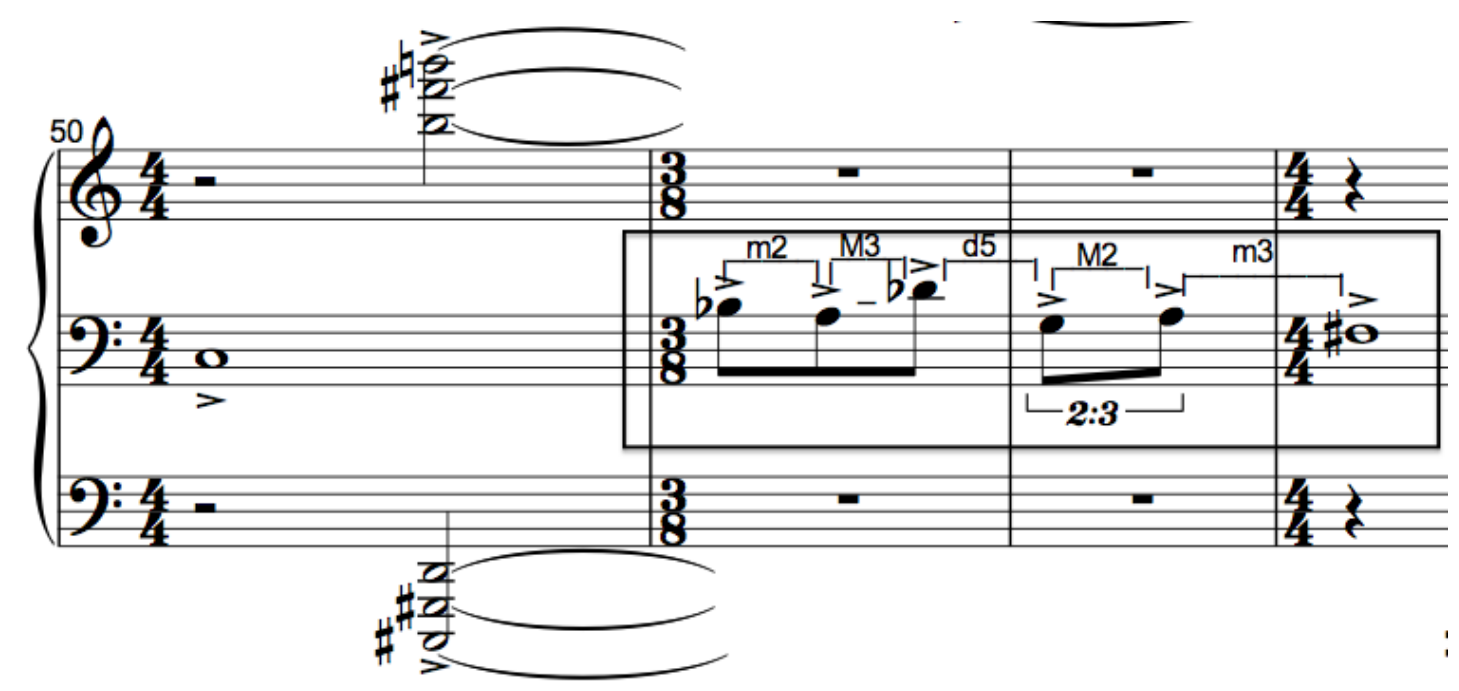

All the repeating motifs unify the whole composition. Although other parameters, as previously mentioned, provide contrast, these motifs provide unity.

\section{Hesitant}

The last movement, "Hesitant," was actually finished first. It is a revision of one of the small piano pieces that Prangcharoen wrote earlier while studying with Dhamabutra at the beginning stages of his training as a composer. The first version, a single movement work for piano, was entitled Sonatina. It was premiered in his first composition recital in 2000, performed by Kit Young at Thai-German Cultural Center, Bangkok. However, because of the composer's dissatisfaction of the first version, he decided to make a revision of the piece and use it as the last movement of Three Minds. The original version of Sonatina was withdrawn and has been lost.

According to the composer, the last movement "Hesitant" describes confusion of mind. This state is portrayed through expansion of tonality. The obscure tonality is 
equivalent to a hesitating mind trying to find an answer for a question or to make a right decision. The structure of this movement is displayed below:

\section{Structure}

Table 3.2 Formal structure of "Hesitant," compound ternary form

\begin{tabular}{|l|l|}
\hline Section & Measure \\
\hline A & $1-7$ \\
\hline Theme A & $8-13$ \\
\hline Theme B & $14-21$ \\
\hline Theme A & $22-29$ \\
\hline Transition 1 & \\
\hline B & $30-39$ \\
\hline Theme C & $40-45$ \\
\hline Transition 2 & $46-54$ \\
\hline Theme D & $55-60$ \\
\hline Transition 3 & \\
\hline A & $61-64$ \\
\hline Theme A & $65-69$ \\
\hline Theme B & $70-72$ \\
\hline Theme A & $73-74$ \\
\hline Material from Theme D & $75-80$ \\
\hline Coda & \\
\hline
\end{tabular}

The structure of "Hesitant" is the most complex among the three pieces. In the large picture, it is in compound ternary form. Section A itself is ternary with subsections A B A. Section B presents themes C and D. In this section, an ostinato pattern is prominent whenever theme $\mathrm{C}$ is present. The pattern continues in transition 2 that leads to 
theme D. Section A returns again in $\mathrm{m} .61$ but in different register from the beginning. The transitional passage (mm. 73-74) derives from theme $\mathrm{D}$ of section $\mathrm{B}$ and leads to the coda where ostinato patterns are present throughout. Knowing that the original version of this piece is called "Sonatina," it is possible that this unique compound ternary form may be a result from the modification of sonata form.

\section{Texture}

Most of the time, the left hand plays the melody. Ostinato patterns in the right hand are characteristically used as an accompaniment. Often in the transitional passages, both hands move by linear progression where both hands are equally important.

Transition 2 is composed of a canonic passage where the left hand imitates the right hand with a sixteenth-note pattern that encompasses three quarter-note beats (see example 3.7). Transition 3 (mm. 55-60) features a toccata-like passage, similar to mm. 61-62 of "Fierce." It consists of a single line; accented notes additionally divide the single line into two voices. This two-part texture is reinforced by the division of material between the hands; the accented notes are played only by the left hand. In the coda, ostinato patterns are played in the bass. This single-line ostinato also has some notes accented, again creating two layers. At the same time, the right hand plays a pulsating chord. This section therefore has three layers: the pulsating chord in the right hand, the accented notes in the single-line ostinato, and the ostinato left hand itself. 


\section{Thematic Material}

The melody of theme A features a two-descending-note motif (see example 3.4). This motif is inverted in theme $\mathrm{B}$ (see example 3.5). In section $\mathrm{B}$, these descending two notes are present again at the end of each phrase (see example 3.6). In this section, Prangcharoen introduces a four-measure-long pattern as ground bass. A new figure appears in the next subsection, transition 2 (see example 3.7). The composer uses the sixteenth-note pattern that encompasses three quarter-note beats set in the canonic writing. This pattern repeats sequentially and imitates each other nearly throughout the subsection. The fragment of motif 1 from "Absent" appears in theme D (see example 3.8) but with some intervals altered. This helps to make the cycle coherent, as does the toccata-like passage of "Fierce" that returns in this last movement in transition 3. Example 3.9 compares the passage from "Fierce" with the one from transition 3.

Example 3.4 Two-descending-note motif in $\mathrm{m} .1$

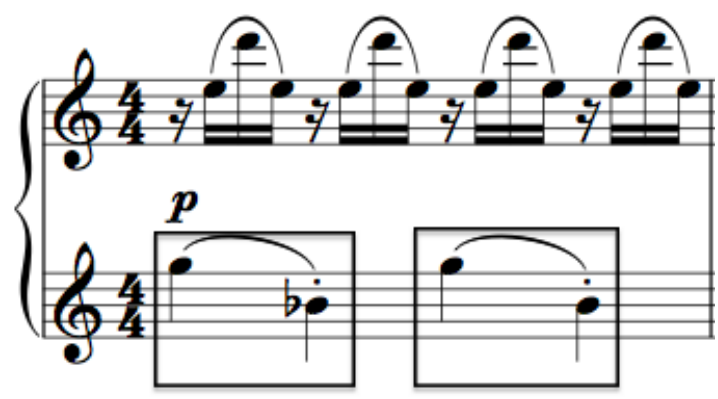


Example 3.5 Inversion of the motif in theme B, m. 9

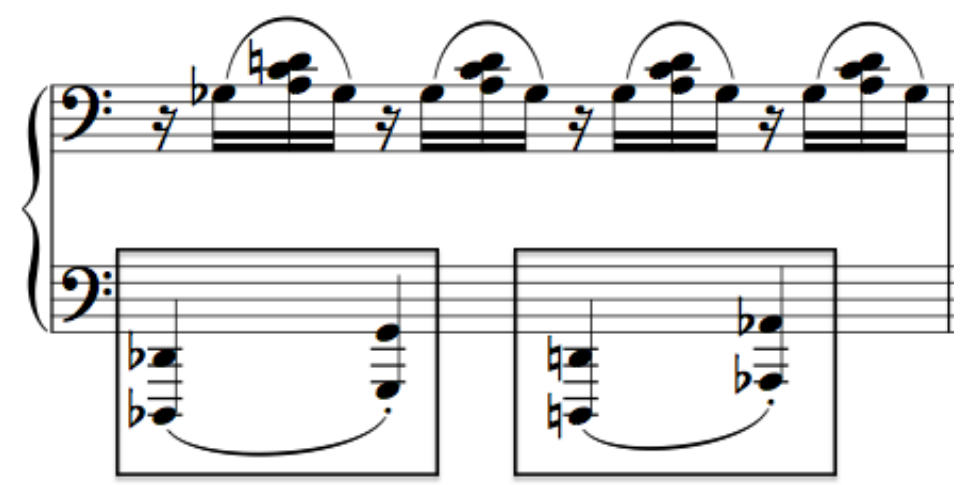

Example 3.6 The motif in section B in the right hand and ground bass in the left hand
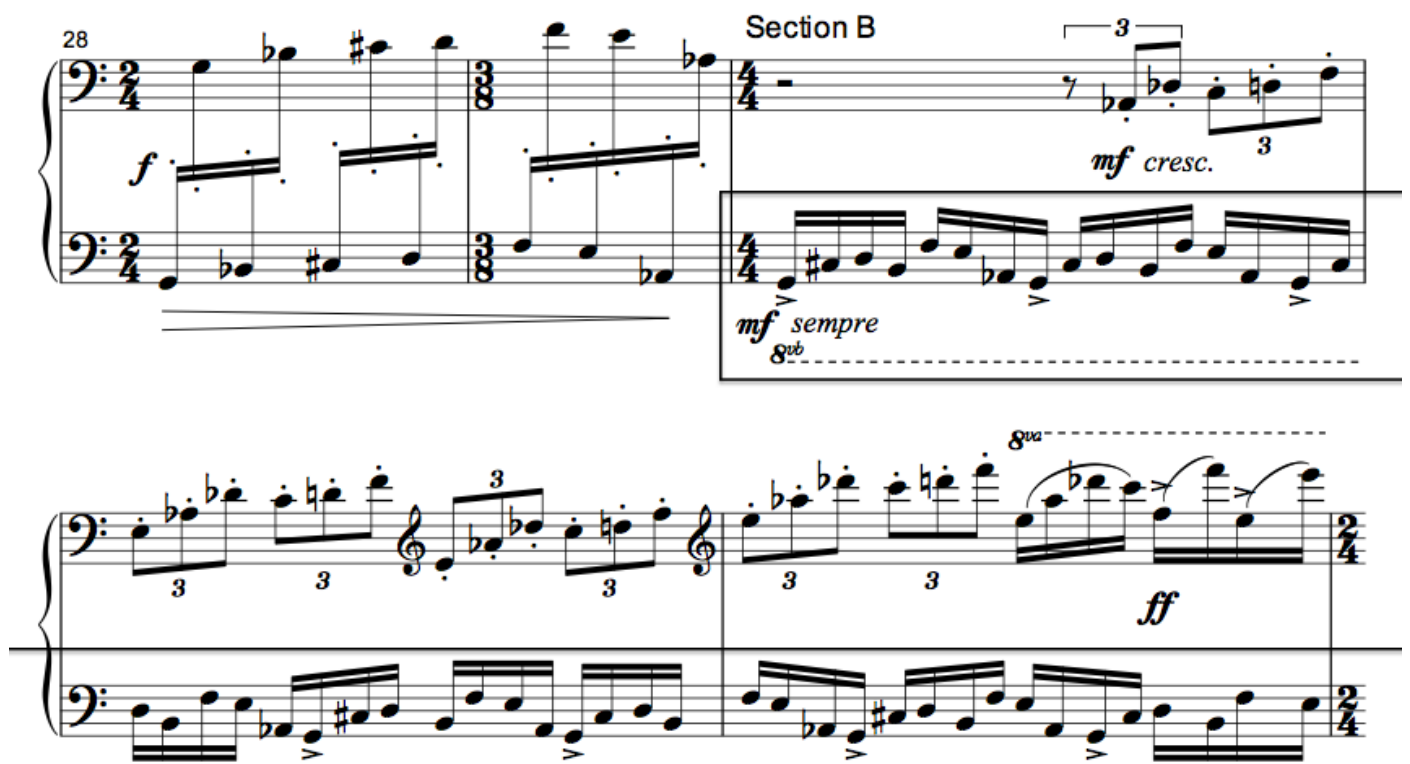

(8) 

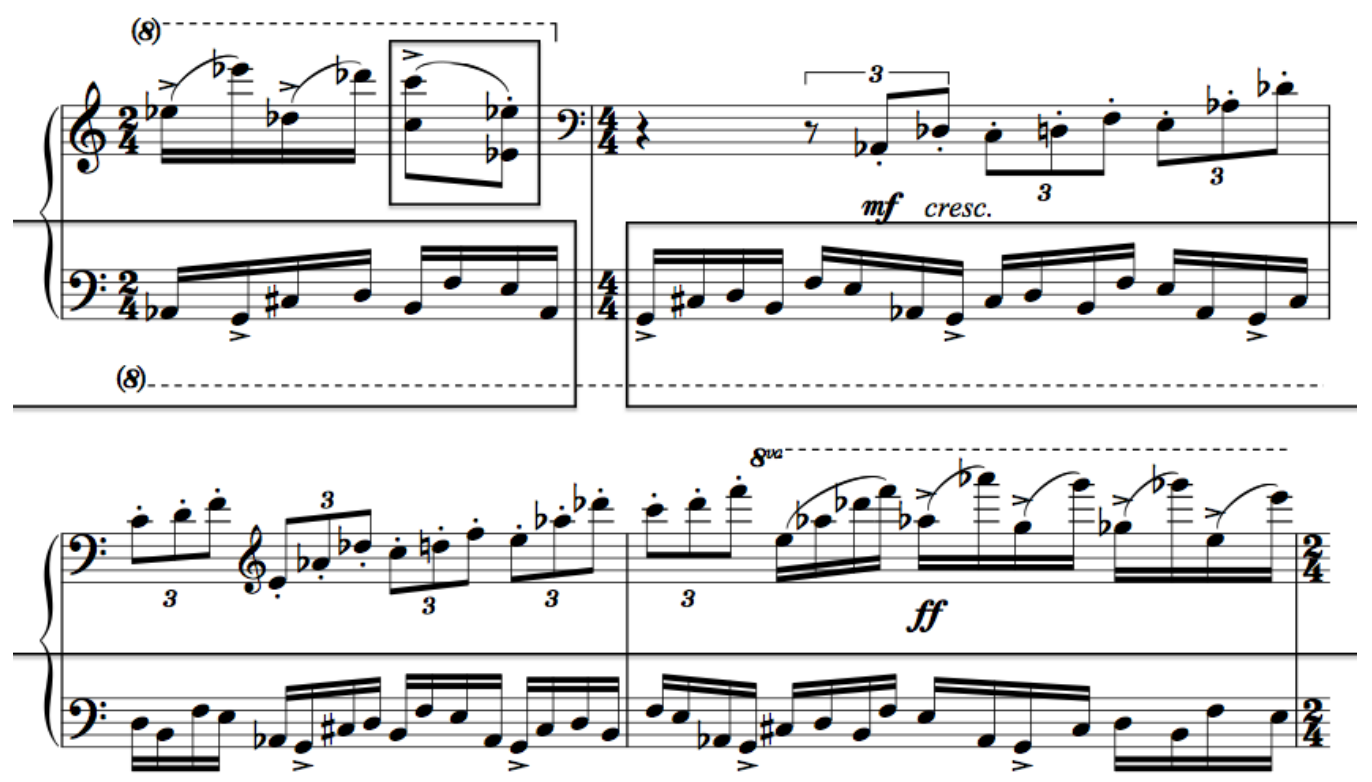

(8)
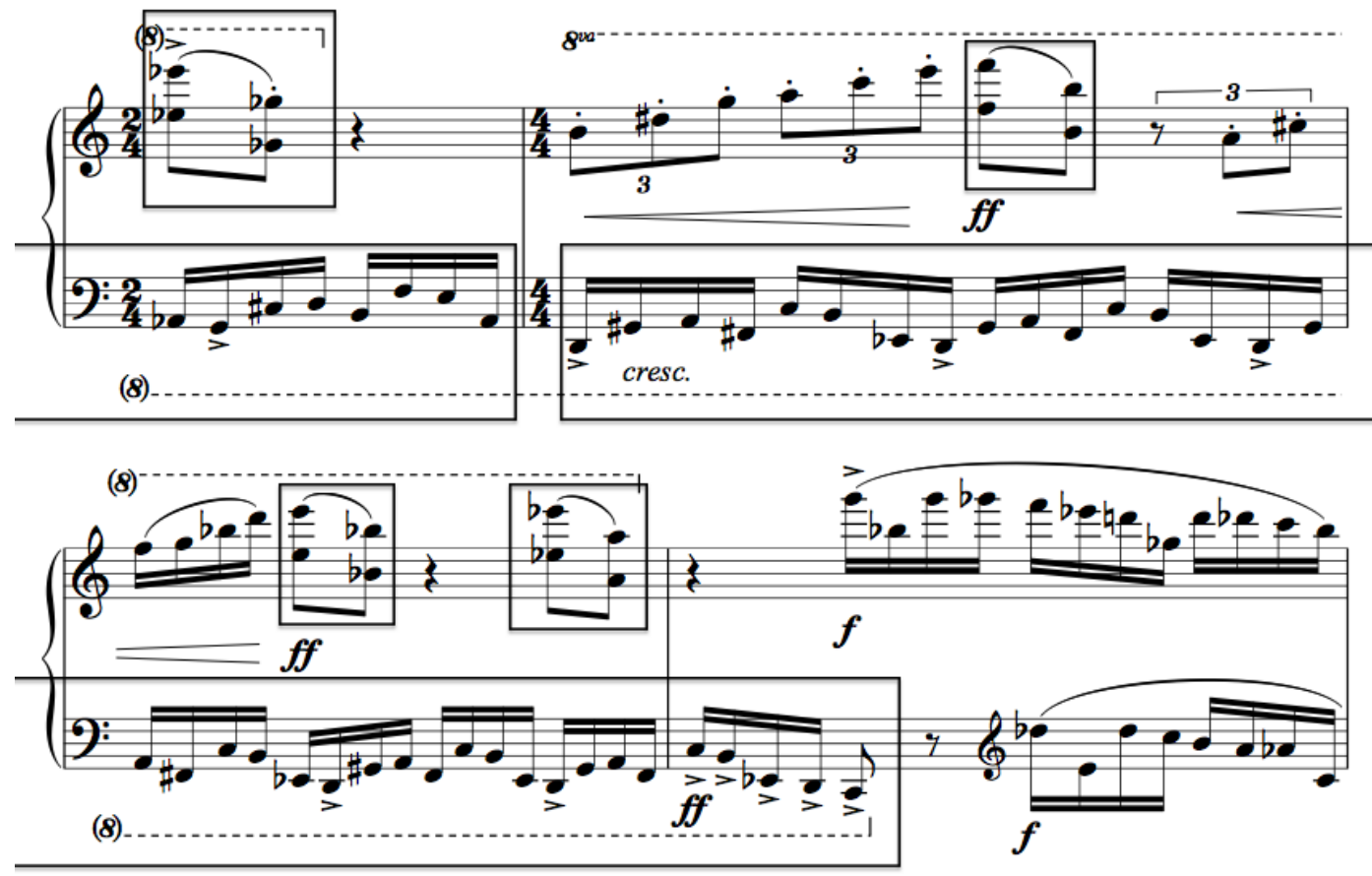
Example 3.7 Mm. 39-43 in transition 2
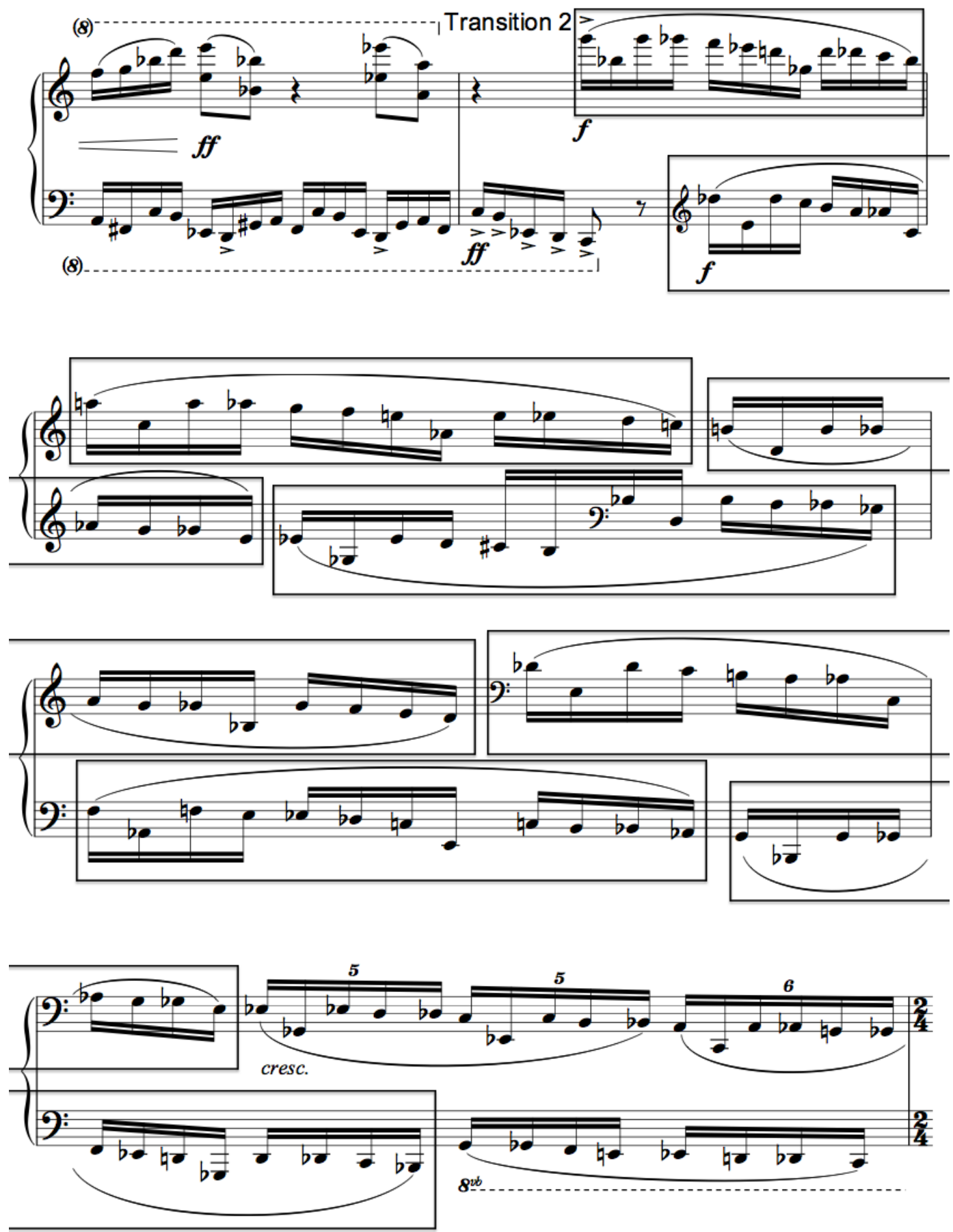
Example 3.8 Fragment of motif 1 of "Absent" in theme D
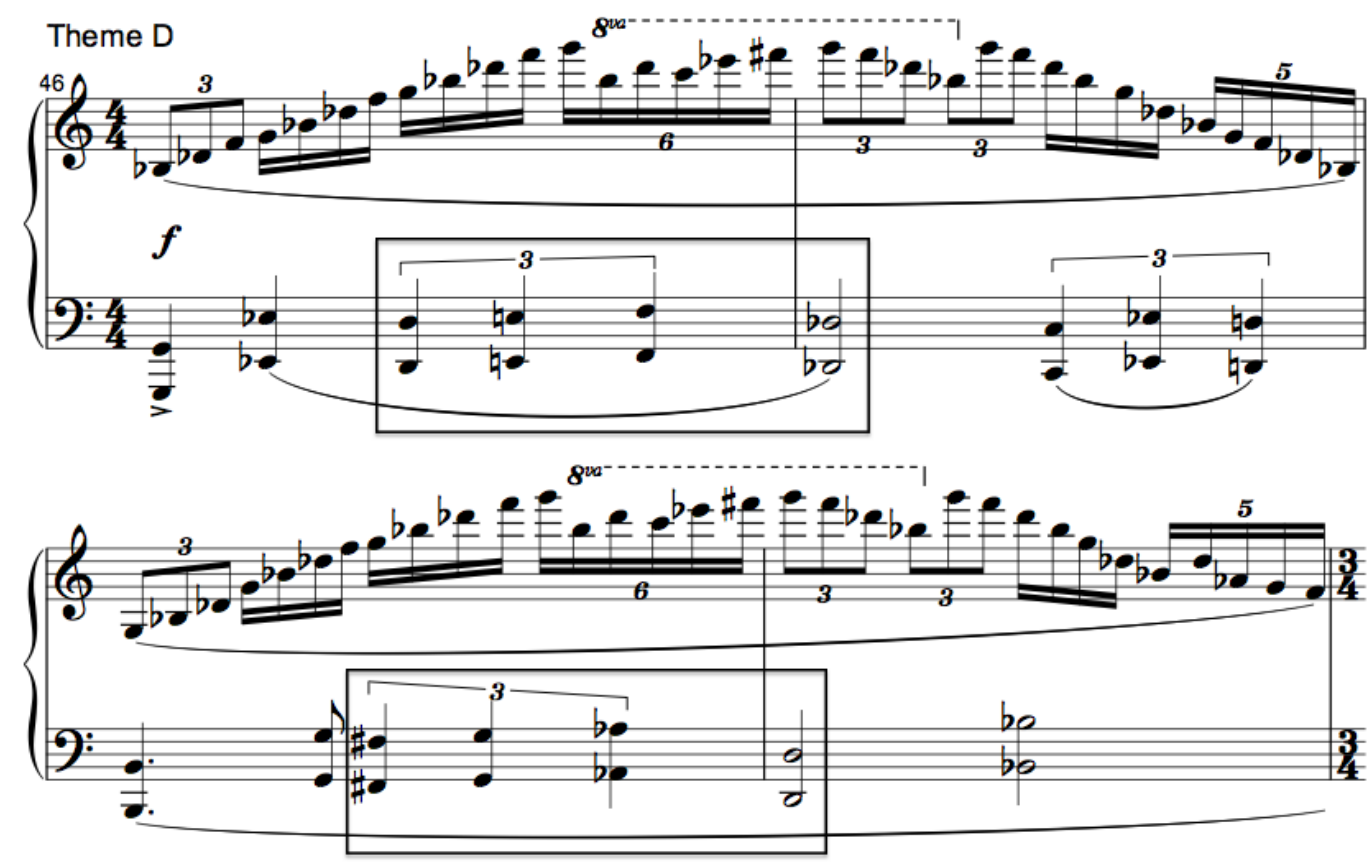

\section{Example 3.9}

3.9.1 Mm. 61-62 from "Fierce"

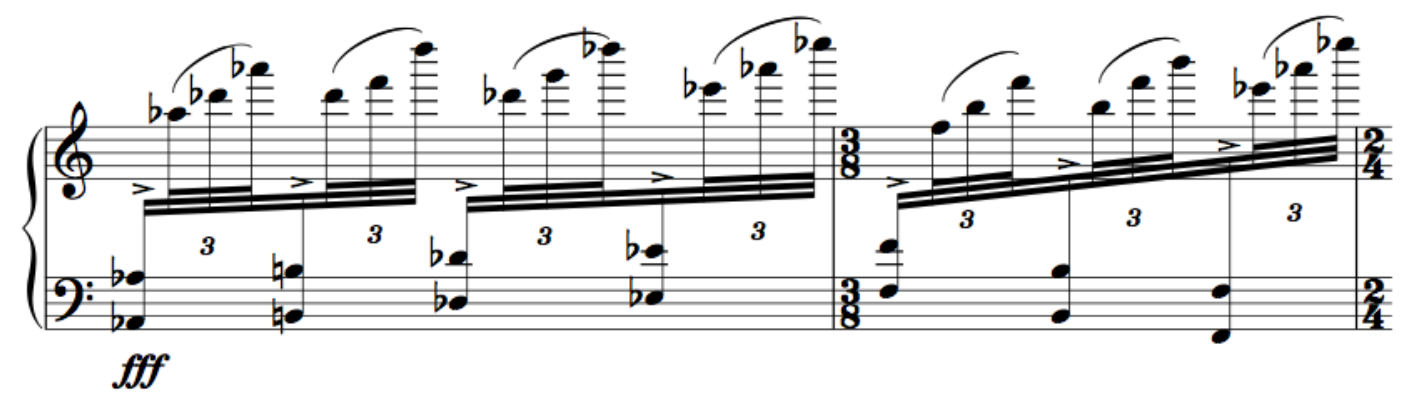




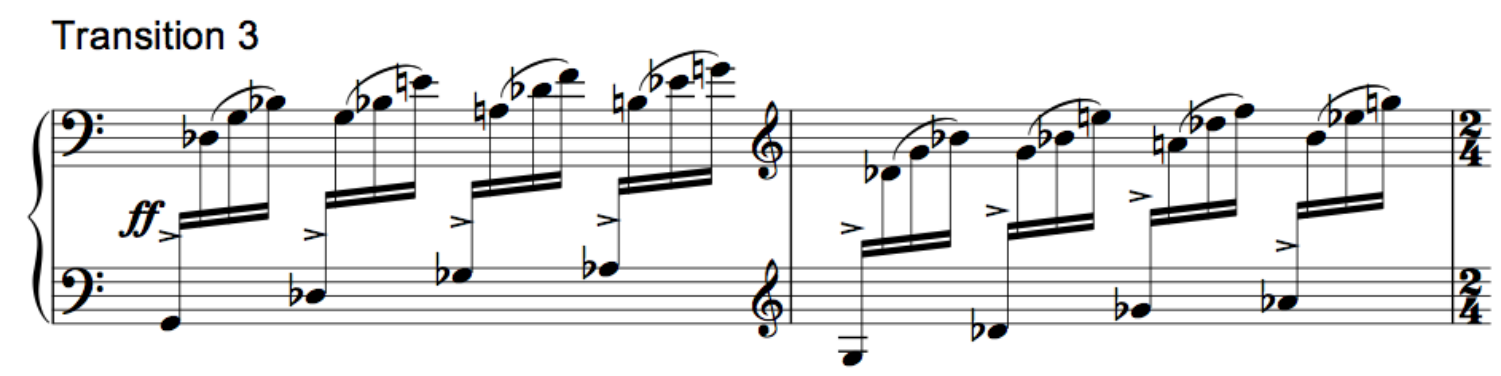

This piece has no influence from Thai traditional music and it is not bound within the tonal system. The uniqueness of this piece is the compound ternary form. If it is modified from the original version "Sonatina," a title that implies a variety of sonata form, it is however close to the traditional third movement Minuet and Trio of the Classical period more than the first movement sonata form. Theme A in section A, which—given the compound ternary structure—returns many times, characterizes the piece. This distinctive melody, with its burlesque character, makes the music fun and enjoyable while the rapid, often motoric, virtuosic texture creates an exciting conclusion to the whole cycle of Three Minds. 


\section{CHAPTER 4}

\section{THE ANALYSIS OF "FIERCE"}

This chapter discusses "Fierce" in deeper detail. The analysis is divided into five aspects: 1) formal structure, 2) texture, 3) rhythm, 4) pitch, and 5) Thai musical influences. In addition, some aspects are linked together as they are inseparable: for example, rhythm and pitch aspects when the same motivic pitch figures repeat with the same rhythmic patterns. The author also suggests, under Thai Musical Influences, performance practice of this piece.. This might be especially useful to non-Thai readers.

\section{Formal Structure}

The formal structure of "Fierce" is shown in table 4.1 below. The movement, marked Allegro rhythmico, lasts approximately three minutes.

Table 4.1 The formal structure of "Fierce"

\begin{tabular}{|c|c|c|}
\hline & Sub-section & Measure \\
\hline \multicolumn{2}{|l|}{ Introduction } & $1-2$ \\
\hline \multirow{4}{*}{$\begin{array}{c}\text { Section } \\
1\end{array}$} & A & $3-10$ \\
\hline & Transition & $11-14$ \\
\hline & B & $15-25$ \\
\hline & $\mathrm{C}$ & $26-37$ \\
\hline \multicolumn{2}{|l|}{ Transition } & $38-43$ \\
\hline \multirow{5}{*}{$\begin{array}{c}\text { Section } \\
2\end{array}$} & $A^{\prime}$ & $44-53$ \\
\hline & Transition & 53 \\
\hline & $\mathrm{B}^{\prime}$ & $54-64$ \\
\hline & Transition & $65-67$ \\
\hline & Closing & $68-77$ \\
\hline
\end{tabular}


The piece has two main sections; section 2 is the repetition of section 1 with variations. In addition, the movement has an introduction and a coda. Sub-section A contrasts subsection B in terms of characters and material. Section C (mm. 26-37) introduces a new ostinato figure in the bass while the right hand develops two-note motifs, one with a descending motion and another with an ascending motion, from section $\mathrm{B}$ (see example 4.1). The motifs make sections $\mathrm{B}$ and $\mathrm{C}$ related. The bass ostinato figure in section $\mathrm{C}$ continues in the transition (mm. 38-43). This passage leads to the return of section A in m. 44. The composer varies the second statement of sections A and B, making the second half of the piece a variation of the first half. The piece ends with a coda, starting at $\mathrm{m} .68$. In this last section, materials from sections $\mathrm{A}, \mathrm{B}$, and the introduction return and conclude the piece.

\section{Example 4.1}

4.1.1 Two-note motifs, mm. 15-17 in section B

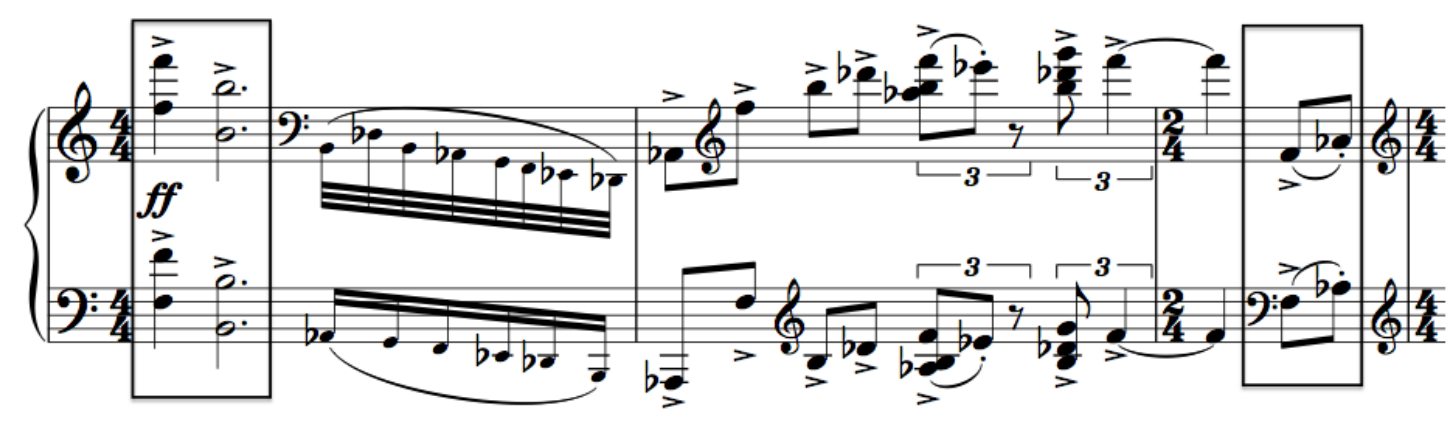




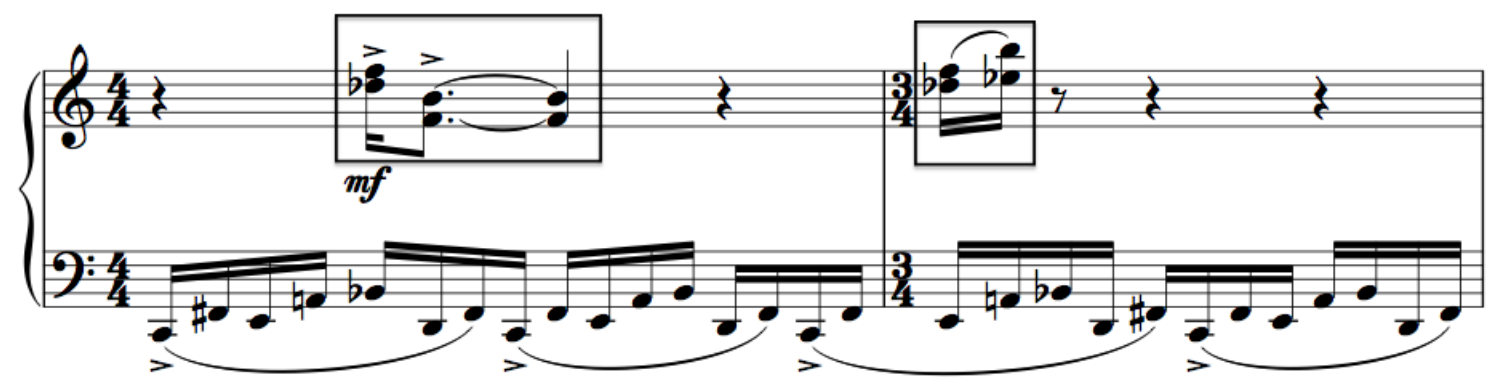

\section{Texture}

As this is a fast piece, at times the music progresses with a single-line texture. Such a texture enables a player to play very fast, as in a toccata. The single line is sometimes doubled at an octave such as in section B (see example 4.1.1; for the whole section B, see example 4.15), which requires slower rhythms compared to the previous sections. At times, two or more lines happen together in a contrapuntal manner. This thickens the texture of the piece and complicates the passages at the same time.

In section A (both the first and second statements), ostinato figures are present nearly throughout the section. At a surface level, it seems to progress with a single-line texture, but certain notes are brought out with accents. This creates two different layers. Example 4.2 shows the beginning of section A, both the first and second statements. 
Example 4.2 Section A

4.2.1 Mm. 3-5

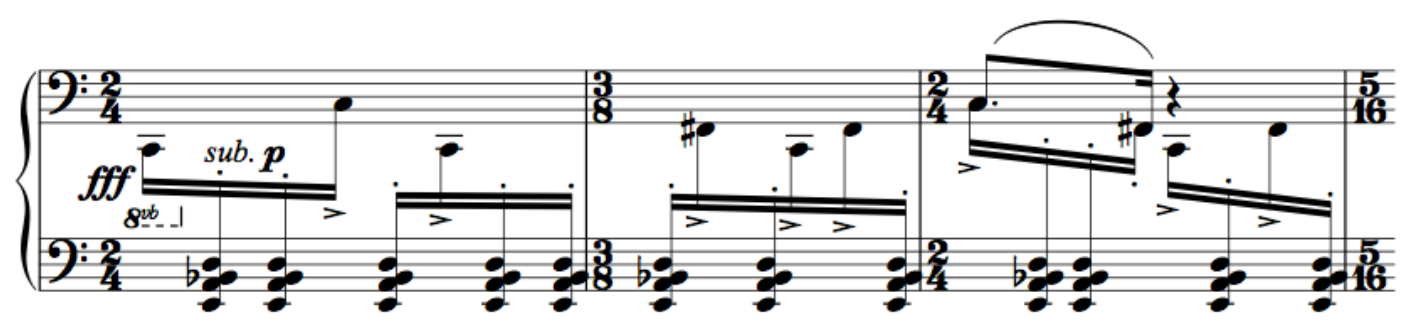

4.2.2 Mm. 44-47

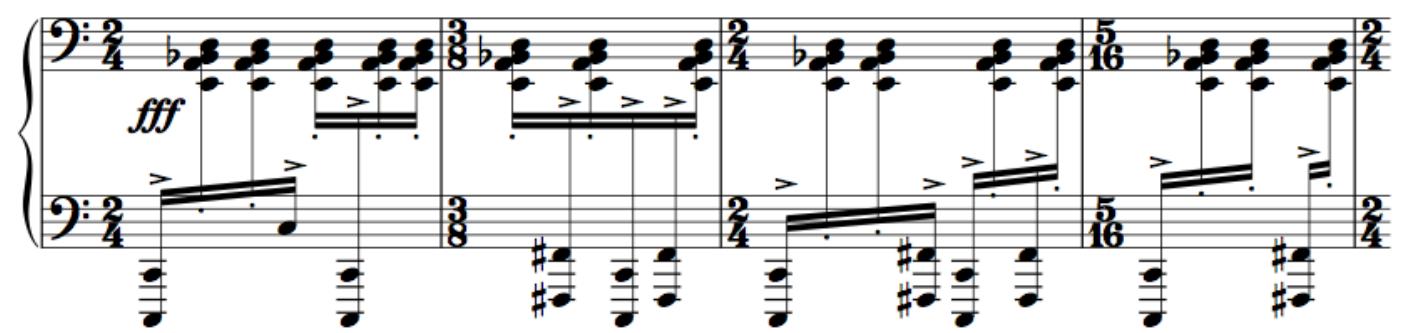

Section C (see example 4.1.2; for the whole section C, see example 4.16), with similar technique to section A (i.e. single-line ostinato with certain notes accented) plus the addition of the top part, seems to create three layers: 1) the top part played by the right hand, 2) the accented notes in the left-hand ostinato, and 3) the ostinato itself in the left hand. However, the accents in the ostinato also clarify its own figure as it emphasized the first note of the figure. These accents distinguish the motivic content and contradict the meter. If the accents are considered to be used to distinguish the pattern, this section progresses with two-part texture. Throughout the section, the hands are independent from each other, contrasting the parallel motion in the preceding section B (mm. 15-25). 
The contrapuntal texture of section $\mathrm{C}$ continues in the transition (see example 4.3; for the whole transition section, see example 4.23), where different ostinato patterns are present simultaneously. Accents do not always synchronize between hands because the accents mark the beginning of each repetition of the ostinato patterns and the two hands have ostinatos of different lengths.

Example 4.3 Beginning of the transition, mm. 38-39

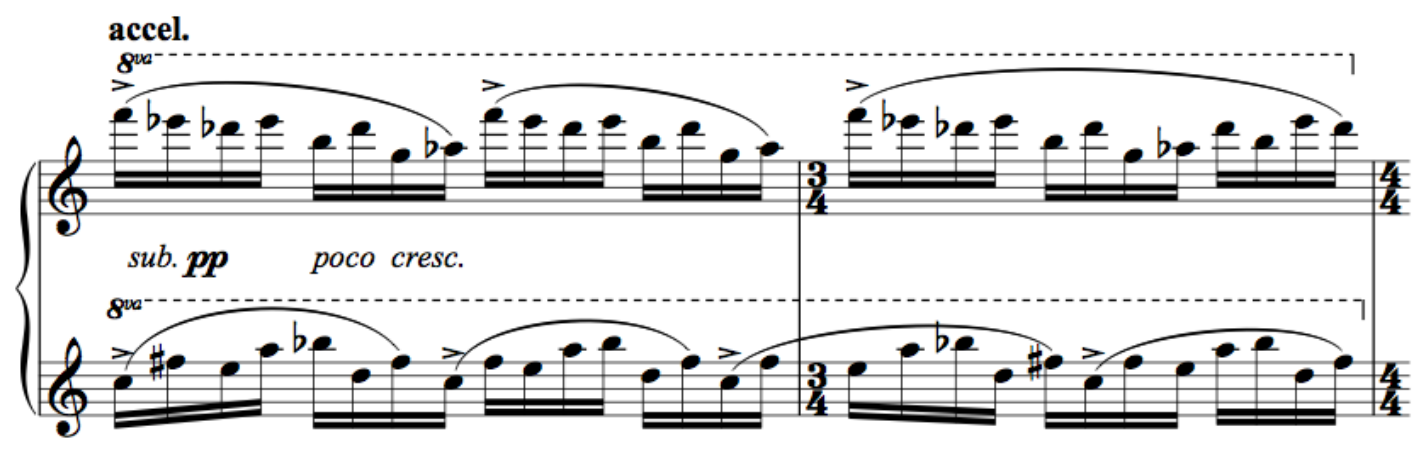

Section B' at mm. 54-64 differs greatly from section B at mm. 15-25. This time the parallel motion alternates with contrapuntal texture. In m. 54, the two-note motif starts the section. While most thematic material of section B remains, the composer also inserts an ostinato pattern, the derivative of the one from section A, in the bass line. Hence, the second statement of section B consists of two kinds of texture: parallel motion like in the first statement consistently interrupted with a two-independent-voice texture (see example 4.4). 
Example 4.4 Section B', mm. 54-64
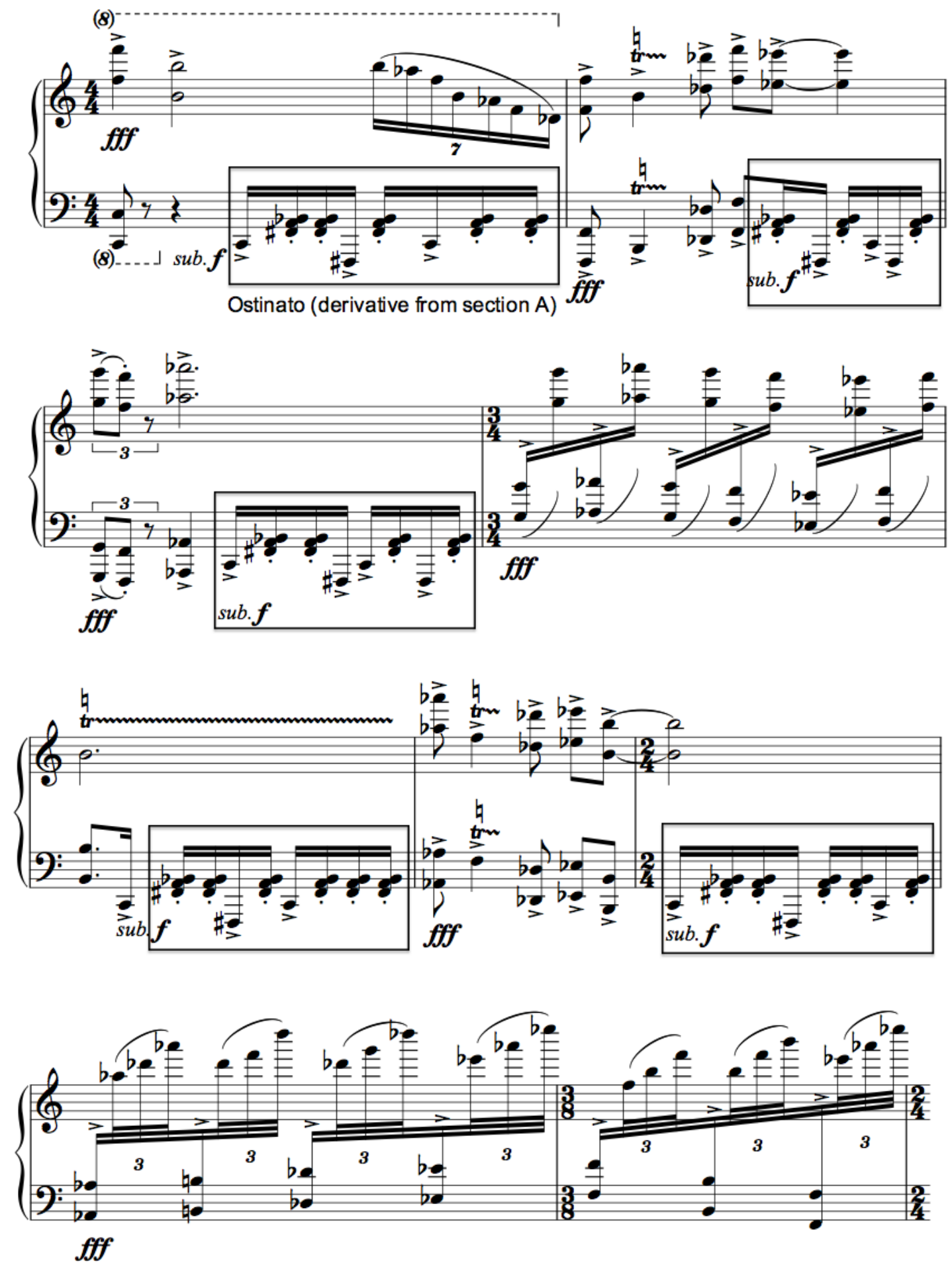


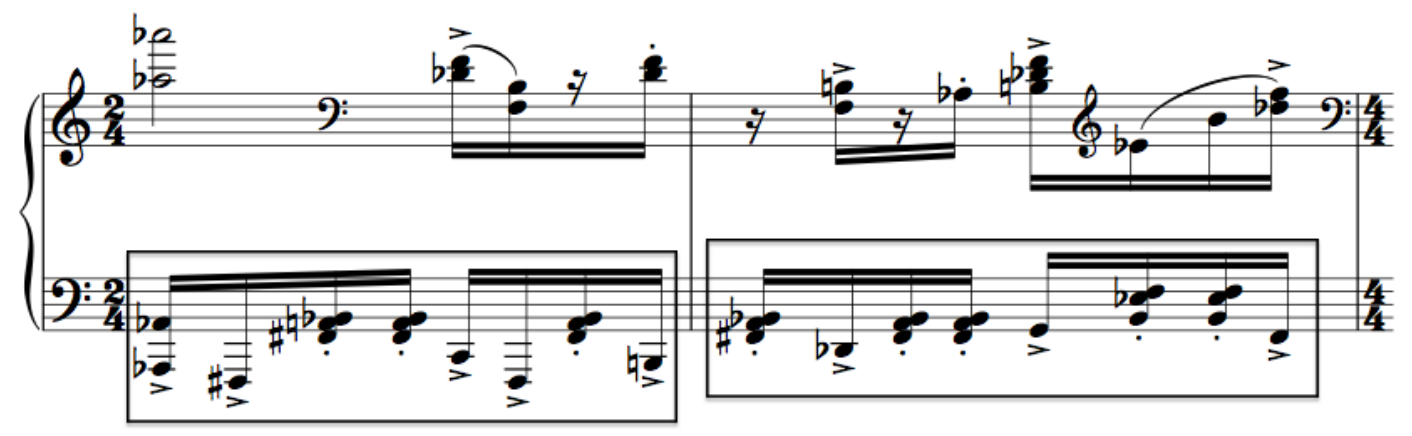

The transition at mm. 65-67 interrupts the two-independent-voice texture of the previous section with similar motion (see example 4.5). This motion is, however, not parallel in either an intervallic or a rhythmic aspect. The ascending lines of both hands lead to the coda, mm. 68-77, in a single-line texture. Although the ostinato pattern from section A returns here, all notes now are accented and cannot be divided into two layers like before (see example 4.11). Arpeggiated chords are present in mm. 75-76. The anacrusis to the final measure returns to similar, but not parallel, motion between two hands, as in section B, leading to the end of the piece (see example 4.6). 
Example 4.5 Mm. 65-67
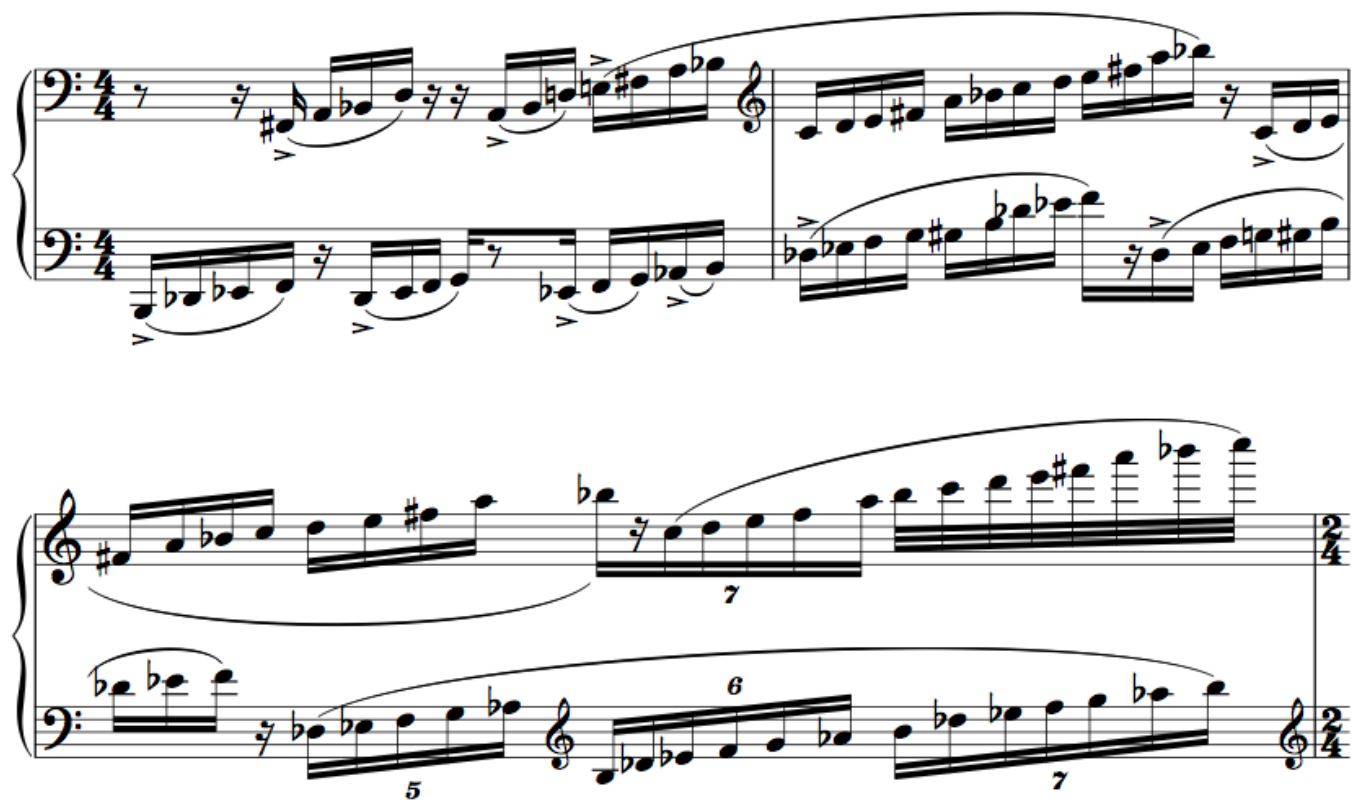

Example 4.6 Mm. 74-77

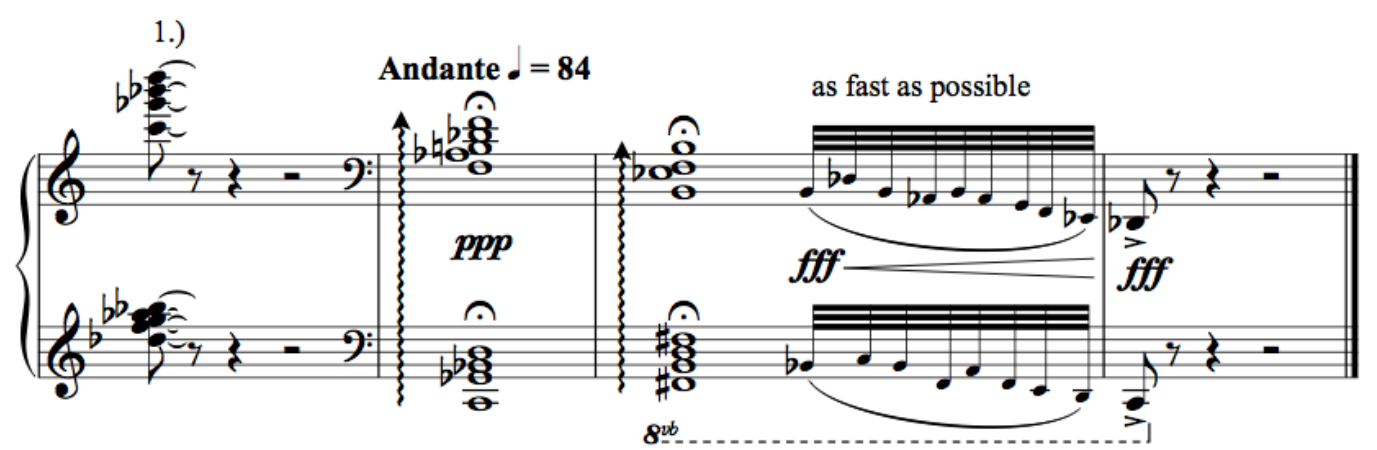

1.) wait until the sound fade away, gently play the next chord inside the fading sound 


\section{Rhythm}

The primary interest of this movement lies in the realm of rhythm, including meter. The tremolo first measure is in 5/4. This tremolo returns again in the coda, exactly with the same notes, but it is set in two measures of 4/4, first with sixteenth-notes then with a thirty-second-note figure. Example 4.7 displays these distinct tremolos. The tremolo in the first measure starts off the piece at which point, for the listener, a meter is not yet established. The tremolo in $\mathrm{m} .72$ is played with sixteenth-notes, the rhythm that has been heard consistently since m. 68 while these sixteenth-notes go through different meters. The listener can perceive the latter tremolo in the context of $4 / 4$ and for this reason the two tremolos differ from each other.

\section{Example 4.7}

4.7.1 M. 1

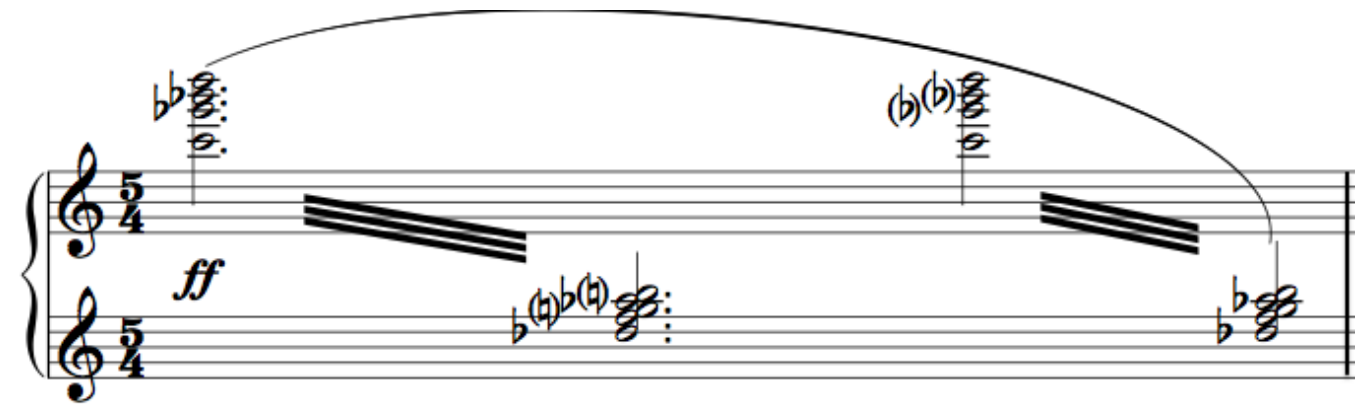




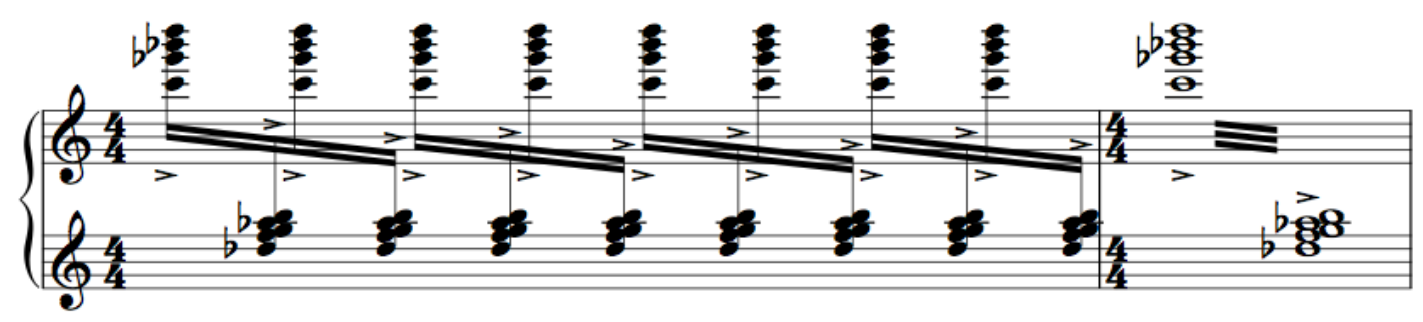

The meter of m. 2 changes to 4/4, which might seem to give a comfortable symmetrical feel, were it not that the measure is filled with quintuplets. The meter of $4 / 4$, however, does in fact creates symmetry when the second half of the measure repeats the first half material, albeit in the lower register (see example 4.8).

Example 4.8 M. 2

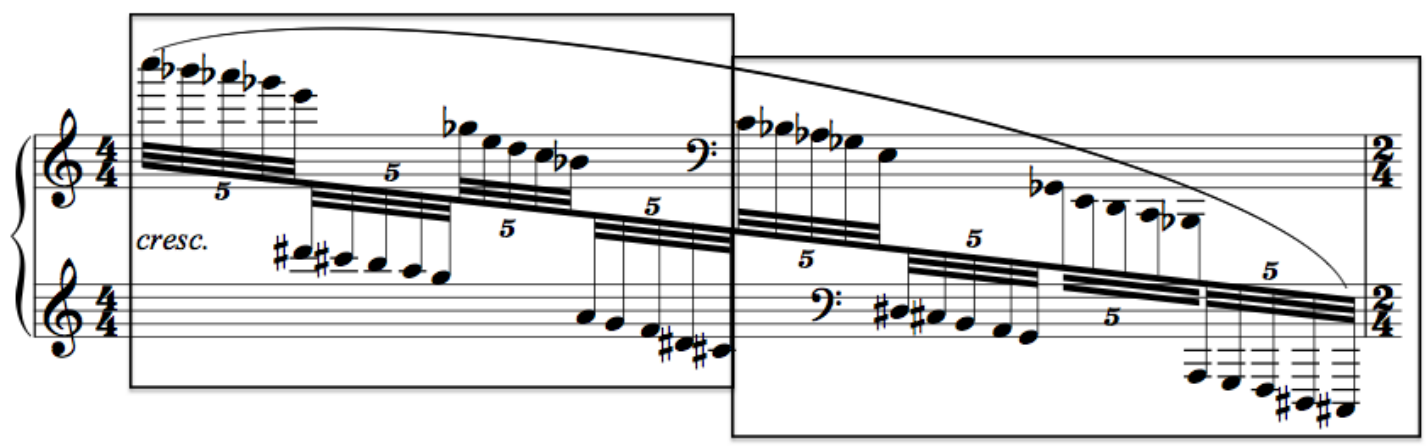

Section A, starting in m. 3, creates the most rhythmically and metrically complex passage in the piece; the same applies to the section's restatement starting in $\mathrm{m}$. 44 . Table 4.2.1 shows the successive irregular time signatures and accents. This table can be compared with table 4.2.2, which shows the diagram of the section's restatement. For the excerpts from section A, see example 4.9 below. 
Table 4.2

4.2.1 The diagram of time signatures and groups of notes marked by accents, mm. 3-10

\begin{tabular}{|c|c|c|c|c|c|c|c|c|}
\hline Measure & 3 & 4 & 5 & 6 & 7 & 8 & 9 & 10 \\
\hline $\begin{array}{l}\text { Time } \\
\text { Signature }\end{array}$ & $2 / 4$ & $3 / 8$ & $2 / 4$ & $5 / 16$ & $2 / 4$ & $2 / 4$ & $2 / 4$ & $7 / 16$ \\
\hline $\begin{array}{l}\text { Group of } \\
\text { Notes } \\
\text { marked } \\
\text { by } \\
\text { accents }^{48}\end{array}$ & 12312123 & 412112 & 12311212 & 12312 & $\begin{array}{l}1234+ \\
16 \text { th- } \\
\text { note } \\
\text { septuplet }\end{array}$ & 12312312 & 12311212 & 1231231 \\
\hline $\begin{array}{l}\text { Number } \\
\text { of Notes } \\
\text { within a } \\
\text { group }\end{array}$ & $\begin{array}{ll}3 & 24\end{array}$ & 212 & $\begin{array}{lll}3 & 122\end{array}$ & 32 & $\begin{array}{l}4 \\
+ \\
\text { septuplet }\end{array}$ & $\begin{array}{lll}3 & 3 & 2\end{array}$ & $\begin{array}{ll}3 & 122\end{array}$ & $\begin{array}{lll}3 & 3 & 1\end{array}$ \\
\hline
\end{tabular}

4.2.2 The diagram of time signatures and groups of notes marked by accents, mm. $44-53$

\begin{tabular}{|c|c|c|c|c|c|c|c|c|c|c|}
\hline Measure & 44 & 45 & 46 & 47 & 48 & 49 & 50 & 51 & 52 & 53 \\
\hline $\begin{array}{l}\text { Time } \\
\text { Signature }\end{array}$ & $2 / 4$ & $3 / 8$ & $2 / 4$ & $5 / 16$ & $2 / 4$ & $2 / 4$ & $2 / 4$ & $2 / 4$ & $5 / 16$ & $6 / 4$ \\
\hline $\begin{array}{l}\text { Group of } \\
\text { Notes } \\
\text { marked } \\
\text { by } \\
\text { accents }\end{array}$ & 12312123 & 412112 & 12311212 & 12312 & 12341234 & 12312123 & 12312312 & 12311212 & 12312 & $\begin{array}{l}1234+ \\
\text { etc. }\end{array}$ \\
\hline $\begin{array}{l}\text { Number } \\
\text { of Notes } \\
\text { within a } \\
\text { group }\end{array}$ & 324 & 212 & 3122 & 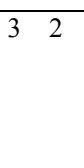 & $4 \quad 4$ & $\begin{array}{lll}3 & 2 & 3\end{array}$ & $\begin{array}{lll}3 & 3 & 2\end{array}$ & 3122 & 32 & $\begin{array}{l}4+ \\
\text { etc. }\end{array}$ \\
\hline
\end{tabular}

\footnotetext{
${ }^{48}$ Number 1 is where an accent is placed. Each number represents a sixteenth note.
} 
Example 4.9

4.9.1 Mm. 3-10
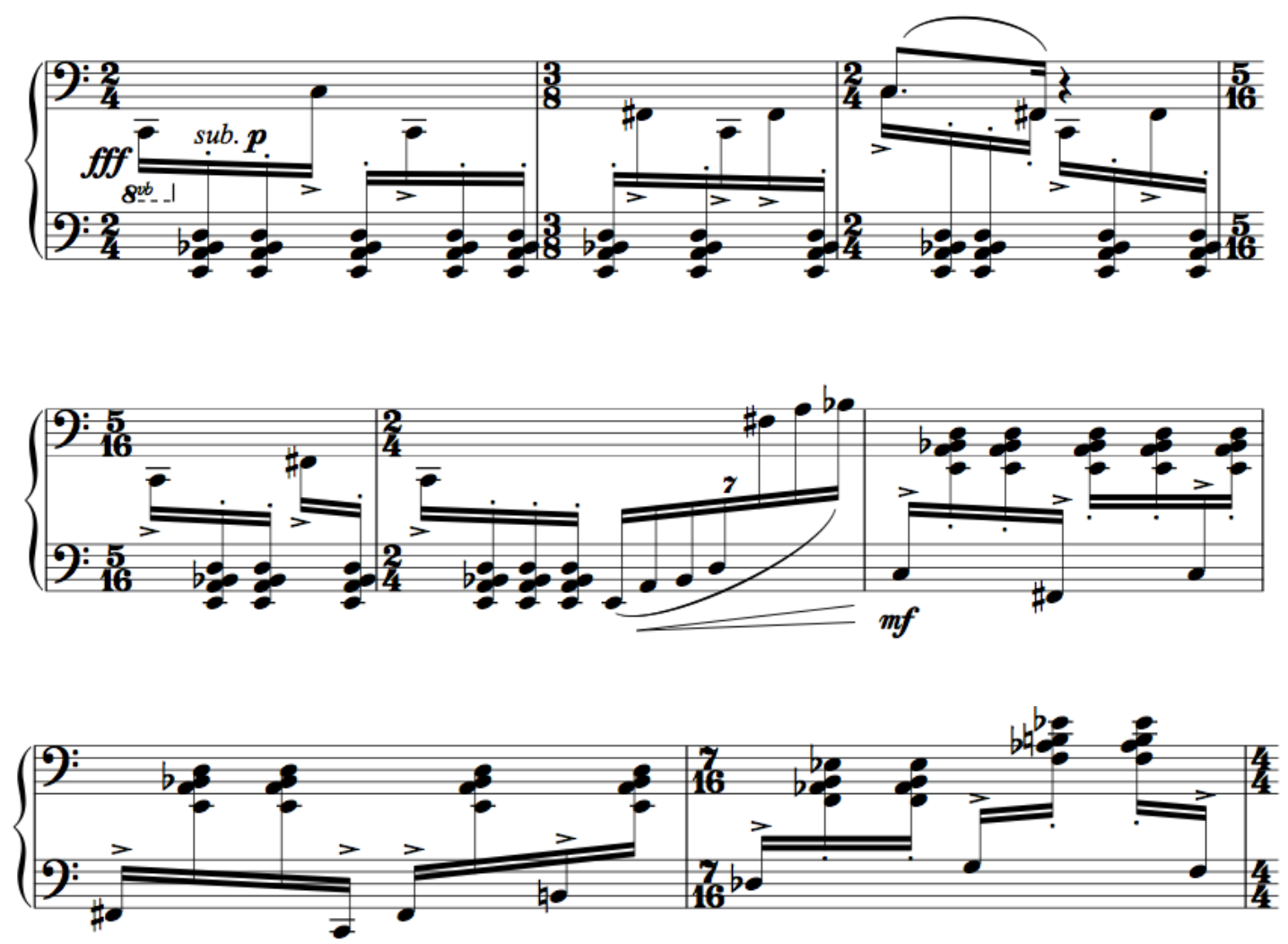
4.9.2 Mm. 44-53
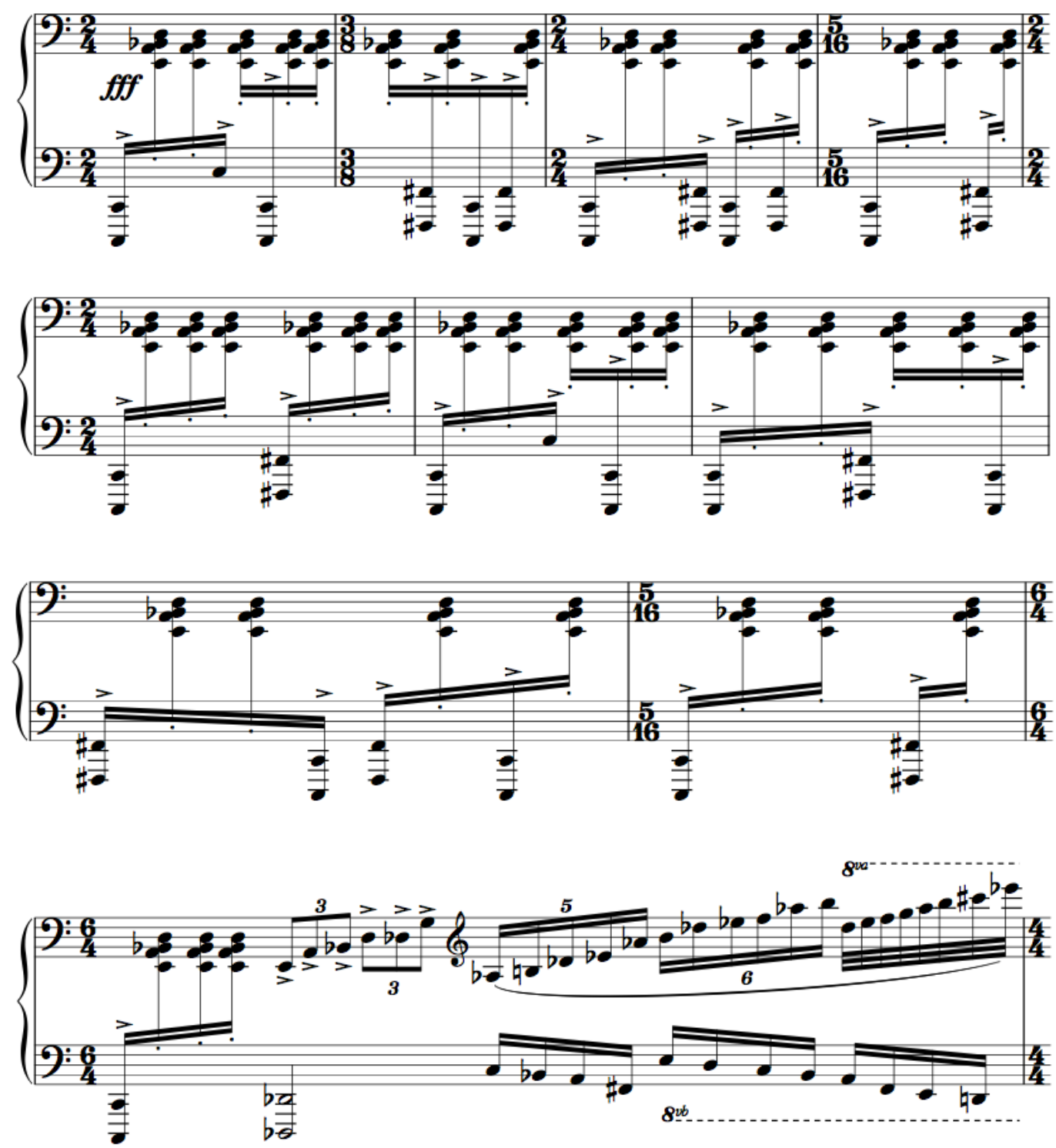

The accents are marked in order to correspond to figures that alternate between a single note and a pulsating chord. The single note is always accentuated and is doubled at an octave in the second statement of section A. It is interesting to note the uncomfortable effect produced when the composer keeps neither the meter nor accents regular. Measures 3-4 could be renotated as 9/16 and 5/16 in order to correspond with the natural 
fall of the accented note F\# on the first beat of $\mathrm{m} .4$, but the composer's actual notation with $2 / 4$ and $3 / 8$ respectively displaces the downbeat of $m$. 4 . Measure 6 introduces asymmetrical quintuple time, which is followed by the symmetrical $2 / 4$ in m. 7 . However, the composer puts a septuplet in the second half of m. 7, and this makes it very challenging for a performer to change the pulse and articulate the right rhythms. The similar place in the restatement of A is $\mathrm{m} .48$. However, this time the rhythm remains symmetrical throughout the measure. A comparison of tables 4.2.1 and 4.2.2 shows that the accent pattern remains same only for the first 4 measures of section A; it starts to vary at the fifth measure of the section, with the exception that mm. 50-51 return to the same pattern as in mm. 8-9. This irregular pulse presumably imitates the state of an angry mind, perhaps depicting an irregular heart rate, and a peripatetic, circumlocutory and interruptive chain of ideas.

Sections B, C, and the transition (mm. 38-43) are more stable in terms of meter. There are only two places where metric changes affect the change of pulse: mm. 18-21 with time signatures $4 / 4,5 / 8,3 / 8$, and $3 / 4$; and $\mathrm{mm}$. $61-63$ with time signatures $2 / 4,3 / 8$, and 2/4 respectively. When the sections gain metric stability, the composer, however, uses syncopations as well as cross-rhythms to complicate the rhythmic domain. In m. 15, the right-hand thirty-second-note figure is placed over the left-hand sixteenth-note sextuplet, creating cross-rhythm. Syncopations are featured with the short-long rhythms, a result of the extension of the two-note motif (see example 4.1). In section $\mathrm{C}$ and the transition (from m. 26 of section C to m. 43 of the transition), an ostinato pattern in the bass features a homogeneous rhythm. However, the composer uses accented notes that correlate with the ostinato but disagree with the meter to create syncopations. This 
ostinato pattern, shown in example 4.10, explains the meter changes from $4 / 4$ to $3 / 4$ in mm. 26-27, 28-29, 32-33, 34-35, 38-39, and 40-41. With the time signatures 4/4 and 3/4, the fourth repetition of the pattern ends exactly at the end of $3 / 4$ measure. This will be discussed again in the Pitch section and fully shown in examples 4.22 and 4.23.

Example 4.10 Mm. 26-27

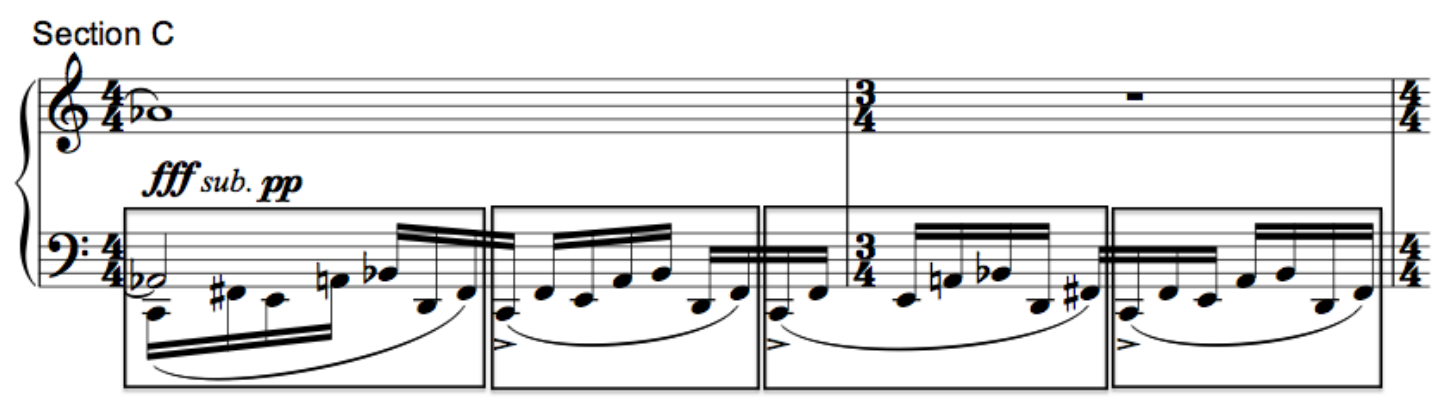

In the coda, the material from section A returns, mm. 68-71, and the successive time signatures of $2 / 4,3 / 8,2 / 4,5 / 16$ of the first four measures of section A remain (see example 4.11). The material from section B concludes the piece with a cross-rhythm: the right-hand thirty-second-note nontuplet over eight thirty-second notes in the left hand (see example 4.12). 
Example 4.11 Mm. 68-71
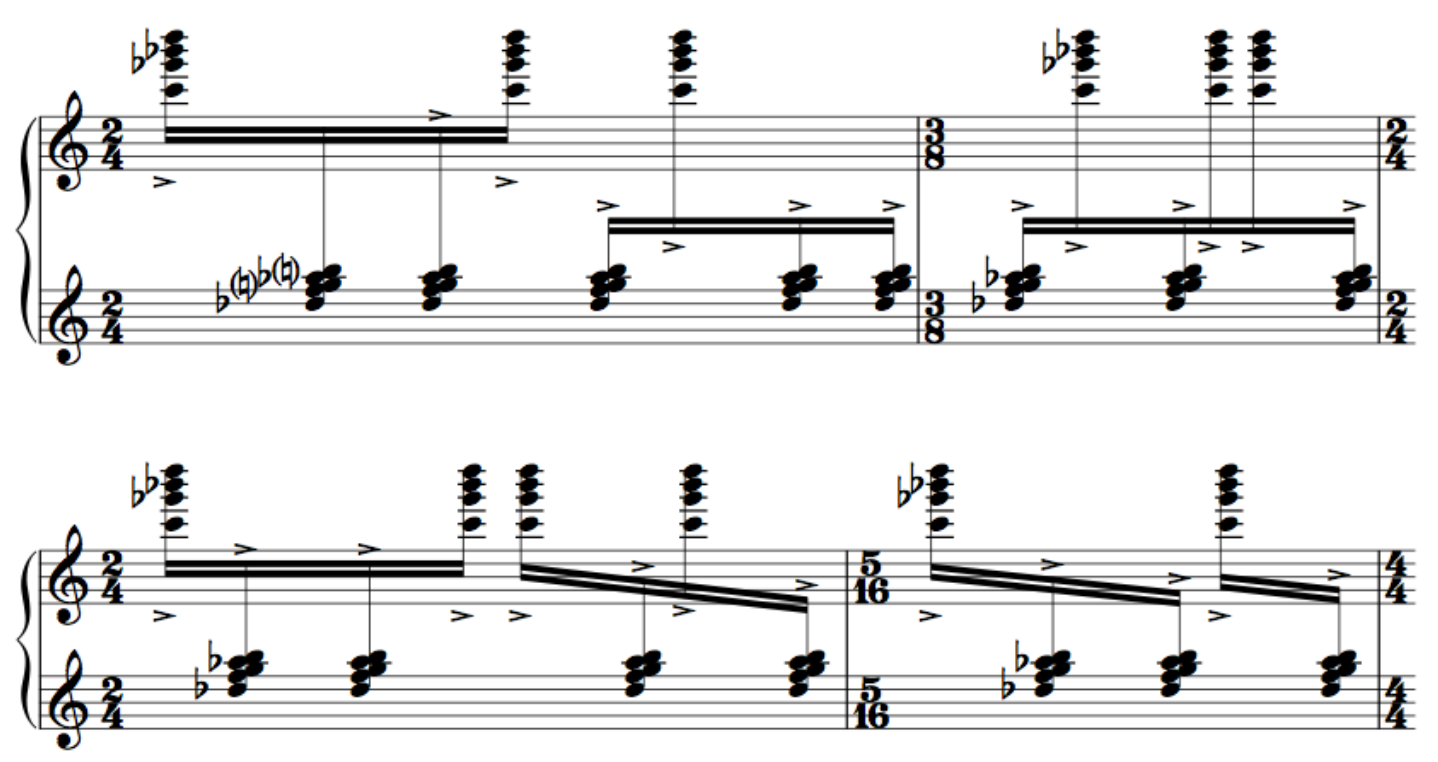

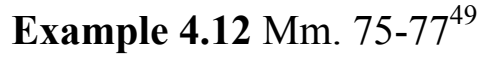

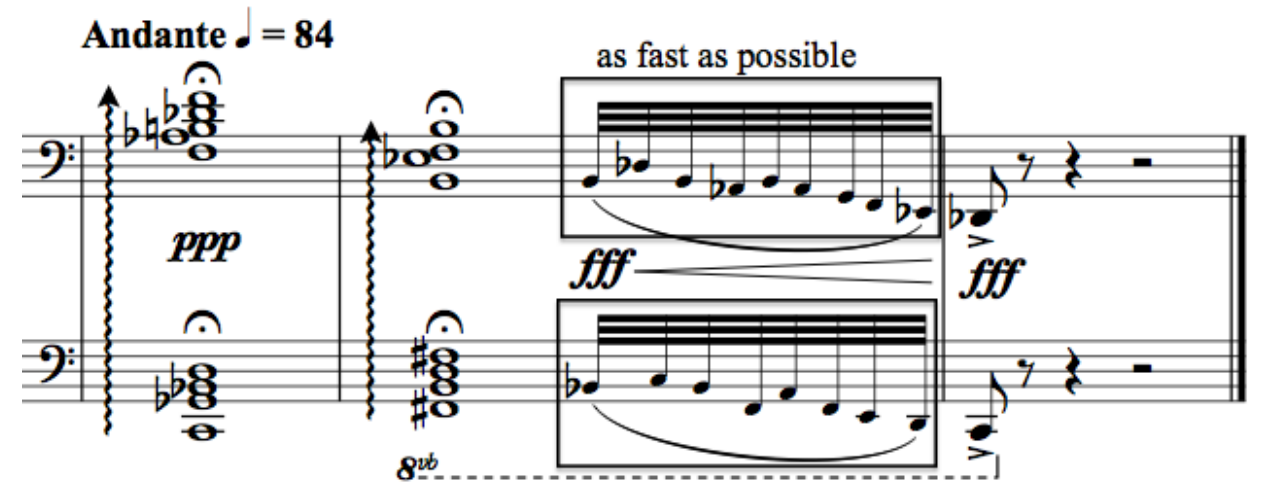

${ }^{49}$ N.B.: the left-hand chord on the downbeat of $\mathrm{m} .76$ is misprinted. The correct note is Bb, not B-natural. 


\section{Pitch ${ }^{50}$}

This section discusses two aspects of pitch: 1) pitch class sets used in the piece and 2) prominent thematic ideas such as motifs. ${ }^{51}$ This section also relates to what is previously discussed under Rhythmic Idea section when the ostinato pattern of section $\mathrm{C}$ is used with the pattern of metric change. Moreover, some thematic ideas in this piece will be compared to the similar ones in the other two movements of Three Minds.

\section{$\underline{\text { Pitch Class Sets }}$}

In this piece, the composer uses two pitch class sets shown in figure 4.1 below.

The two hexachords are complementary and are member of Forte's set class 6-34.

Figure 4.1 Two pitch class sets in "Fierce"

Pitch class set 1

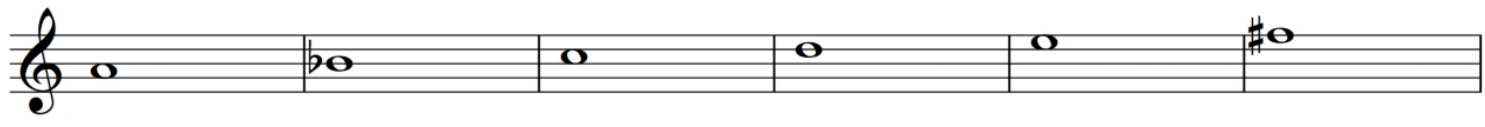

Pitch class set 2

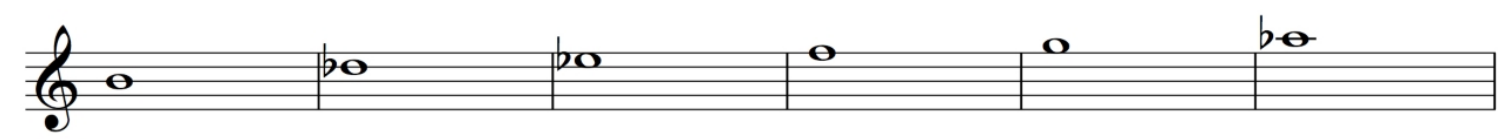

In $\mathrm{m} .1$ (see example 4.7.1), the right hand plays a chord consisting of $\mathrm{C}, \mathrm{Gb}, \mathrm{Bb}$, and D. These pitches come from pitch class set 1; the pitches A and E are omitted. The

\footnotetext{
${ }^{50}$ The terminology associated with the concept of pitch class sets will be used rather freely and intuitively in this document. Often, pitch names will be used and specific registers will be implied.

${ }^{51}$ To facilitate the reading of this section, traditional note names will be used here instead of numbers when pitch class sets are discussed.
} 
left hand chord includes $\mathrm{Db}, \mathrm{F}, \mathrm{G}, \mathrm{Ab}$, and $\mathrm{B}$, deriving from pitch class set 2; only $\mathrm{Eb}$ is omitted. In m. 2 (see example 4.8), pitch class sets 1 and 2 are combined and set in the descending scalar form that still retains the structure of the five-note whole-tone segments with appended half-steps, the structure of each pitch class set above and an instance of set 6-34. Measures 3-9 of section A use group 1; this changes in m. 10 to pitch class set 2 (see example 4.9.1). In mm. 11-12 (example 4.13), the right hand consists of the notes from pitch class set 1 and the left hand from pitch class set 2 . Both hands contrast each other by using different pitch class sets. This contrast continues in mm. 13-14, shown in example 4.14, but with some exceptions; the circled notes belong to the opposite group. As another interpretation, these pitches can be considered part of a transposed segment. For example, the last part of m. 14 in the right hand with the structure $\mathrm{H}-\mathrm{W}-\mathrm{W}-\mathrm{W}^{52}$ can be considered to be transposed from the beginning of $\mathrm{m} .13$ in the right hand, the same notes that initiate pitch class set 1 in Figure 4.1, while the left hand in the second beat of $m .13$ retains this intervallic structure of the first beat in the right hand.

Example 4.13 Mm. 11-12

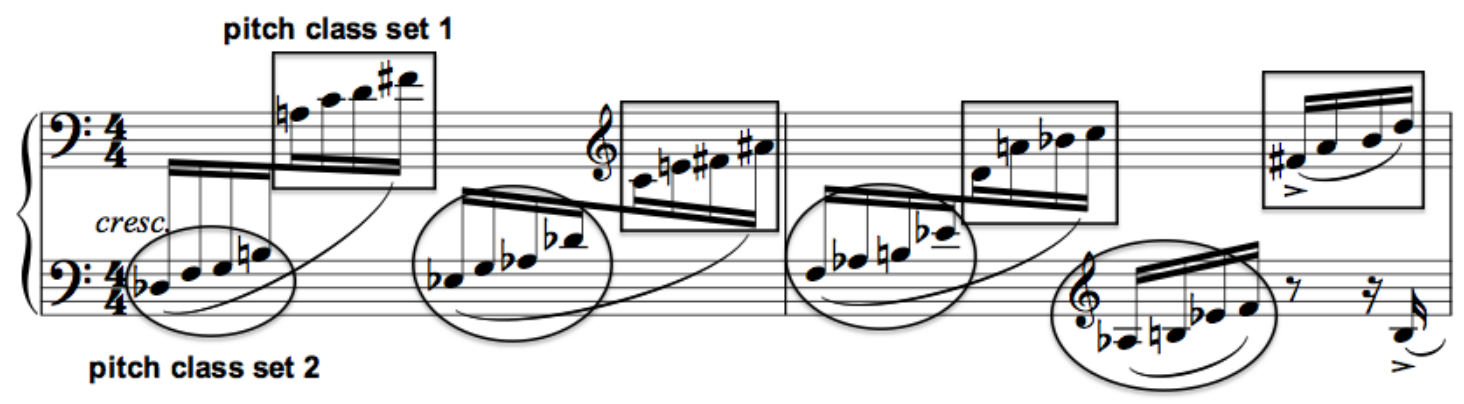

52 "H" is short for "half" and "W" is short for "whole." 
Example 4.14 Mm. 13-14

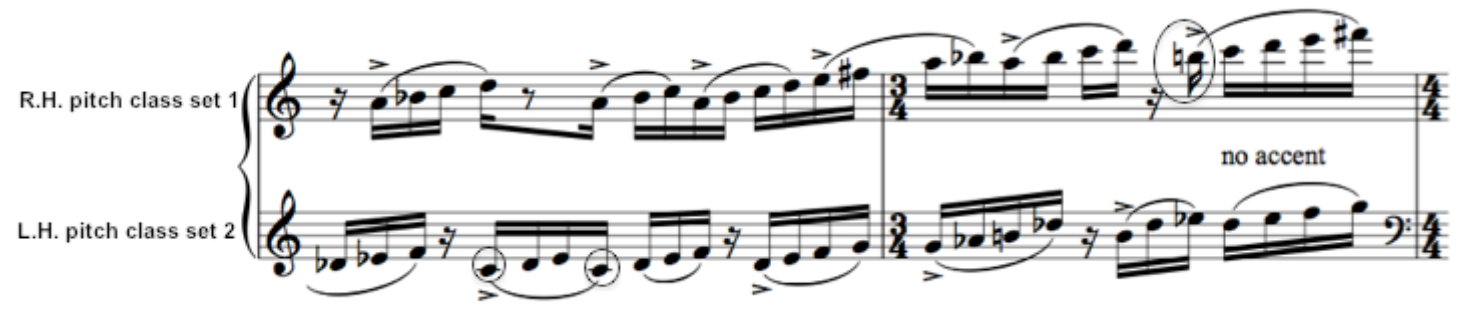

Section B, mm. 15-25, uses only pitch class set 2 (see example 4.15). The melody ends on the downbeat of m. 26 where section C starts (example 4.16). In this section, the right hand continues to play the notes from pitch class set 2, but the left hand plays an ostinato pattern consisting entirely of notes drawn from pitch class set $1 .{ }^{53}$ Exceptions are in $\mathrm{m} .37$; the circled notes in example 4.16 belong to the opposite group. The right hand plays the figure previously played by the left hand, while the left hand (starting at the fourth sixteenth-note in m. 37) transposes the same figure up a tone.

\footnotetext{
${ }^{53}$ When the ostinato pattern is incomplete, such as at the beginning of $\mathrm{m} .30$, only five notes from the pitch class set are used.
} 
Example 4.15 Section B, mm. 15-25
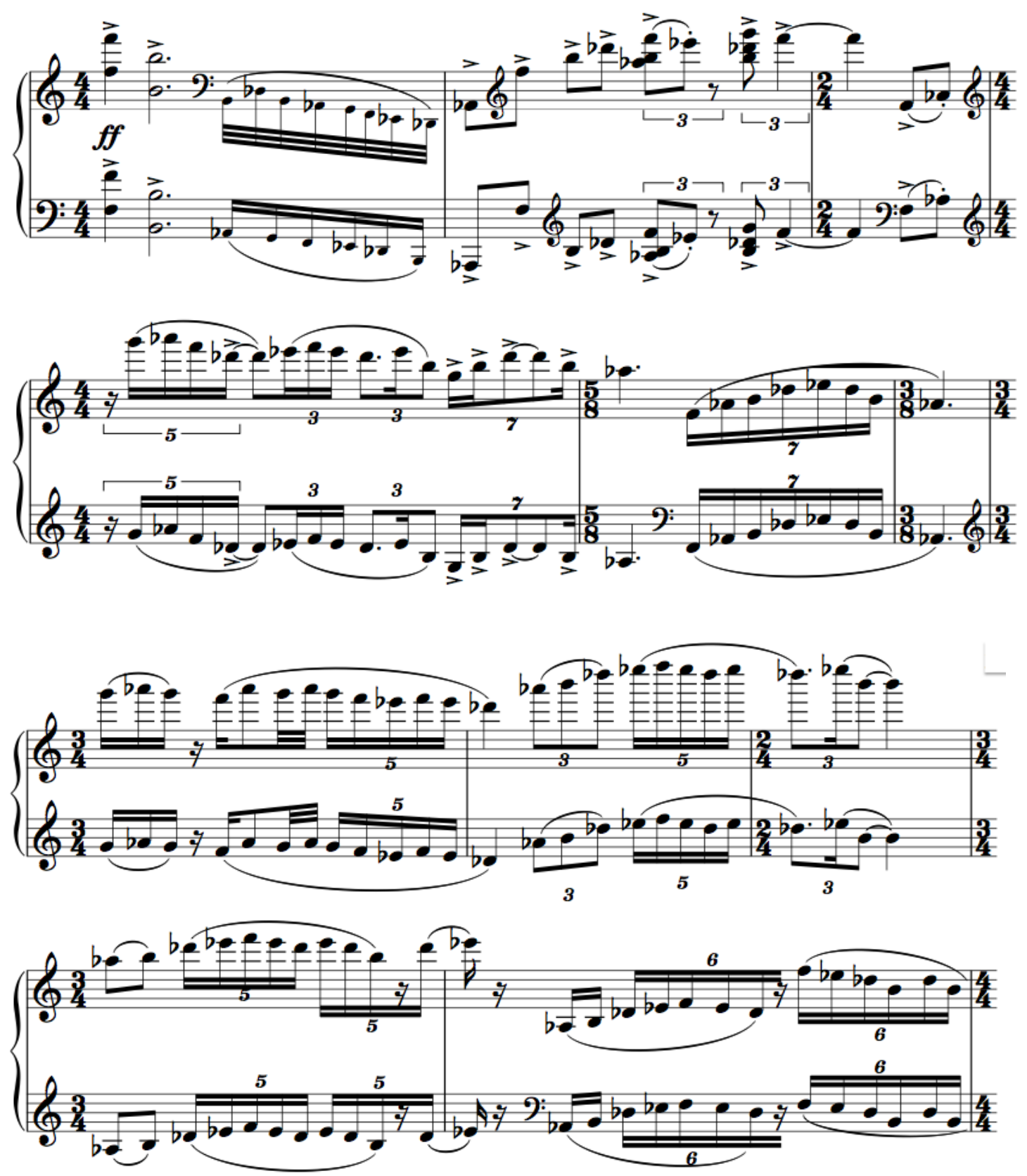
Example 4.16 Section C, mm. 26-37
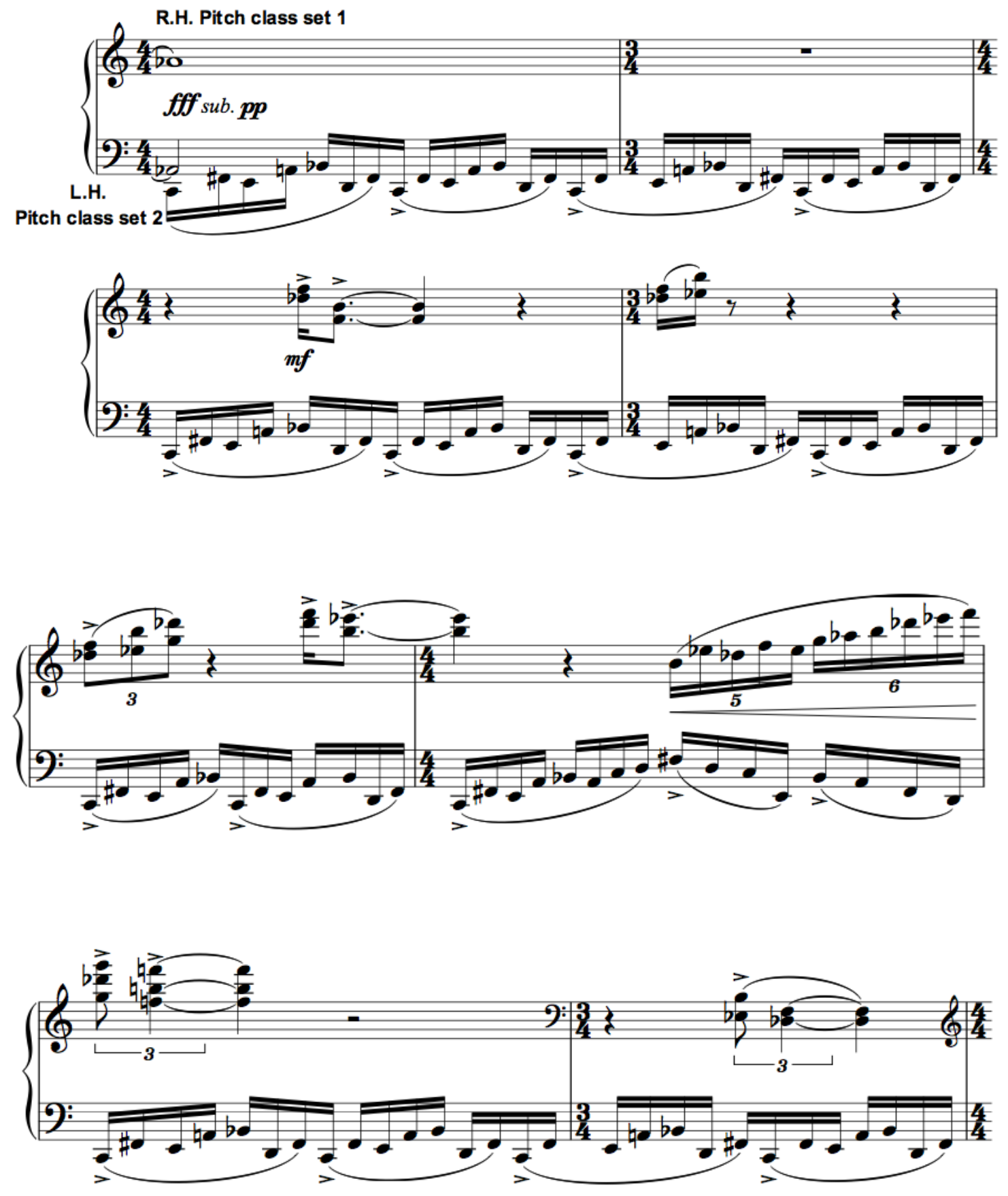

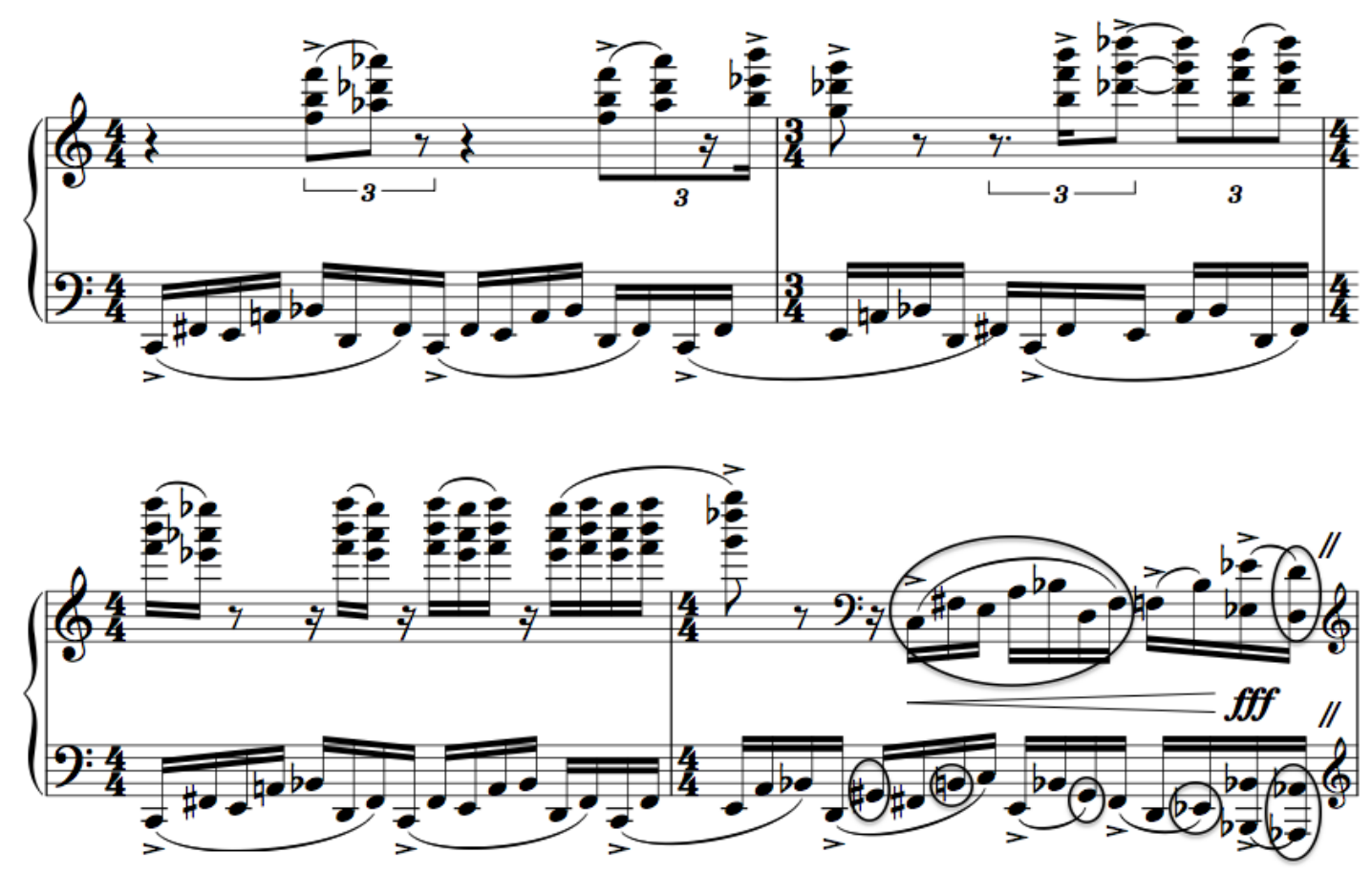

The transition, mm. 38-43, strictly uses pitch class set 2 in the right hand and pitch class set 1 in the left (see example 4.23). Section A', mm. 44ff. (see example 4.9.2), employs pitch class set 1 in both hands; the one exception is in $\mathrm{m} .53$ (see example 4.17), where notes from pitch class set 2 intervene. 
Example 4.17 M. 53

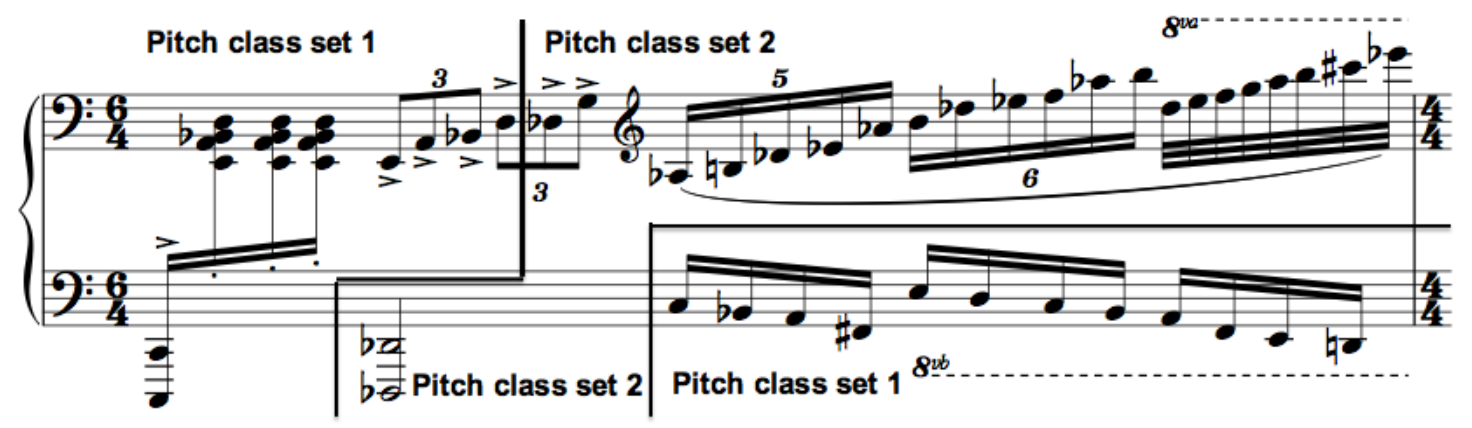

In section $\mathrm{B}^{\prime}, \mathrm{mm}$. 54ff., pitch class set 2 would be predicted to be ubiquitous, since the first statement of this section strictly uses only the notes from this group. However, the composer also includes the material from section A, which is based on pitch class set 1, in the bass. Example 4.18 below shows this section; what comes from section A (marked with rectangles) remains in pitch class set 1, the rest uses pitch class set 2. Some exceptions are in mm. 63-64, the last two measures of example 4.18. The left hand ostinato, derived from section A, appears sometimes with the notes from pitch class set 2 (the ones not confined with rectangles). 
Example 4.18 Section B', mm. 54-64, the rectangles mark pitch class set 1
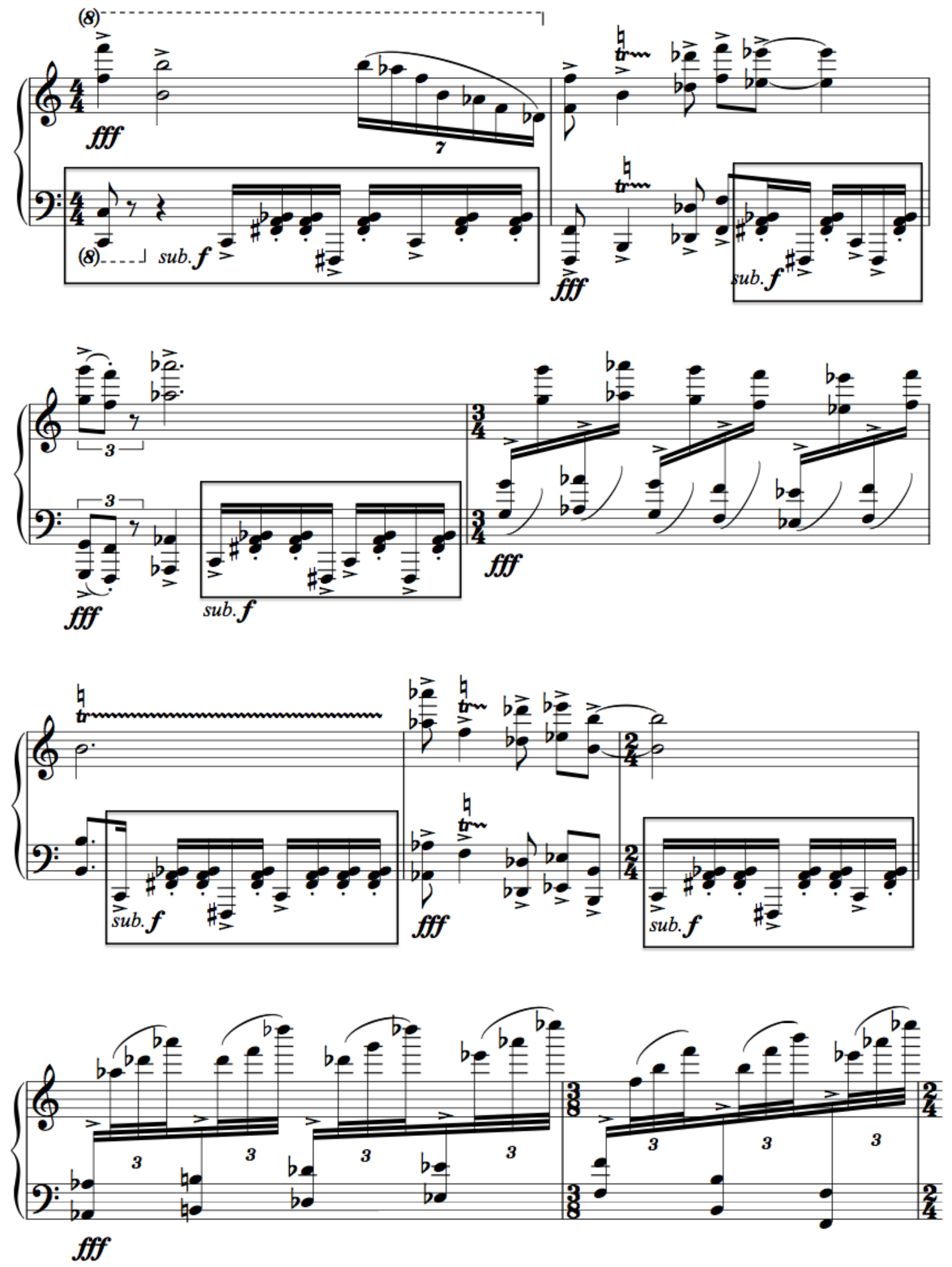


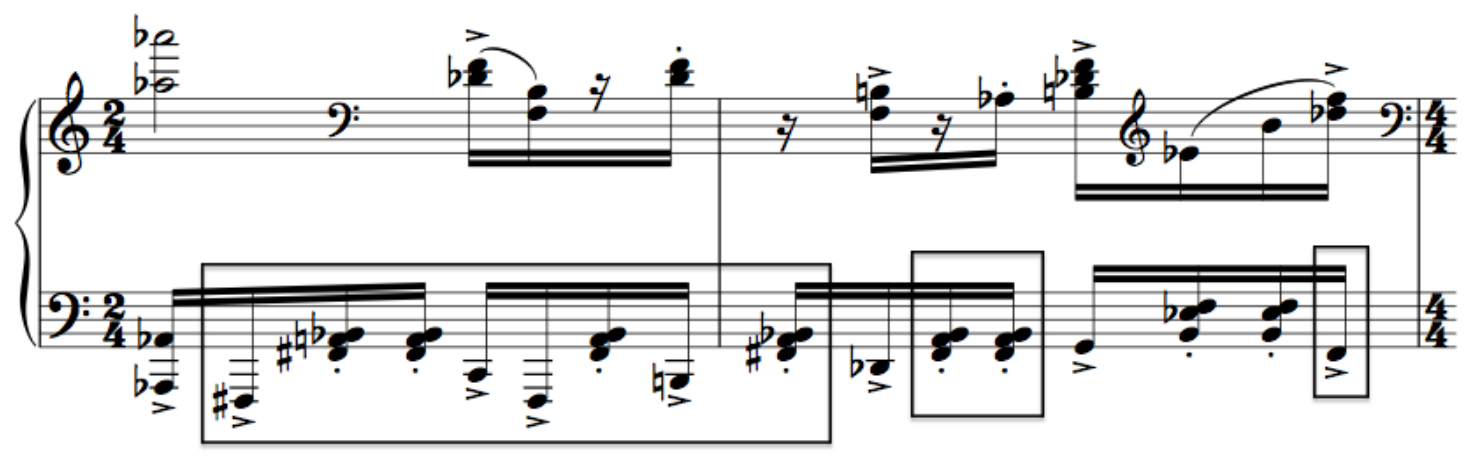

The transition, mm. 65-67, strictly employs pitch class set 1 in the right hand and pitch class set 2 in the left hand. See example 4.19 below.

Example 4.19 Transition, mm. 65-67

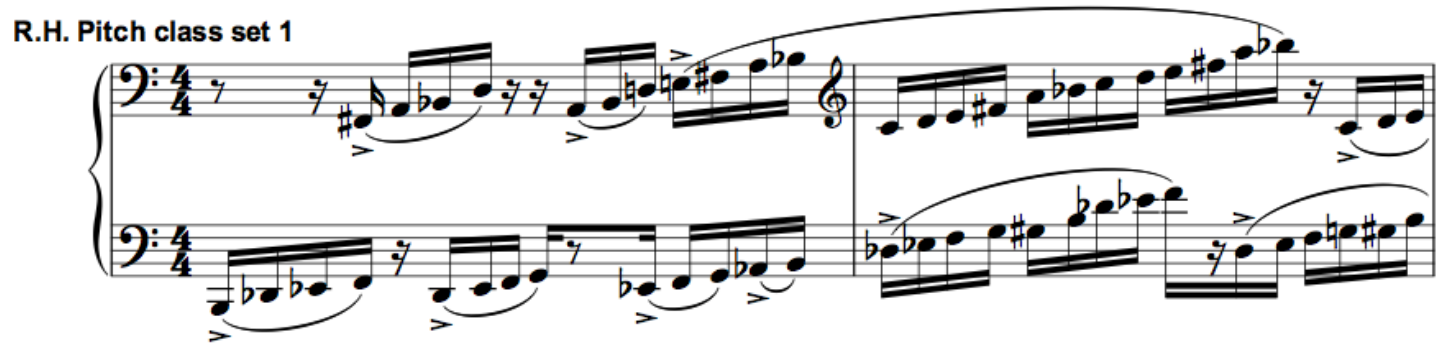

L.H. Pitch class set 2

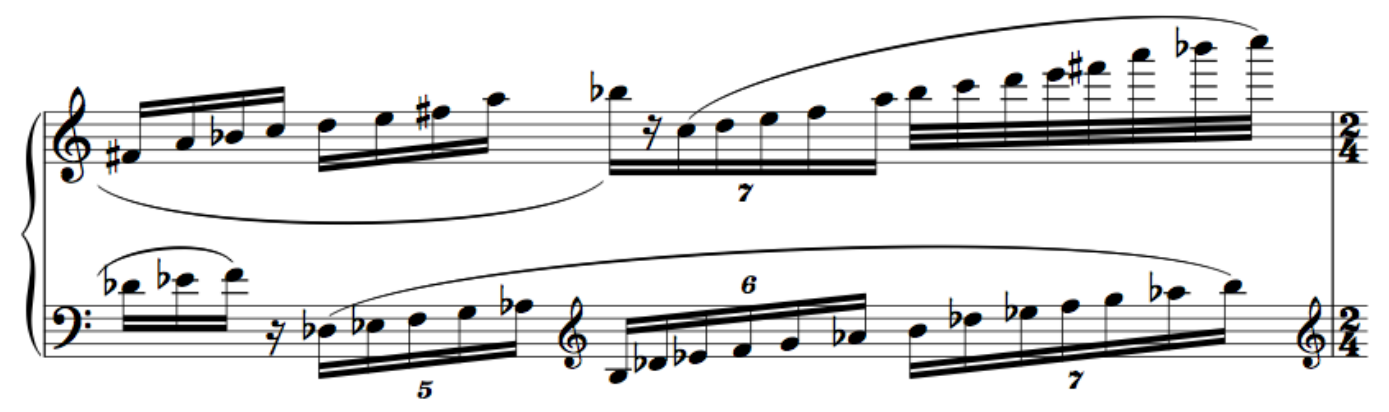


The coda takes the rhythmic and textual figures from section A, but the pitch content of the chords derive from the first measure, hence the right hand is based on pitch class set 1 and the left hand on pitch class set 2 (see examples 4.11 and 4.7). The pitch class sets exchange positions between hands in the last three measures (mm. 75-77); the right hand plays pitch class set 2 and the left hand plays pitch class set 1 (see example 4.12).

The two pitch class sets discussed in this section demonstrate how the piece is constructed both horizontally and vertically. Most of the time, the composer uses the pitch class sets straightforwardly, appearing mostly in the original forms, and only at certain points do both groups mingle. Table 4.3 below summarizes where both pitch class sets are used throughout the piece.

Table 4.3 Two pitch class sets used in each section of "Fierce"

\begin{tabular}{|l|l|l|l|l|}
\hline Section & Measure & Left Hand & Both Hands & Right Hand \\
\hline Introduction & 1 & Pitch class set 2 & & Pitch class set 1 \\
\hline & 2 & & $\begin{array}{l}\text { Pitch class sets } \\
1+2\end{array}$ & \\
\hline A & $3-9$ & & Pitch class set 1 & \\
\hline & 10 & & Pitch class set 2 & \\
\hline Transition & $11-12$ & Pitch class set 2 & & Pitch class set 1 \\
\hline & $13-14$ & $\begin{array}{l}\text { Pitch class set 2 } \\
\text { (with C) }\end{array}$ & $\begin{array}{l}\text { Pitch class set 1 } \\
\text { (with B) }\end{array}$ \\
\hline B & $15-25$ & & Pitch class set 2 & \\
\hline C & $26-36$ & Pitch class set 1 & & Pitch class set 2 \\
\hline Transition & 37 & & $\begin{array}{l}\text { Pitch class sets } \\
1+2\end{array}$ & \\
\hline A' & $44-43$ & Pitch class set 1 & & Pitch class set 2 \\
\hline Transition & 53 & & $\begin{array}{l}\text { Pitch class set 1 } \\
1+2\end{array}$ & \\
\hline B' & $54-60$ & $\begin{array}{l}\text { Pitch class sets } \\
1+2\end{array}$ & & Pitch class set 2 \\
\hline & $61-62$ & & &
\end{tabular}




\begin{tabular}{|l|l|l|l|l|}
\hline & $63-64$ & $\begin{array}{l}\text { Pitch class sets } \\
1+2\end{array}$ & & Pitch class set 2 \\
\hline Transition & $65-67$ & Pitch class set 2 & & Pitch class set 1 \\
\hline Coda & $68-74$ & Pitch class set 2 & & Pitch class set 1 \\
\hline & $75-77$ & Pitch class set 1 & & Pitch class set 2 \\
\hline
\end{tabular}

\section{Thematic Idea}

Each section of "Fierce" features at least one prominent figure. These figures serve two purposes: they distinguish the section from the others and, when the same figure returns in a later section, they enable the listener to easily recognize a variation of the previous section. As discussed earlier, the material in the introduction returns in the coda: specifically, the tremolo shown in example 4.7 is present in both sections. The two chords that compose the tremolo provide the harmony for mm. 68-71 (see example 4.11), but these chords are set in the prominent rhythmic figure of section A. Example 4.20 shows the figure in section A divided by the boxes according to the accents, and compares that passage to $\mathrm{m} .68$, in the coda, that uses the same figure but with the two chords previously found in the tremolo.

\section{Example 4.20}

4.20.1 Figure in section A, m. 3

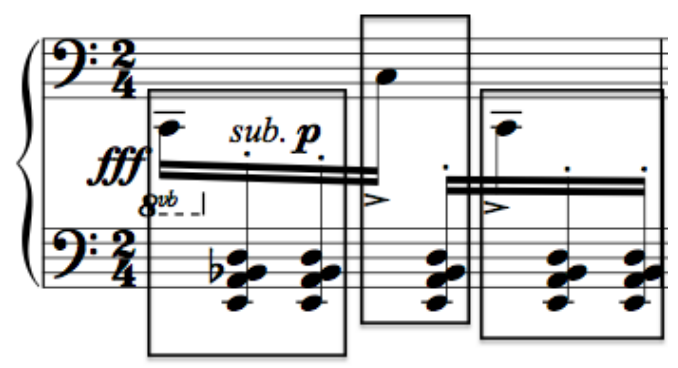


4.20.2 The figure from section A, played with the two chords from the tremolo, m. 68 .

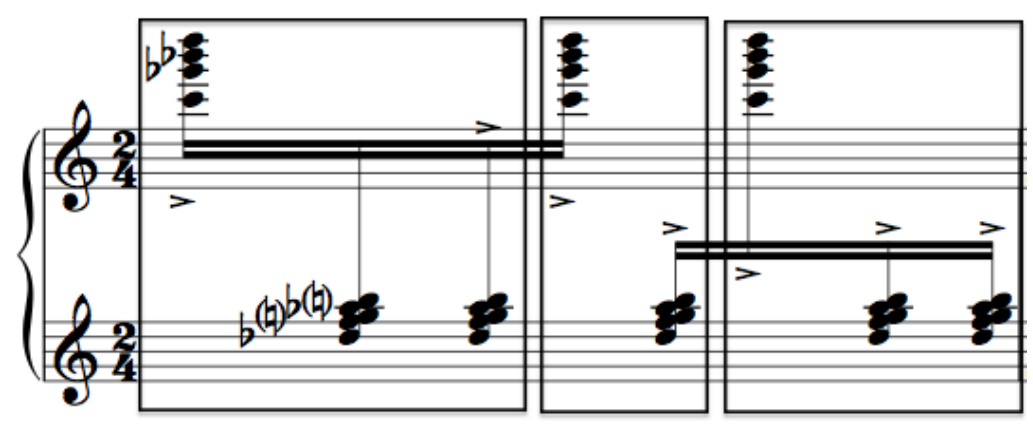

Section B, as noted above, features a two-note motif: a tritone. Example 4.21.1 (below) marks all figures derived from this motif. Some are inverted, and the descending tritone $(\mathrm{G}-\mathrm{Db})$ in $\mathrm{m} .18$ is embellished. This descending tritone is prefigured in section $\mathrm{A}$ (see example 4.9.1) between the accented notes $\mathrm{C}$ and $\mathrm{F} \#$ as well as the slurred $\mathrm{C}-\mathrm{F} \#$ in m. 5, and is played straightforwardly in $\mathrm{m} .15$ of section $B$ with the notes $F$ and $B$. The tritone F-B is also repeated melodically in $\mathrm{m} .16$ after the register change and appears harmonically on the third beat as well as with the notes $\mathrm{Db}-\mathrm{G}$ on the fourth beat. This descending tritone figure also returns in the last movement "Hesitant" in mm. 38-39 (see example 4.21.2). 


\section{Example 4.21}

4.21.1 Two-note motif of section $\mathrm{B}$, mm. 15-18
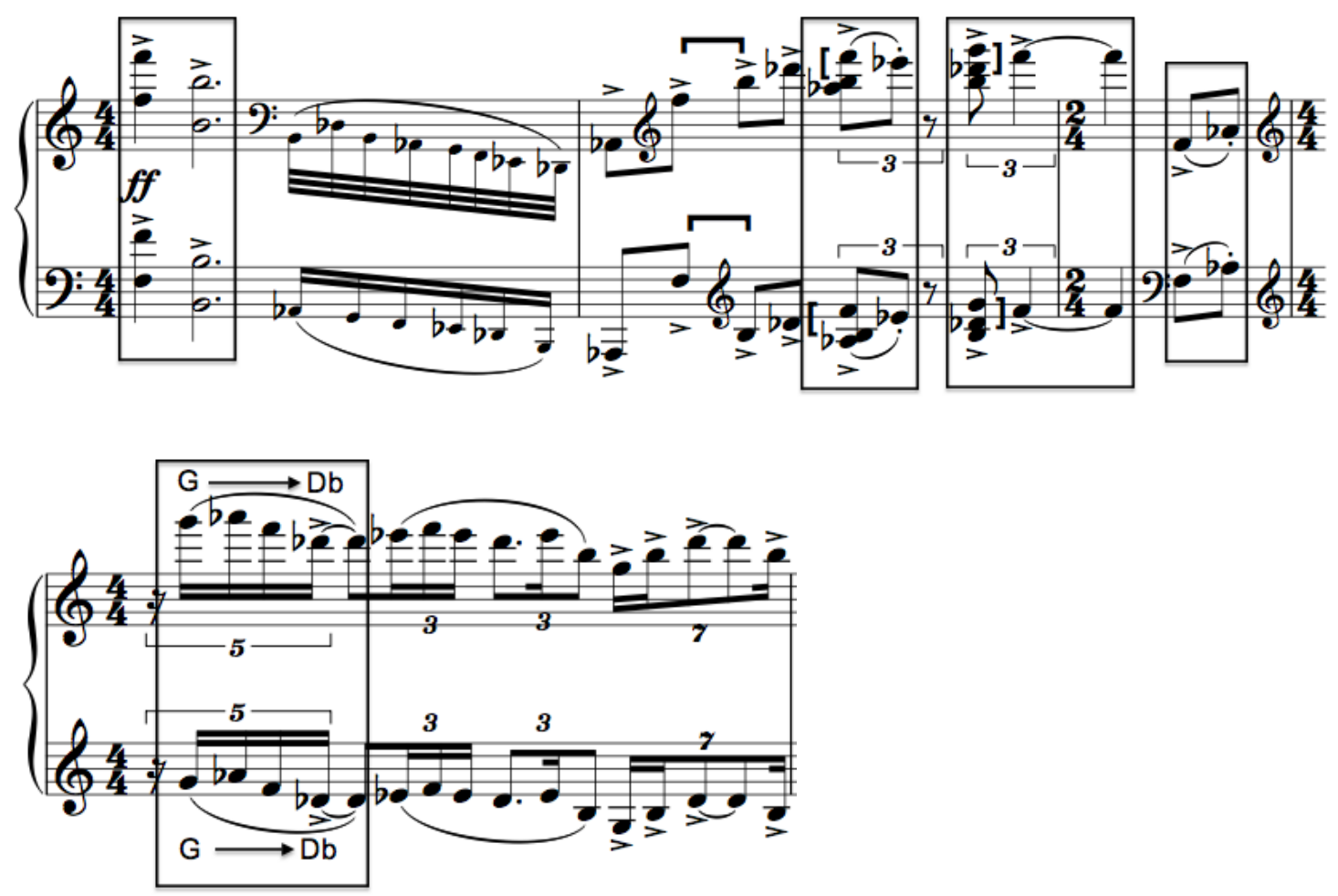

4.21.2 Two-note motif (descending tritone) in mm. 38-39 of "Hesitant"

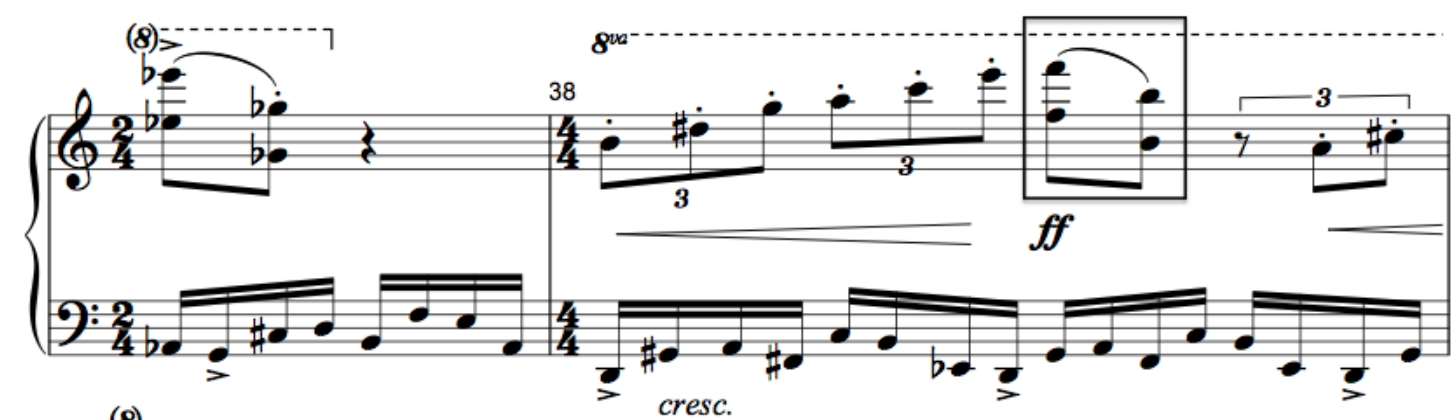

(8) 


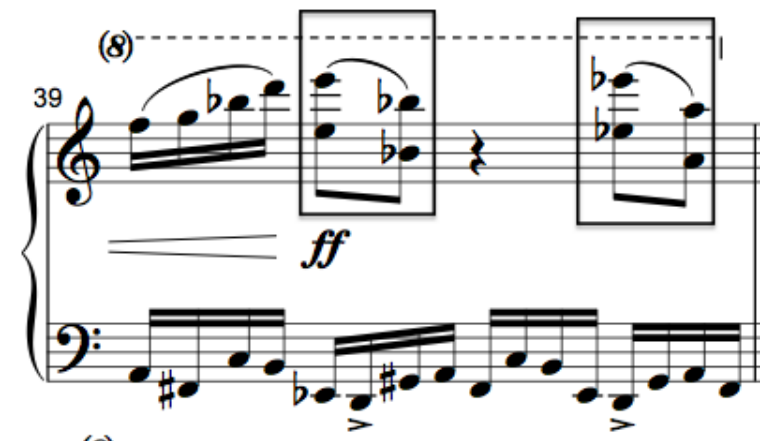

(8).

Section $\mathrm{C}$ features an ostinato pattern in the bass. Example 4.22 marks the pattern each time it repeats. The accents correlate with the pattern, but not with the meter. This explains why the time signature of $4 / 4$ alternates with $3 / 4$; the fourth repetition of the pattern ends exactly at the end of the $3 / 4$ measure. This passage, however, can be viewed either as two-measure unit (4/4 plus 3/4, hence four regular accented notes over two measures) or as $7 / 16$ meter according to the accents (an interpretation which weakens the significance of the quarter-note beat).

Example 4.22 Ostinato pattern in section C, mm. 26-37

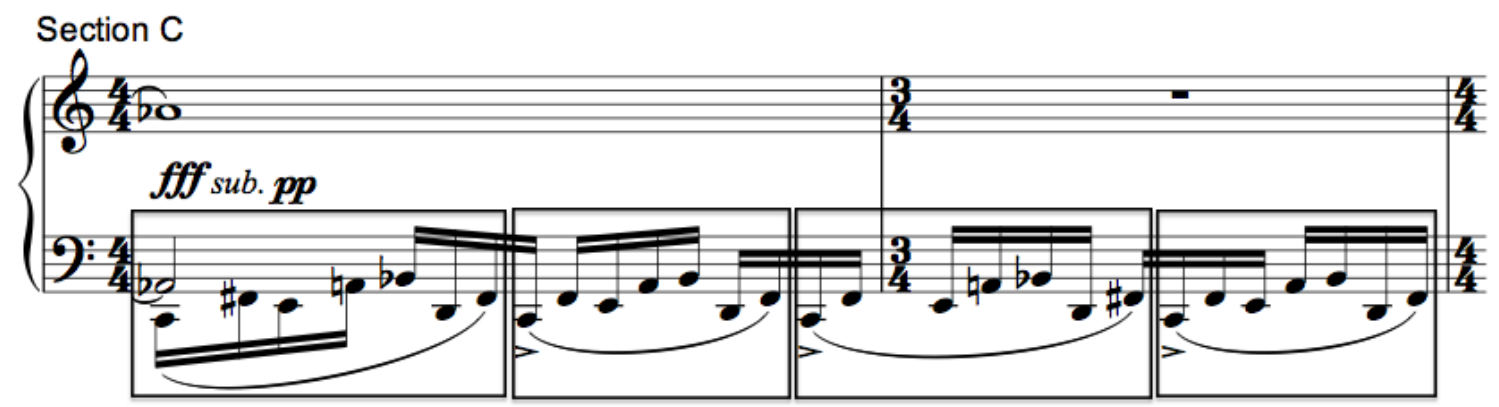



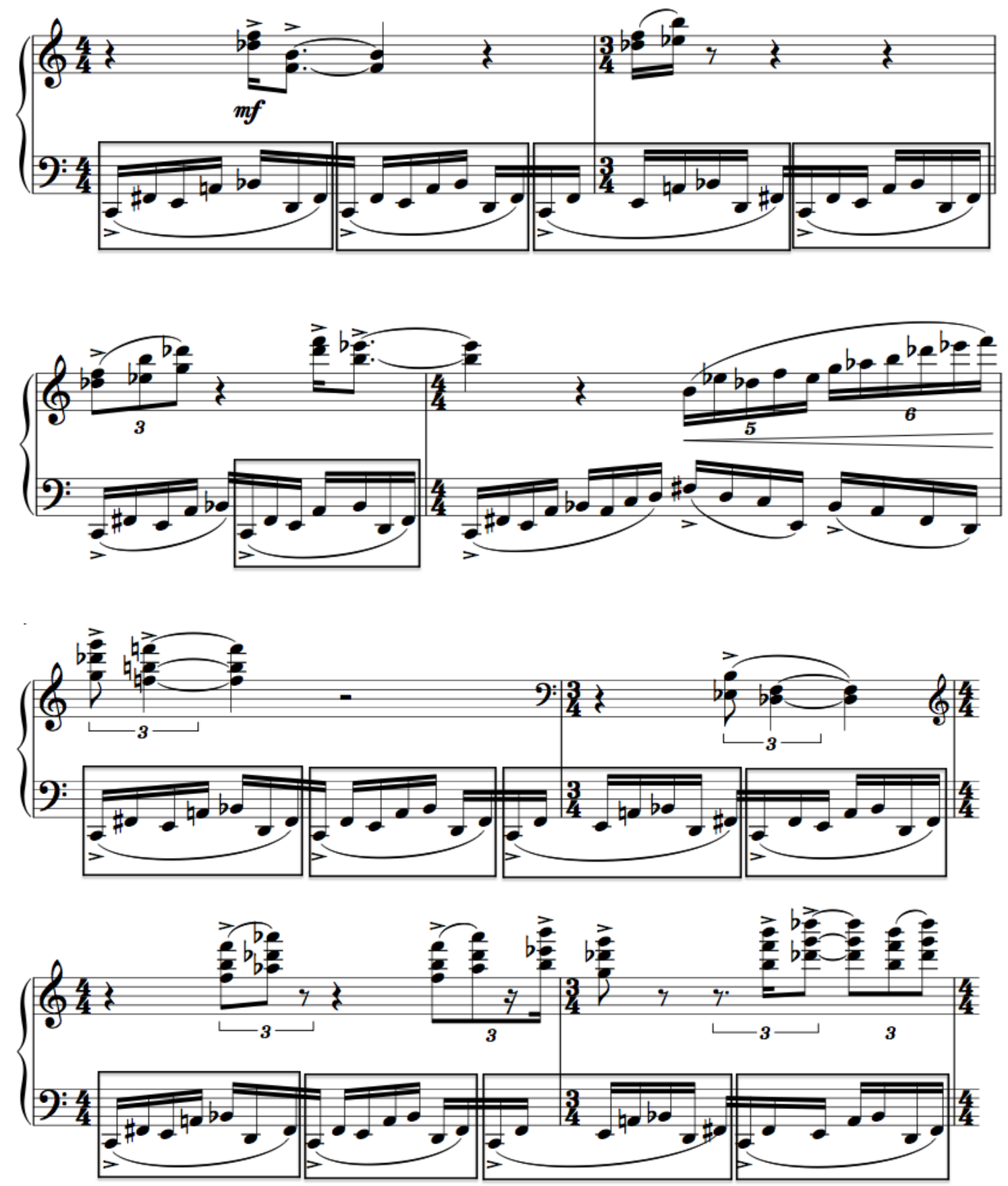


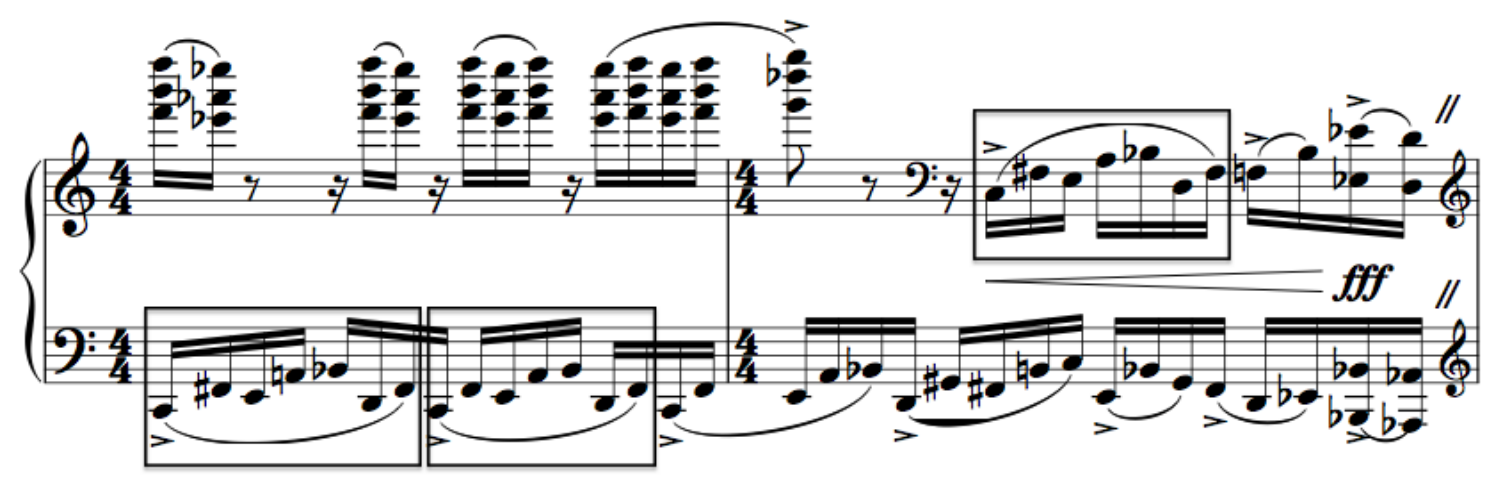

This ostinato pattern remains in the bass in the transition (see example 4.23). The composer introduces another pattern in the right hand. This new pattern is longer than the one in the bass, resulting in the unsynchronized accents between the two hands. The pattern in the right hand agrees with the time signature $4 / 4$, but not with $3 / 4$. In mm. 39 and 41 , in example 4.23 below, the composer uses four notes in retrograde order to complete the measures.

Example 4.23 Ostinato patterns in transition, mm. 38-43

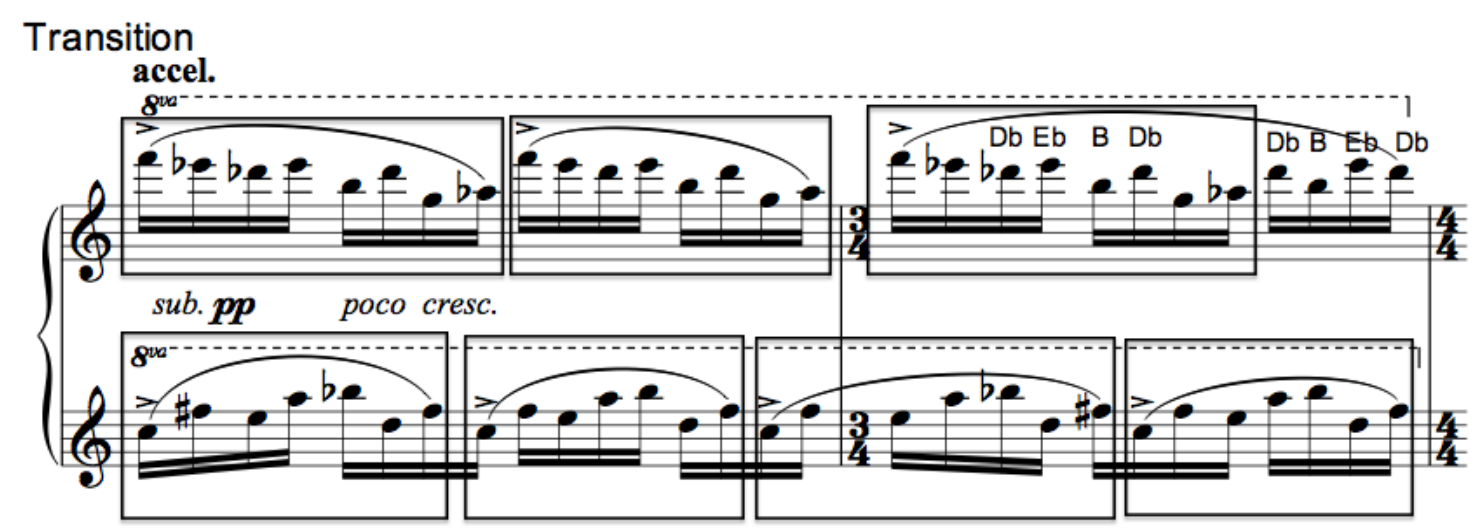



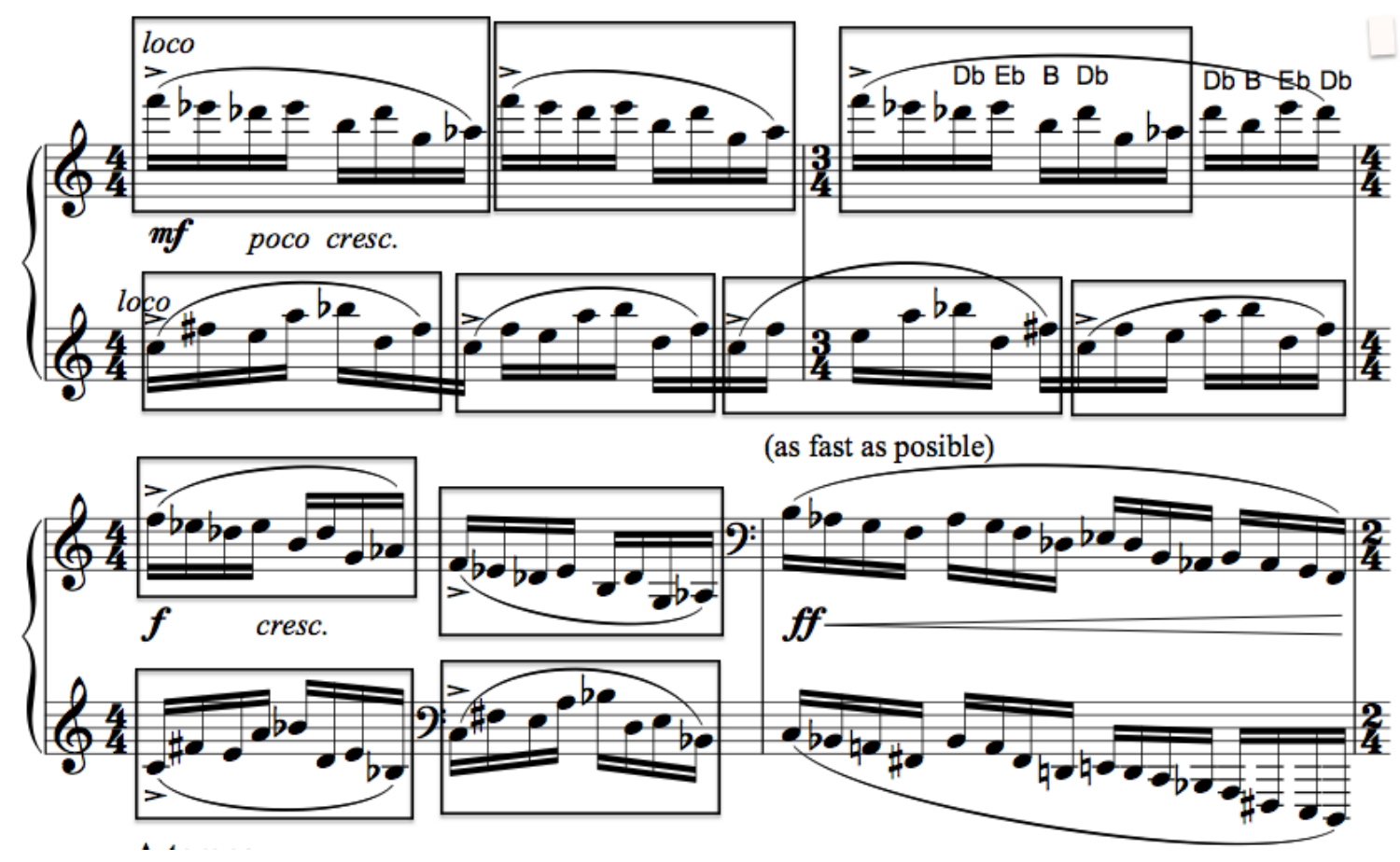

\section{"Fierce" and Other Movements}

Section B' at mm. 54-64 prefigures similar passages in "Hesitant." Example 4.24 compares the passages from both pieces. M. 57 of "Fierce" is similar to mm. 28-29 and 58-59 of "Hesitant," and mm. 61-62 of the former resemble mm. 55-57 of the latter. These figures provide some elements of unity to the cycle. 
Example 4.24

4.24.1 Mm. 56-62 of "Fierce"
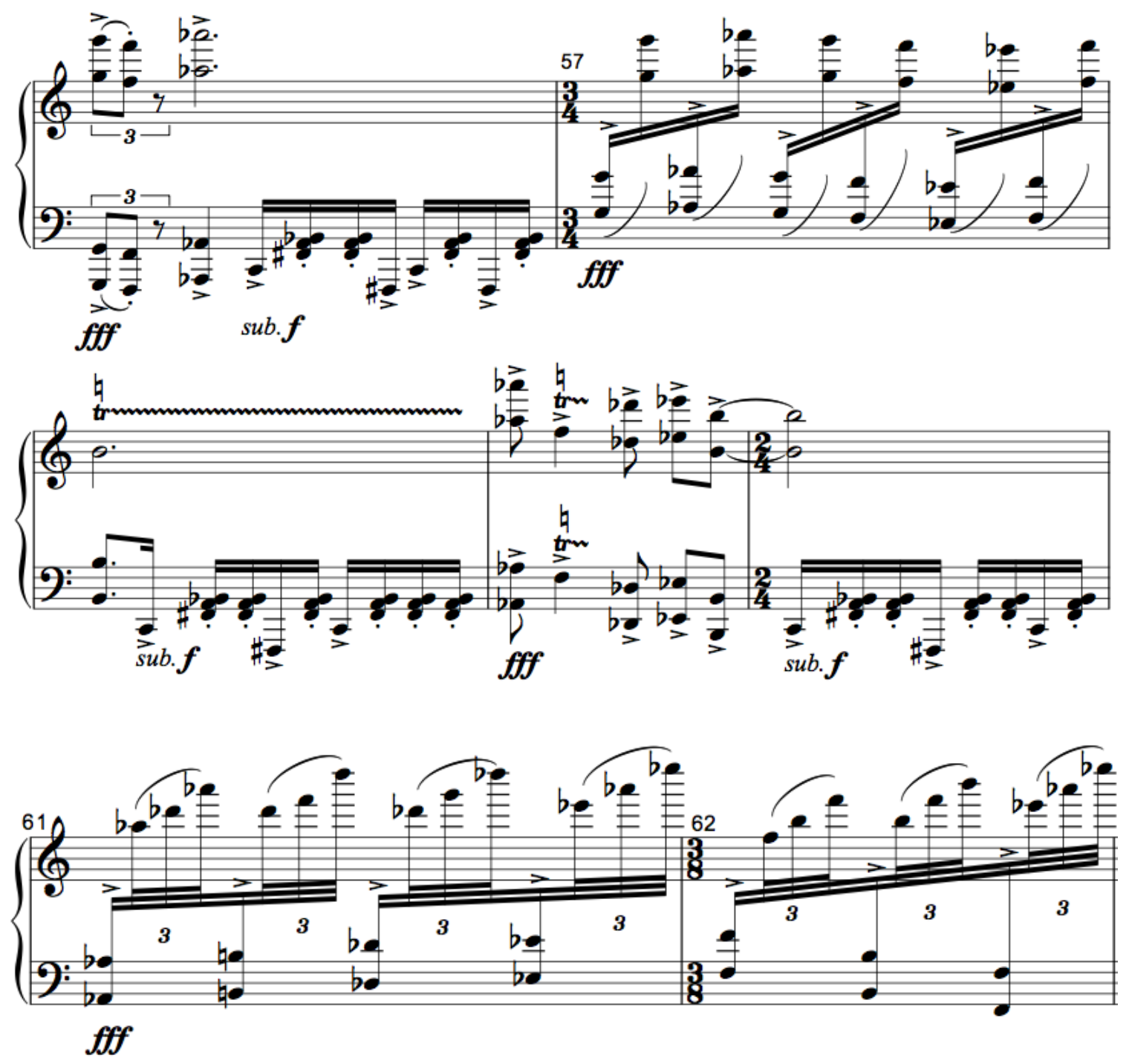
4.24.2 Mm. 28-29 of "Hesitant"

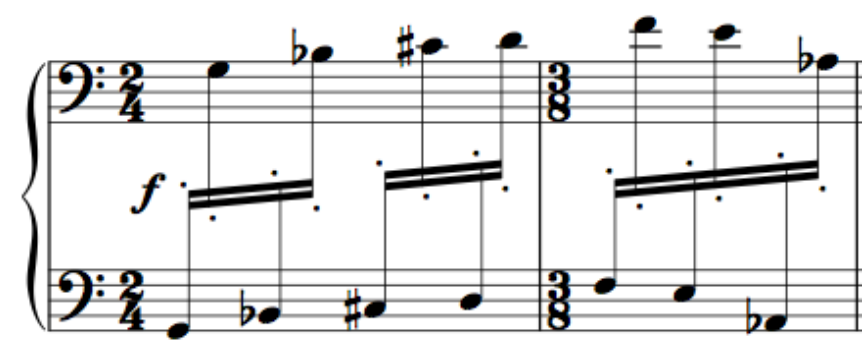

4.24.3 Mm. 55-60 of "Hesitant"

Transition 3
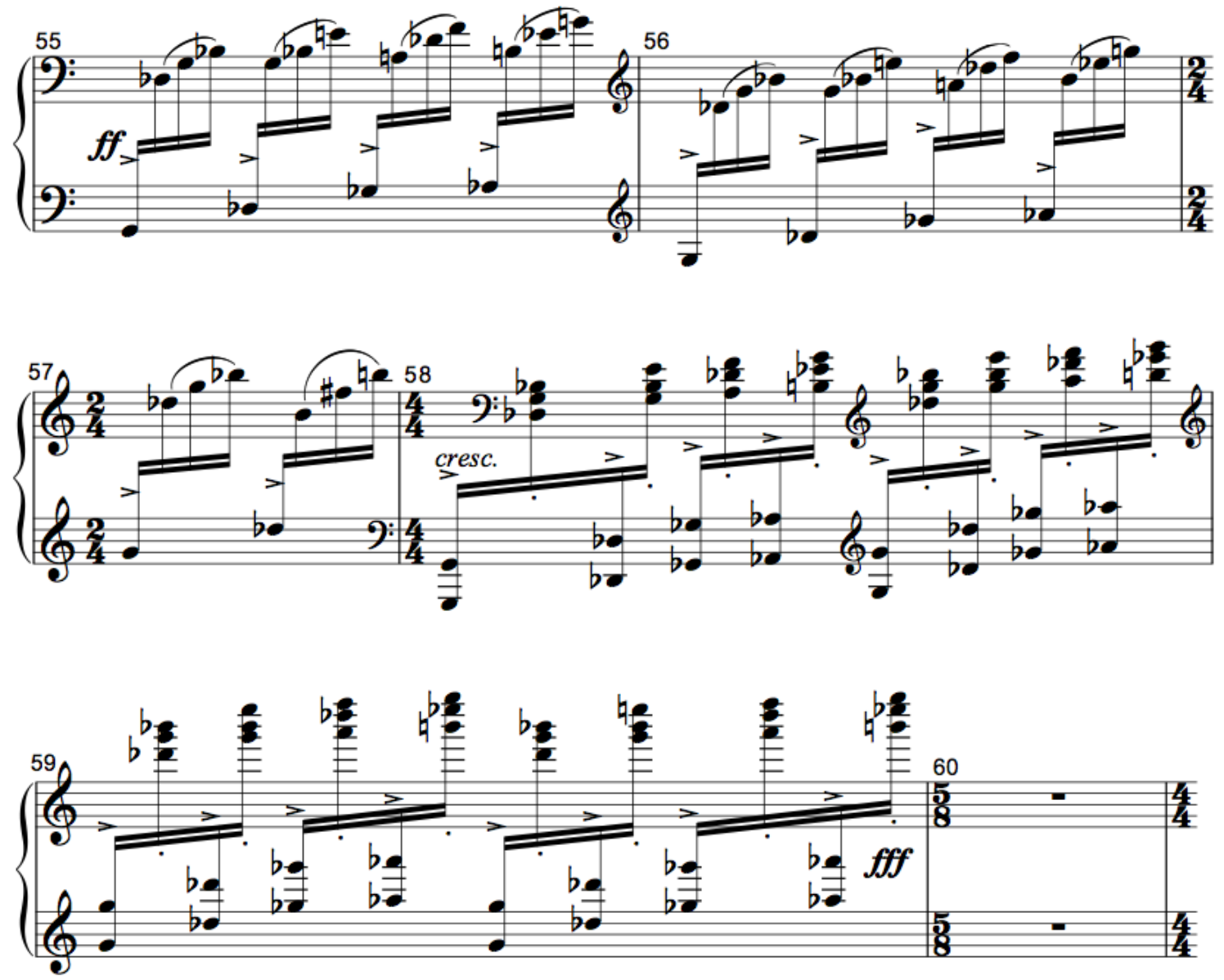
Similarly, the arpeggiated chords in $\mathrm{mm} .75-76$ of the coda are a figure that recurs in "Absent." Example 4.25 compares the figure in both pieces.

\section{Example 4.25}

\subsubsection{Mm. 74-76 of "Fierce"}

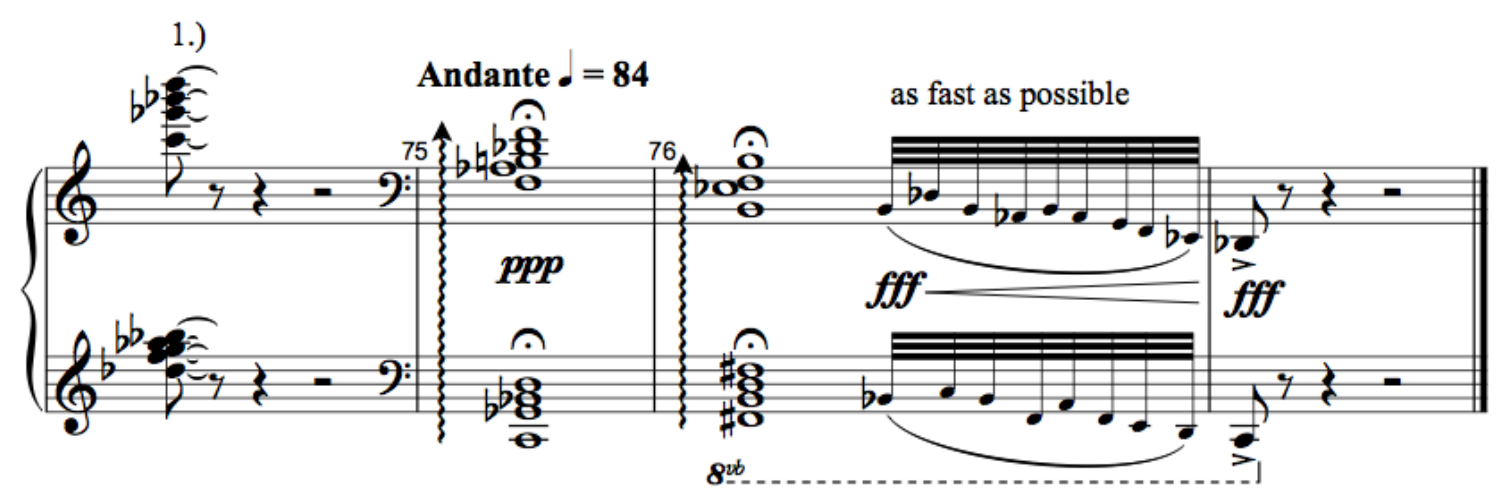

1.) wait until the sound fade away, gently play the next chord inside the fading sound

\subsubsection{1 of "Absent"}

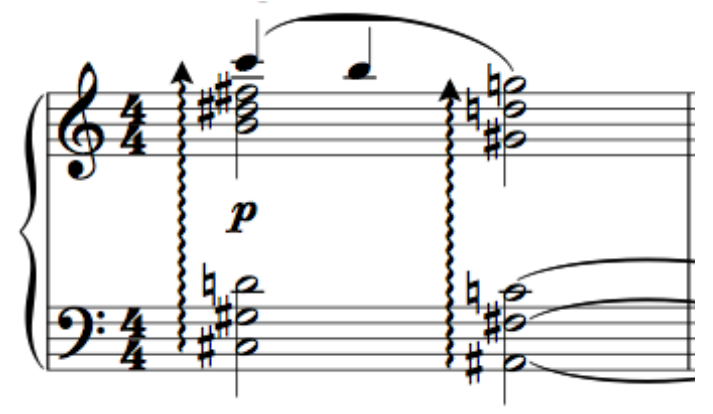

"Fierce" ends with a figure drawn from section B. Example 4.26 compares m. 15 with mm. 76-77. Because $\mathrm{m} .15$ is in section B which employs only the pitches from pitch class set 2 , the notes between two hands are limited to only six pitch classes. In mm. 76-77, the composer uses complementary pitch class sets between hands, and this creates 
more dissonance, similar to cross-relations in tonal music; these direct "cross-relations" are marked in example 4.26.2 with arrows. The tension at the end of the piece is much greater although the figure is borrowed from section B.

\section{Example 4.26}

4.26.1 Mm. 15

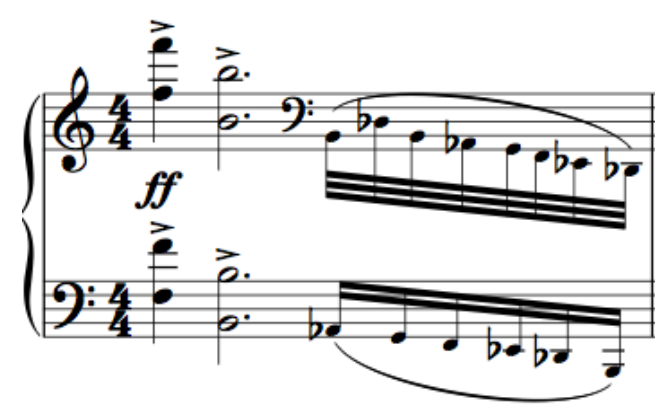

4.26.2 Mm. 74-77

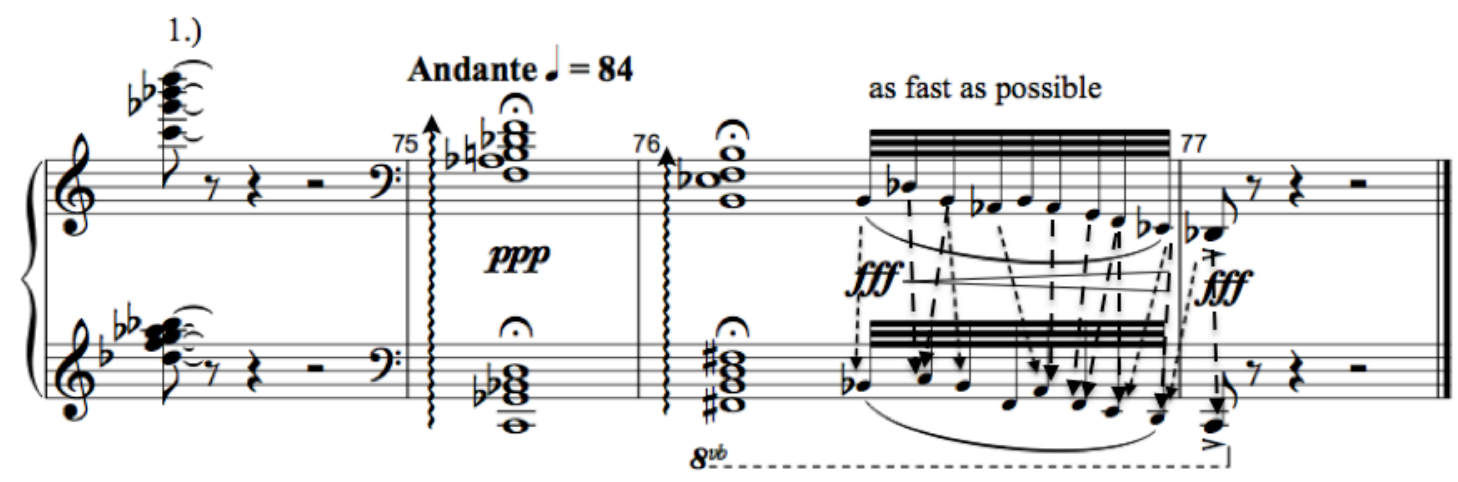

1.) wait until the sound fade away, gently play the next chord inside the fading sound 


\section{Thai Musical Influences}

Thai influences in "Fierce" can be divided into three main areas: 1) the extramusical element, 2) the influence of Thai musical instruments, and 3) pitch. Through these three areas, with different levels of transparency, Thai musical style as well as Thai culture infuses this piece. In addition, the section "Performance Practice" is added at the end with some suggestions of Thai and western styles that mix together in this piece.

\section{The Extra-Musical Element}

The title of the cycle Three Minds reflects the composer's thought during his meditation. Prangcharoen was born and lives as a Buddhist. Buddhism is an inseparable part of Thai culture, in which this religion takes important roles in everyday life. Not only the ceremonies in which people participate, but also certain Buddhist precepts are considered moral standards respected by all people in the society. The basic precepts, known as "five precepts," ${ }^{, 54}$ make people respect each other. Other very important, but less fundamental, precepts teach us how to deal with one's own emotions. During Prangcharoen's meditation, he observed his own mind. Three emotions that came to his thoughts are, in a sense, transcribed into these three pieces. Anger is an important theme in Buddhism, often discussed as worsening our mind, with the inevitable conclusion that people should learn to calm themselves down and divert the mind from the state of anger. However, it should be underlined that, when saying that the thought came to him during a meditation, the composer indicates that "Fierce" depicts anger metaphorically, describing the state of mind imaginatively, rather than a quasi-autobiographical depiction of the

\footnotetext{
${ }^{54}$ Five precepts include 1) Refrain from killing animals, 2) Refrain from taking others' belongings without permission, 3) Refrain from sexual intercourse with others' wife or husband, 4) Refrain from lying, and 5) Refrain from drinking alcohol, which can cause recklessness.
} 
intense emotion as the composer might have experienced himself. This extra-musical resonance is defined within Thai culture, especially the Buddhist precept that anger is to be observed by the mind and subjected to constant control.

\section{The Influence of Thai Musical Elements}

The piece drew inspiration from a Thai percussion instrument called ranad, a wooden xylophone played with two mallets. Often the two hands play an octave apart in a parallel motion. The influence of ranad is conspicuous in section B where the music progresses in just such a motion. Example 4.27 shows the beginning of section B; this parallel motion resembles a ranad technique called tee-chak ( ตีฉาก) in which the two hands play an octave apart with an equal weight; in addition, once the mallets hit the wooden bars the player needs to lift the mallets up immediately to create a good resonant sound. ${ }^{55}$ With the doubling at an octave in both hands and the leap between $\mathrm{F}$ and $\mathrm{B}$, the pianist needs to lift the hands up automatically to progress from one to another. The similar technique of ranad is used in mm. 24-25 of "Fierce," where the player needs to balance the weight as well as the synchronization between two hands (see example 4.28).

\footnotetext{
55 "Fueg tee ranad khan puen than (Introduction to Basic Ranad Playing)," Sornchai Prathumthong, http://www.thaigoodview.com/library/teachershow/sakaew/sornchai_p/ranad/sec04p04.html. (accessed December 2, 2015).
} 
Example 4.27 Section B, mm. 15

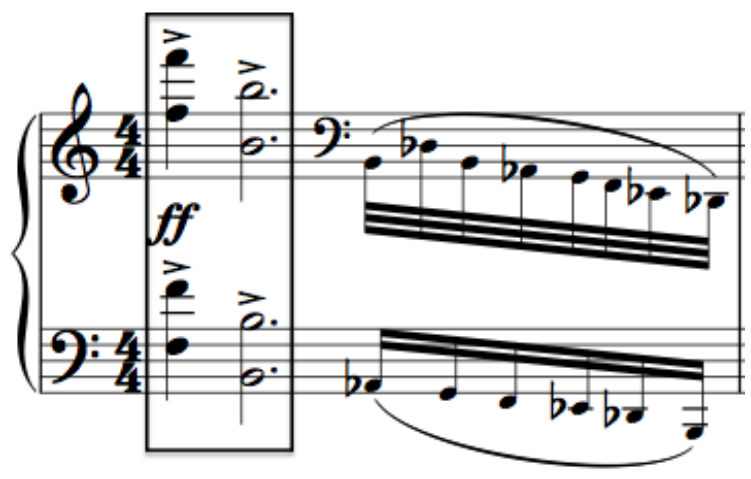

Example 4.28 Section B, mm. 24-25

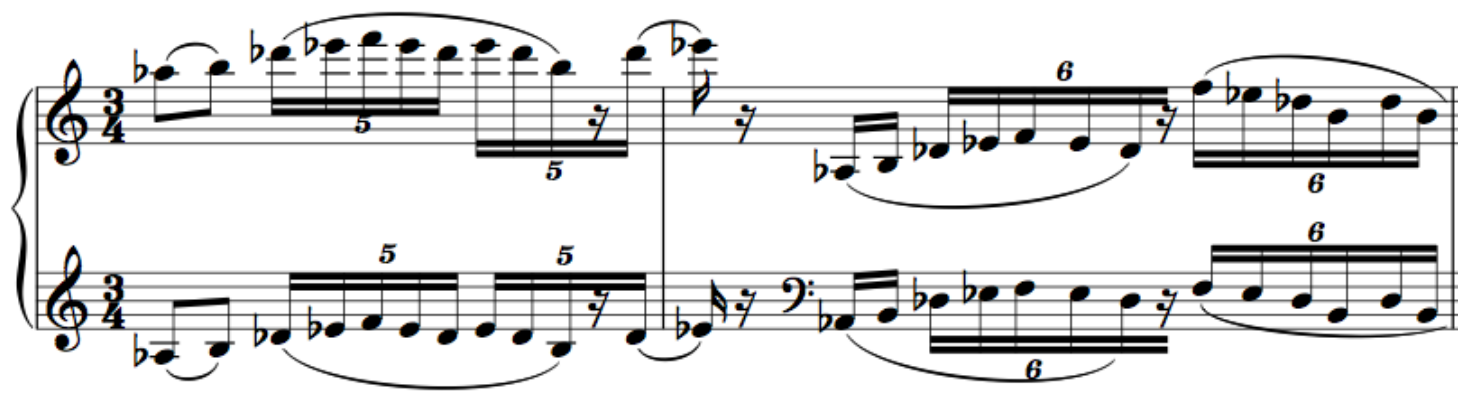

The style of section B also resembles another ranad technique called sabad ${ }^{56}$

which is the written-out upper mordent here (see example 4.29). Sabad is the common instrumental technique that characterizes Thai music and is found in passages of most Thai musical instruments.

\footnotetext{
${ }^{56}$ Sabad in Thai traditional music is a group of three notes played successively and fast. The figure in "Fierce" that is equivalent to an upper mordent in western music is, however, more common in other Thai musical instruments than in ranad. Most common sabad figures in ranad music are either a three-note ascending line or a three-note descending line.
} 
Example 4.29 Section B

4.29.1 Sabad in mm. 18

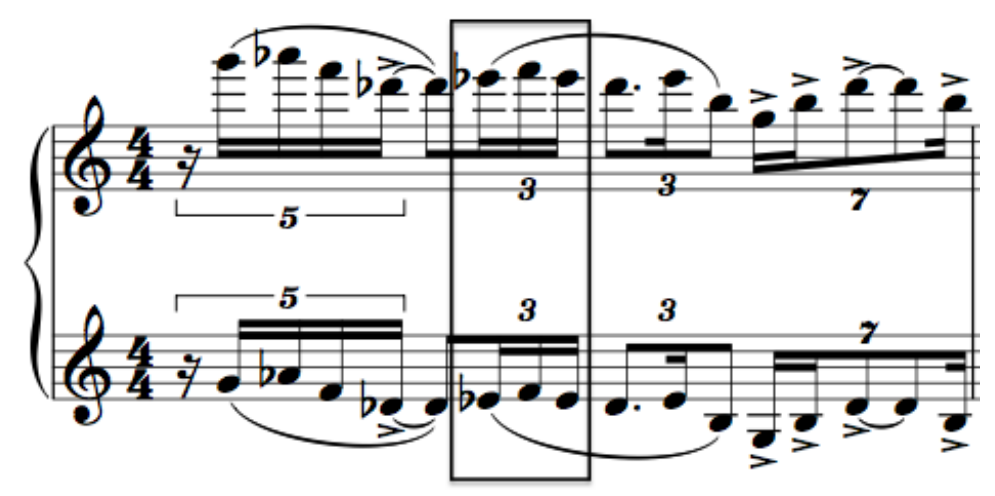

4.29.2 Sabad in mm. 21

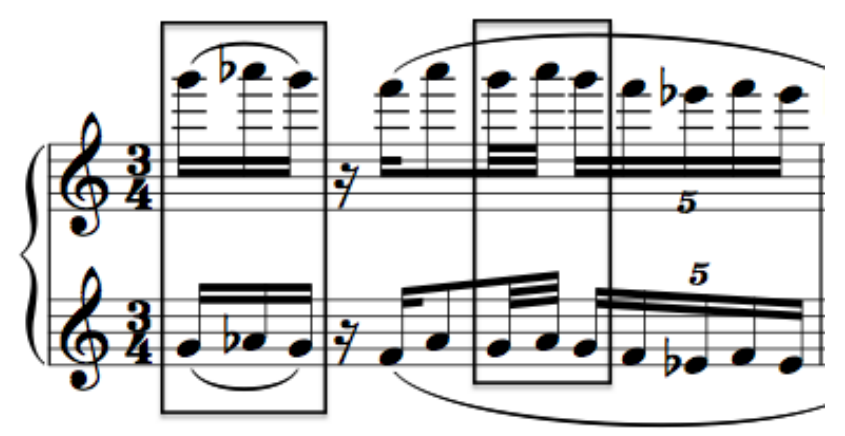

Example 4.30 is an excerpt from Loy Luean Sam Chan. The part is arranged for ranad $e k^{57}$ and transcribed into western music notation by Pornchai Polnikrot who turned the tune into a characteristic ranad passage. In this excerpt, it shows the common parallel motion in ranad music as well as sabad technique. Measures 39-40 of the excerpt include three-ascending-note sabad that is more common in ranad than the mordent figure such as found in mm. 41-42 of the same excerpt.

57 Ranad ek is the high-pitched ranad. It has the most projecting sound among all types of ranad. 
Example 4.30 An excerpt from Loy Luean Sam Chan, ranad ek part, mm. 39-42 ${ }^{58}$

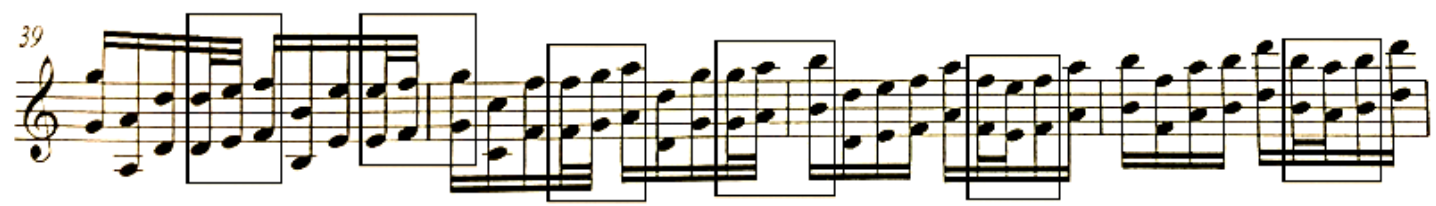

The grandiose opening of "Fierce," with its tremolo, reflects a Thai percussion instrument technique called gror ( กรอ). Gror in ranad is executed by alternating two mallets very quickly and evenly, often on two different wooden bars. This technique is found both at the opening and at the end of "Fierce." The composer expands this technique when applied to the piano by assigning each hand a chord instead of the single note that a mallet can play at a time on ranad. Example 4.31 below is an excerpt from Choet Chin transcribed into western music notation by Phaitoon Chaycharoen; the upper line is for khong wong yai ${ }^{59}$ ( ฆ้องวงใหญ่) and the lower line is played by ranad thum ${ }^{60}$ ( ระนาดทุ้ม ). The excerpt shows a long tremolo between two notes, five steps apart.

\footnotetext{
${ }^{58}$ Pornchai Polnikrot, "Khan tam tang diaw ranad ek pleng 'Loy Luean Sam Chan' (A New Solo Composition for the Thai Ranadake Derived from the Song 'Loy Luean Sam Chan')" (MM thesis, Mahidol University, 2011), 53.

${ }^{59}$ Khong wong yai is a set of gongs ordered in a circle. The player sits in the middle of the circle and plays with two mallets. The transcription in example 4.31 shows ranad thum part with khong wong yai part because khong wong yai is the main instrument in Thai traditional music ensembles. While other instruments improvise based on the melody of a composition, khong wong yai plays the strict melody without changing.

${ }^{60}$ Ranad thum is a low-pitched ranad.
} 
Example 4.31 An excerpt from Choet Chin, khong wong yai and ranad thum parts, third movement, mm. 21-23

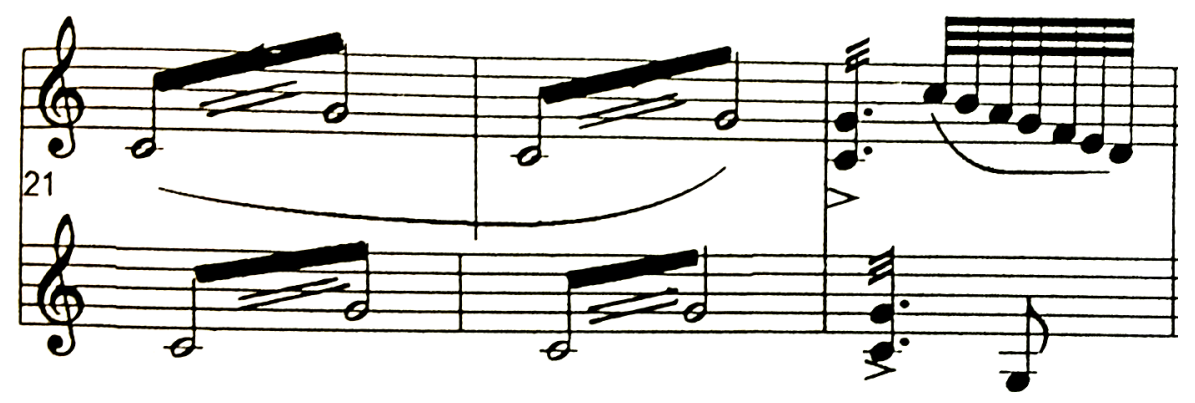

Pitch

In terms of the pitch aspect, the interval of a tritone is often found in this piece.

This interval may result from the blending between the tuning systems of western music and Thai traditional music. Jiradej Setabundhu compares the two tuning systems in his dissertation, as shown in figure 4.2.

Figure 4.2 Comparison between western temperament and Thai tuning system ${ }^{62}$

Tempered scale
cent: 0

\footnotetext{
${ }^{61}$ Phaitoon Chaycharoen, "Khan wikraoe tang ranad thum pleng Choet Chin (An Analysis of Ranad Thum's Melody on Choet Chin)" (master's thesis, Srinakharinwirot University, 1999), 268.

${ }^{62}$ Jiradej Setabundhu, "Aspects of Thai Music and Compositional Techniques in Selected Works of Jiradej Setabundhu” (DMA diss., Northwestern University, 2001), 2.
} 
The Thai tuning system evenly spaces seven pitches in an octave. Setabundhu emphasized the fourth degree of scale in the Thai tuning system as the only one note that is sharpened when compared to the same scale degree in the western tuning system. All the other notes in the Thai tuning system are flattened from the normal scale degree notes in the western system.

With the quasi-whole tone scale in Thai tuning system that has equidistant seven pitches in an octave, the distance from the first scale degree to the fourth scale degree is similar to a tritone: although still distinct from a tempered fa, the Thai fa is only a little sharp, while the distance between mi and fa is quite distinct from the tempered semitone found in the major scale in western music. This most remarkable interval is replicated in the distance from sol to do, in that it, too, is a little larger than a perfect fourth. The pentatonic scale commonly used in Thai music and considered to be a subset of the equidistant heptatonic source scale, such as the set of do-re-mi-sol-la, when transcribed to western music, is commonly notated with the pitches C-D-E-G-A. This transcription creates a sound in many ways similar to that used in Thai music. Sometimes passing notes are used in addition to the five notes of the pentatonic scale. For the set of do-re-misol-la, when fa is added as a passing note, the interval do-fa creates the sound similar to a tritone. Although this connection might seem remote in its blending of two historically independent tuning systems, it is in fact supported by a western composition: this blending between two tuning systems is found in a work by the Baroque composer Michel Richard de Lalande (1657-1726) called Airs of Siam, the title of which advertises the influence of Thai music that the composer heard at the court of Louis XIV. Jittapim Yamprai suggests that the tritone interval found in Lalande piece may be the result of the 
different tuning system in Thai music that creates the oddity within the French musical language of that era. ${ }^{63}$

Prangcharoen has a preference for the tritone in his compositions, and Three Minds is no exception to this generalization. Bearing in mind that textures in "Fierce" were inspired by the ranad, it is no surprise that the characteristic interval of a tritone is quite prominent. As noted above, Ranad is tuned with a heptatonic scale in which each note is spaced evenly in accord with the Thai tuning system. Playing through all the wooden bars of ranad stepwise creates an oddity, from a Western perspective, that is similar in certain respects to a whole-tone scale, with its shared feature of equal successive intervals. The tritone, that does not infer either major or minor modes and is found in non-diatonic scales of western music, and which in particular pervades the whole-tone scale, may be the best approximation for this oddity. In addition, in Thai music, a fourth may be found as a harmonic interval. Example 4.32 below shows an excerpt from the fourth movement of Choet Chin in which both khong wong yai and ranad thum play the harmonic interval at the end of each phrase. This harmonic fourth, understood within Thai music's characteristic equal-interval heptatonicism, is larger than a perfect fourth and could be considered close to a tritone.

\footnotetext{
${ }^{63}$ Jittapim Yamprai, "Michel-Richard de Lalande and the Airs of Siam," Early Music xli: 3 (2013).
} 
Example 4.32 An excerpt from Choet Chin, fourth movement ${ }^{64}$

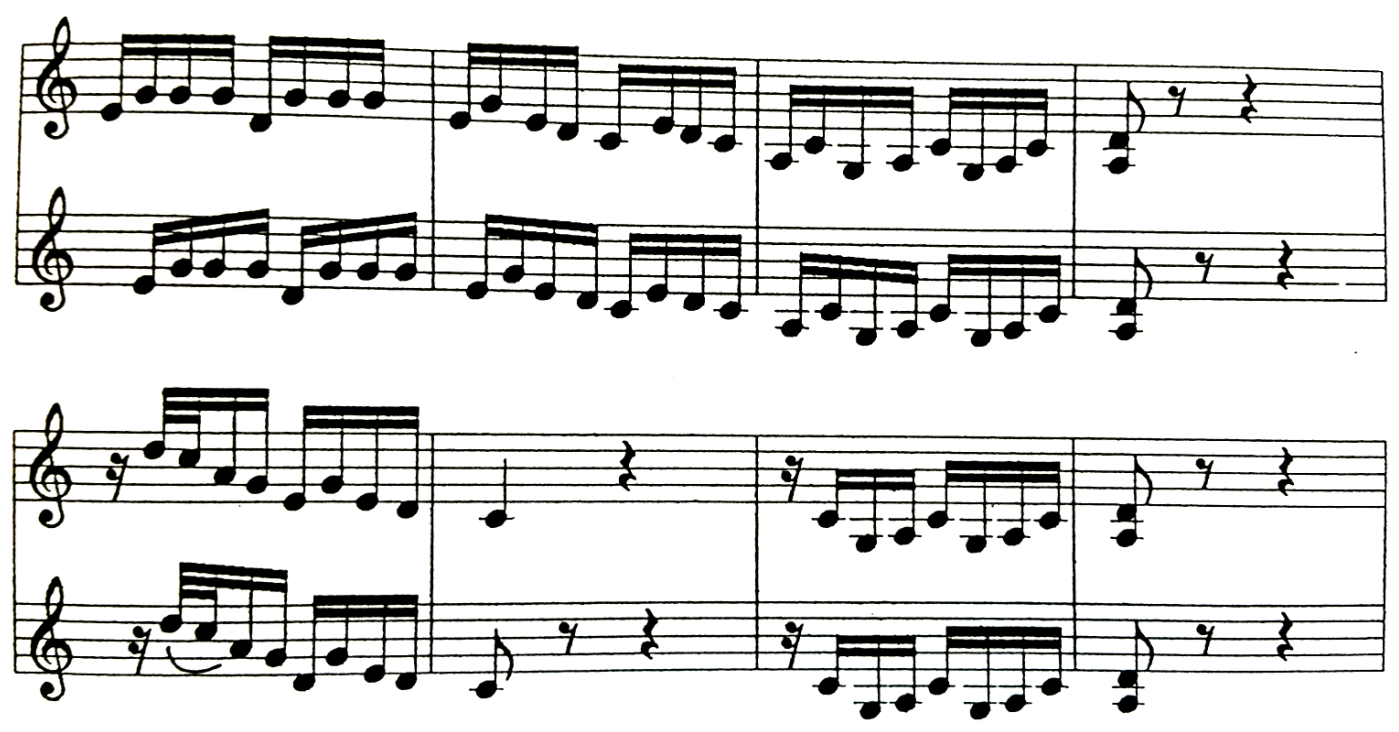

\section{Performance Practice}

"Fierce," inspired by ranad, is percussive in style. Respecting the performance practice of this piece, it would help if a performer had ranad music in mind. Many passages of this piece imitate ranad as modified to allow performance on the piano. However, the instruments are different and the composer also exploits features of the piano.

The grandiosity at the opening of the piece is like a Thai overture that signals the commencement of a performance and calls people to pay attention. The music progresses at a generally fast pace, alternating with somewhat peaceful passages. Section A with the ostinato pattern may represent the western style, while section B with the influence of

\footnotetext{
${ }^{64}$ Phaitoon Chaycharoen. "Khan wikraoe tang ranad thum pleng Choet Chin (An Analysis of Ranad Thum's Melody on Choet Chin)" (MM thesis, Srinakharinwirot University, 1999). 279.
} 
ranad represents the Thai style. In the composer's preface Three Minds, he wrote that the two materials combine together at the end of "Fierce" to create more energy, equivalent to what an angry mind creates. The combination of materials is most conspicuous in the second statement of section B, where the figure from section A intervenes. Specifically, section B is characterized by ranad, here a representative of Thai music, while the ostinato figure from section A is Western in character. When these two are combined, it reflects a blending of the two cultures. At the end of the piece, it is marked "as fast as possible." This also recalls Thai music that often becomes faster toward the end. ${ }^{65}$ The performance practice of Thai music may be useful in order to better understand this piece. The ambience of Thai musical performance, especially the grandiosity of the opening, the use of Thai-characteristic materials, and the excitement toward the end, are all reflected in this piece.

${ }^{65}$ All these are my own interpretation, excepting only the one sentence that refers to the composer's notes. 


\section{CHAPTER 5}

\section{CONCLUSION}

This chapter is divided into two sections and summarizes 1) Prangcharoen's biography and his music as an overview and 2) the analysis of Three Minds, the main focus of this research topic.

\section{Narong Prangcharoen and His Music}

Thai native composer Narong Prangcharoen emerged prominently as a prolific classical music composer in 2000s while he was still a composition student. Genres of his compositions include orchestral works, concertos, works for wind ensemble, chamber works, and works for solo instruments, chorus, and musical theater. He received numerous prizes from composition competitions, and these assured him many commissions to come as well as engagements with many orchestras around the world.

Since completing his doctoral degree in 2010, Prangcharoen remains active as a composer and a lecturer. As a composer, he is currently composer-in-residence of the Pacific Symphony Orchestra and of the Thailand Philharmonic Orchestra (TPO). As a lecturer, he is currently teaching at the Community Music and Dance Academy of the UMKC Conservatory of Music and Dance. He is also the founder and artistic director of the Thailand International Composition Festival (TICF), which takes place every year in Thailand to promote contemporary classical music. 
His music features a synthesis of Thai and Western music, which is a key ingredient to his uniqueness. This synthesis is found in his melody, texture, and instrumentation.

For the melody, pentatonicism is used. He often constructs his melody using the anhemitonic pentatonic scale characteristic of Thai traditional music. Apart from creating his own melody with Thai flavor, he also uses quotations from Thai traditional music; consequently, often the tunes that he quotes are also pentatonic.

For texture, he constructs his music based primarily on melody and linear motion. This creates the heterophonic texture characteristic of Thai traditional music, in which all parts in an ensemble play the same melody but each part embellishes it freely.

For instrumentation, we find the pervasive use of percussion instruments, also characteristic of Thai traditional music, a relationship he carries so far as sometimes even to imitate techniques of Thai percussion instruments.

All three aspects above show the influence of Thai traditional music. However, not all of his music clearly displays this influence. As said earlier, it is a synthesis. Moreover, the dominant source is Western: his music should be understood primarily in the context of Western music. Specifically, it features many compositional techniques found in contemporary music.

\section{The Analysis of Three Minds}

Three Minds is one of three compositions for piano that Prangcharoen has composed. Commissioned and composed in 2003 for Bennett Lerner to include in his recital program, this work was entitled Three Minds not only to mean three different 
states of mind, but also to parallel the work by Copland called Three Moods which was included in the same recital program.

Three Minds has three movements: "Fierce," "Absent," and "Hesitant," which conforms to most classical music compositions in that it has the fast-slow-fast scheme. The first movement, "Fierce," expresses ferocity, anger, and madness. The second movement, "Absent," describes a state of an empty mind without any thought. The last movement, "Hesitant," describes a hesitating mind with full of confusion. These programmatic ideas arose when Prangcharoen was ordained as a Buddhist monk and immersed himself in the practice of meditation. All three of these specific states of minds arose during meditation, especially when he focused on how people's minds can affect their lives. He tried to transcribe his ideas into the music. A summary of the analysis of each movement follows.

\section{Fierce}

This movement is the only one of the three movements that has specific Thai influences. It is heavily indebted to the sound and technique of ranad, a Thai wooden xylophone. The structure of this movement is ABC A'B' Coda: the second half is therefore the repetition of the first but with variations. The influence from ranad is apparent in section $\mathrm{B}, \mathrm{mm} .15-25$, in which passages resemble those characteristics of music for ranad, i.e. the use of parallel motion in octaves, as well as sabad technique. Another technique of ranad, gror technique, is found in the opening and ending sections; this is indicated in Western musical notation as tremolo. 
The preference for the tritone might also be a result of the blending between Thai and western music tuning systems. The traditional Thai scale has seven equidistant pitches. This creates a similar character to the equidistant whole-tone scale. Hence the tritone becomes a characteristic interval of the scale, one which a diatonic scale does not emphasize. With the different tuning systems, the tritone can become a substitute, when playing on the piano with fixed temperament, for the sound that is found in Thai traditional music. The tritone is found both in the melody of "Fierce" and as a harmonic interval.

Section B', mm. 54-64, is another good example of the synthesis between Thai and Western music. The ostinato pattern of section A, mm. 3-10, interrupts the parallel motion of section B'. The parallel motion represents Thai ranad music while the ostinato pattern, common in contemporary music, represents Western music.

The texture of "Fierce" is similar to a toccata, in that section A progresses with a single-line texture in a fast tempo. Section B, however, with its parallel motion, shows the influence of ranad. In addition, at times the music progresses in a contrapuntal manner, especially in transitional passages.

Rhythm and meter are interesting parameters of this movement. It features metric changes throughout the piece. Irregular rhythms and syncopations are used. According to the composer, this movement describes an angry state of mind. The irregular rhythms and pulse presumably imitate an irregular heart rate that is experienced by an angry person. Moreover, the irregularity also reflects an angry mind with a sequence of thoughts that move from one to another sporadically. 
In terms of pitch, the work uses two pitch class sets which can be designated as instances of set class 6-34. The two pitch class sets complement each other; when both are combined, the union includes all twelve pitch classes. The composer usually uses the pitch class sets straightforwardly in their original forms, although at some points he transposes them or mixes the two sets together.

Prangcharoen also sets characteristic motifs for each section. These motifs sometimes transform. Some patterns are very prominent, as they are used as an ostinato that repeats nearly throughout the section.

\footnotetext{
Absent

This slow movement is in modified strophic form with the scheme: A1-A2-A3A4-A5-Coda. The composer uses one primary motif that creates coherence in the movement. He creates variety within this scheme by varying the motif with different rhythms and intervallic structures. The variation techniques increase between sections as the piece goes on. However, the figure remains prominent, and its thematic derivation is always recognizable. Since these variations always include metric changes, the music hardly stays within one meter for long, with many places featuring metric change as frequently as every measure. Both the variation technique and the metric changes illustrate well the absent-mindedness of this state of mind that, during introspection, delivers unpredictable sequences of thoughts in its caprice.
} 


\section{Hesitant}

This movement was revised from Prangcharoen's early piano piece called Sonatina, a version of the piece that has been lost since the revision became the last movement of Three Minds. The structure of this movement is complex but can be designated as compound ternary form. It may also be considered a deviation from sonata form, as the original version was entitled Sonatina.

The music starts with the melody in the left hand, while the right hand plays an accompaniment in an ostinato pattern. The opening melody features a two-note motif that is repeated and varied, sometimes being used as a phrase extension, at other times appearing in inverted form. A fragment of the primary motif of "Absent" appears in the middle section, and a toccata-like passage resembling the one in "Fierce" is also present in this movement. The fast tempo and the motoric, virtuosic texture, illustratingaccording to the composer - a hesitating mind filled with confusion, create an exciting conclusion to Three Minds.

An analysis of Three Minds is a useful source for not just performer, but also for anyone who wants to study and analyze this piece. The author hopes that this research paper will increase interest in, and enhance understanding of, both this piece in particular and Prangcharoen's compositions in general. 


\section{BIBLIOGRAPHY}

\section{Theses and Dissertations}

Chucherdwatanasak, Nathinee. "Narong Prangcharoen and Cross-Cultural Fusion in Contemporary Composition.” M.M. thesis, University of Missouri-Kansas City, 2014.

Chaycharoen, Phaitoon. "Khan wikraoe tang ranad thum pleng Choet Chin (An Analysis of Ranad Thum's Melody on Choet Chin)." M.M. thesis, Srinakharinwirot University, 1999.

Polnikrot, Pornchai “Khan tam tang diaw ranad ek pleng 'Loy Luean Sam Chan' (A New Solo Composition for the Thai Ranadake Derived from the Song 'Loy Luean Sam Chan').” M.M. thesis, Mahidol University, 2011.

Prangcharoen, Narong. "Sattha for Strings, Piano, and Percussion.” D.M.A. diss., University of Missouri-Kansas City, 2010.

Setabundhu, Jiradej. “Aspects of Thai Music and Composition Techniques in Selected Works of Jiradej Setabandhu.” D.M.A. diss., Northwestern University, 2001.

\section{Websites}

Alliance for New Music Theater. "Kit Young." Accessed February 11, 2015. http://newmusictheatre.org/about/artists/kit-young/

Boekkooi, Paul. "ArtSpoken \& Reviews: Unisa International Piano Competition Overview." Accessed February 3, 2014.

http://www.artlink.co.za/news_article.htm?contentID=29173.

Dhamabutra, Narongrit. Personal website. Accessed February 11, 2015. http://www.narongrit.com/en/index.php.

da Fonseca-Wollheim, Corinna. "Ambitious, with Ives Anchoring: American Composers Orchestra at Carnegie Hall" New York Times, Oct. 29, 2012. Accessed April 8, 2014. http://www.nytimes.com/2012/10/30/arts/music/american-composersorchestra-at-carnegie-hall.html? $\mathrm{r}=0 \& \mathrm{adxnnl}=1 \& \mathrm{adxnnl}=1398053950$ gwQO6R3ooESp6Fk/xMGqiQ.

Mahidol University. "Thailand International Composition Festival," Accessed April 12, 2015. http://www.music.mahidol.ac.th/ticf/index.html. 
McKiggan, Christopher. "Christopher Janwong McKiggan: Pianist, Arranger, Composer, Producer." Accessed October 15, 2014. http://www.mckiggan.org/home.html.

Prangcharoen, Narong. "Narong Prangcharoen: Composer." Accessed October 15, 2014. http://www.narongmusic.com.

Prathumthong, Sornchai. "Fueg tee ranad khan puen than (Introduction to Basic Ranad Playing).” Accessed December 2, 2015. http://www.thaigoodview.com/library/teachershow/sakaew/sornchai p/ranad/sec0 4p04.html.

Taylor, Stephen. Personal website. Accessed February 11, 2015. http://www.stephenandrewtaylor.net/index.html.

Trinity College London. "Music.” Accessed April 3, 2015. http://www.trinitycollege.com/site/?id=55.

The University of Missouri-Kansas City. "Dr. Chen Yi.” Accessed February 11, 2015. http://conservatory.umkc.edu/faculty.cfm? $\mathrm{r}=\% 22 \% 2624 \% 20 \% 0 \mathrm{~A}$.

The University of Vermont. "Faculty_David Feurzeig." Accessed February 11, 2015. http://www.uvm.edu/ music/?Page=faculty/feurzeig.php\&SM=discovermenu.htm $\underline{1 .}$

\section{Periodicals}

Yamprai, Jittapim. "Michel-Richard De Lalande and the Airs of Siam." Early Music 41, no. 3 (2013): 421-37.

\section{Musical Scores (Published)}

Prangcharoen, Narong. Phenomenon for orchestra (2004), King of Prussia, PA:

Theodore Presser, 2014.

- The Migration of Lost Souls for orchestra (2012), King of Prussia, PA: Theodore Presser, 2015.

\section{Musical Scores (Self-Published)}

Prangcharoen, Narong. Anusorn for cello and piano (2005), Kansas City, MO, 2005.

—. Dialogue for soprano, violin, guitar, and harpsichord (2014), 
Kansas City, MO, 2014.

- Elegy for a Great Person (2008) for vocal and guitar, Kansas City, MO, 2008.

_. Lokuttara for wind ensemble (2014), Kansas City, MO, 2014.

_. Pact Ink for solo piano (2014), Kansas City, MO, 2014.

—. Sattha for strings, piano, and percussion (2005), Kansas City, MO, 2005.

—. Shadow for woodwind quintet (2003), Kansas City, MO, 2003.

- The Temple in the Mist for solo piano (2000), Bangkok, Thailand, 2000.

. Three Minds for solo piano (2003), Kansas City, MO, 2003.

- Whispering for soprano saxophone, bass clarinet, piano, and percussion (2008) Kansas City, MO, 2008.

\section{Musical Recordings}

McKiggan, Christopher. Paganimania. Albany Records, 2015, compact disc.

Prangcharoen, Narong. Mantras. Albany Records, 2012, compact disc.

-. Phenomenon. Albany Records, 2009, compact disc. 